Foundations and Trends ${ }^{\circledR}$ in

Human-Computer Interaction

Vol. 1, No. 4 (2007) 277-392

(C) 2008 J. P. Hourcade

DOI: $10.1561 / 1100000006$

\title{
Interaction Design and Children
}

\author{
Juan Pablo Hourcade
}

University of Iowa, USA, hourcade@cs.uiowa.edu

\begin{abstract}
Children are increasingly using computer technologies as reflected in reports of computer use in schools in the United States. Given the greater exposure of children to these technologies, it is imperative that they be designed taking into account children's abilities, interests, and developmental needs. This survey aims to contribute toward this goal through a review of research on children's cognitive and motor development, safety issues related to technologies and design methodologies and principles. It also provides and overview of current research trends in the field of interaction design and children and identifies challenges for future research.

To understand children's developmental needs it is important to be aware of the factors that affect children's intellectual development. This survey analyzes the relevance of constructivist, socio-cultural, and other modern theories with respect to the design of technologies for children. It also examines the significance of research on children's cognitive development in terms of perception, memory, symbolic representation, problem solving, and language. Since interacting with technologies most often involves children's hands this survey also reviews literature on children's fine motor development including manipulation and reaching movements. Just as it is important to know how to aid children's
\end{abstract}


development it is also crucial to avoid harming development. This survey summarizes research on how technologies can negatively affect children's physical, intellectual, social, emotional, and moral development. Following is a review of design methodologies for children's technologies organized based on the roles children may play during the design process including a description of cooperative inquiry and informant design methods. This is followed by a review of design principles obtained through experiences in developing technologies for children as well as research studies. It includes design principles related to visual design (e.g., icons, visual complexity), interaction styles (e.g., direct manipulation, menus), and the use of input devices (e.g., pointing, dragging, using mouse buttons). The latter half of this survey summarizes research trends in the field of interaction design and children, grouping research efforts in the following areas: supporting creativity and problem solving, supporting collaboration and communication, accessing, gathering and exploring content, learning from simulations, supporting children with special needs, interacting with intelligent characters, supporting healthy lifestyles, learning skills, mobile, tangible, and ubiquitous computing, and designing and evaluating technologies. This survey concludes by formulating research challenges for the future and identifying three information age "plagues" children are in danger of facing in the near future. 


\section{1}

\section{Introduction}

The review of the literature on interaction design and children in this survey shows the diversity of research approaches in this field. This diversity comes from a variety of factors. The first is that the researchers come from a variety of fields: computing, education, psychology, art and design, engineering, and so forth. Within each discipline, we come from different research traditions. We approach research using different theories and value research based on different criteria.

For example, some of us prefer quantitative, others qualitative data, others do both. Some will work on novel technologies even if their impact on children's development is unclear, while others prefer incremental research grounded in theory and controlled experiments. Some will develop technologies with the goal of producing measurable developmental goals, others will be mainly concerned about enabling new experiences with technologies. Some will work with children as design partners, others believe it is better to adhere to well developed educational theories. Some will look to design novel ways for children to gain basic skills, others will concentrate on providing children with 
new ways of expressing themselves. Some will concentrate on producing technology, others on novel interactions, guidelines, or design and evaluation activities. Some believe in constructivism, others in constructionism, social constructivism, situated learning, or behaviorism; others just want children to have fun.

We are also geographically diverse. Over the years, the Interaction Design and Children (IDC) conference has received submissions from all continents except for Antarctica. In addition, the share of papers from Europe and North America have been roughly evenly split over the years regardless of the location of the conference, in contrast to other conferences such as CHI. While the Internet has made accessing research materials from other parts of the world significantly easier, geographic diversity still brings different approaches as we have gone through different educational systems, deal with different funding realities, and may even see childhood from different perspectives.

We are diverse in terms of gender. Many of the founding parents of our field are women (e.g., Druin, Cassell). The conference chairs for the IDC conferences have been evenly split by gender, and paper authors have also been evenly split. Interaction design and children may be the only field related to computing where this is the case. I believe this gives the field a tremendous advantage over other areas in computing.

We are diverse in terms of age as well because many of us work with children as design partners. We are still a young field though, and many of our fields' founders had not even started graduate school by the time the first CHI conference took place in 1982 (e.g., Druin was a teenager, Mitch Resnick was working for a magazine). Our youth and intergenerational approach give us some advantages over other fields where novel approaches and radical ideas may not be as well received. At the same time, we are more prone, due to lack of experience, to make mistakes. But we shall learn from them.

Interaction design and children is indeed a young field, but it has strong foundations to build on. Decades of work on child development provide a starting point. Research on children's motor skills can guide the development of low-level interactions. An awareness of the risks that technologies may pose provides warning signs for areas to stay 
away from. Following empirically based guidelines can ease the way. But many challenges remain and my hope is that this survey will be a valuable tool for those who want to become familiar with the field as well as for those looking to get up to date with current research on interaction design and children. 


\section{Cognitive Development}

\subsection{Theories of Cognitive Development}

\subsubsection{Piaget}

Jean Piaget was arguably among the most influential experts on child development during the 20th century. His work has had and continues to have a significant influence in developmental psychology and educational research. His views on how children learn have also affected the field of interaction design and children.

Below, I highlight three aspects of Piaget's work. The first is his view of how children construct knowledge through a process he called adaptation. The second is Piaget's views on the role of maturation, experience, social aspects, and emotional aspects in children's development. The third is Piaget's concept of the developmental stages children go through as they develop.

\subsubsection{Adaptation}

Piaget thought that learning occurs through a process of adaptation, where children adapt to the environment. He saw this adaptation as 
an active process in which children construct knowledge structures by experiencing the world and interacting with it. The idea that children actively construct their own knowledge through experiences and that this construction is based on each individual's existing knowledge structures is referred to as constructivism. This contrasts with the view that children can simply store knowledge imparted by others and that they all perceive and learn from an experience in the same way.

Seymour Papert, a key figure in the genesis of the field of interaction design and children, expanded on Piaget's ideas with his proposal for constructionism. Papert proposes that Piaget's adaptation works best when children are "consciously engaged in constructing a public entity" [229]. In other words, constructing public entities helps children construct knowledge. Papert's ideas have had a great influence in the work on interaction design and children. This is particularly clear in terms of the emphasis of providing children with technologies with which they get to be authors, rather than experiencing worlds and situations that are pre-scripted, or absorbing facts provided by a computer. It also shows in the recurring emphasis of having children participate in designing the technologies that they use. Papert's interest in computers for learning arises in great part from the great variety and complexity of entities children can construct using computers, which thus provide better learning opportunities and empower a shift from learning by being told to learning by doing. Papert also sees computers as providing children with a tool that can connect their interests to subjects that children sometimes lack the motivation to learn such as mathe-

matics. He sees the key to providing better learning opportunities as connecting children's interests to powerful ideas [166].

\subsubsection{Factors Affecting Development}

Piaget cited four major factors that he thought affected development: maturation, experience, social aspects, and emotions. All four have a direct impact on how technologies for children should be designed. In the case of maturation, being aware of what most children are able to accomplish at a given age can provide interaction designers with useful guidelines. The other three factors are crucial in the design of 
educational technologies where children should be provided with new experiences where they can interact with others as part of activities of interest [239].

Children's physical maturation limits what and how they are able to learn. As children grow up, their potential for learning increases. Piaget thought that while maturation certainly plays a role in learning, it does not guarantee that learning will occur. Rather, it limits what children can do [239]. Hence, children's limited cognitive and motor abilities will limit their ability to interact with technologies. This view on maturation needs to be taken in context of evidence that maturation, and in particular cognitive development, are affected by the environment in which children grow [244]. In other words, while children's maturation limits what they can do, the experiences they go through shape neural development and thus affect children's cognition.

Piaget viewed experience as a key factor in adaptation. Experiences are required for building knowledge structures [239]. This underlines the importance of learning about the world by experiencing it rather than being told about it, as Montessori stressed [216]. Technologies can provide unique experiences or augment them through virtual environments and simulations. Children can learn about a variety of subjects through digital libraries, as well as explore data and reach conclusions of their own through information visualization technologies. Authoring environments can also provide valuable experiences in Papert's constructionist sense by giving children the experience of building public artifacts they feel passionate about, and through this experience, contact powerful ideas.

Piaget thought that social interaction played a key role in development by enabling knowledge to be passed from one generation to the next [239]. The core of the contributions to this topic though, comes from socio cultural approaches to development that were pioneered by Lev Vygotsky [327]. We discuss these under Socio-cultural approaches. One important aspect of social issues in development is that the knowledge that gets passed from one generation to the next is not just information, but strategies. In a panel at the IDC 2004 conference, Marvin Minsky and Alan Kay, both Turing Award recipients, highlighted the importance of learning by copying the way more knowledgeable and 
experienced people think and complete tasks. Kay made an interesting point when mentioning that when teachers assign something such as a composition and they do not do it themselves, they are indirectly telling children that it is not interesting. Computers can help in this respect by making links between passionate interests and powerful ideas not only for children, but also for the adults that play a role in children's education [166].

Piaget also highlighted the role that motivation and emotions play in development. He said that children's motivations to learn are in great part due to their drive to grow, love and be loved, and assert themselves [239]. Motivation can be achieved by making learning activities relevant to children's lives and interests as recommended by Dewey, Montessori, and Vygotsky [64, 216, 327]. Papert goes a step further and makes a distinction between activities that are relevant to children's lives and those that children feel passionate about. He believes the latter will be much better at motivating learning [166]. This view highlights the need for providing children with learning opportunities that are flexible or varied enough to help every child find something that speaks to his or her interests. This is an area where computers can prove a positive tool due to their flexibility in providing a variety of experiences and learning opportunities.

More specifically, researchers have taken into account Piaget's views on motivation when providing children with technologies that incorporate learning in entertaining ways. Games are increasingly used for teaching a variety of subjects, and are particularly popular in commercial mathematics learning software geared at elementary school children $[173,179,188,281]$. Fisch [94] provides an overview of basic guidelines to follow when incorporating learning into games. Storytelling is another approach that can make learning more interesting for children. It is often what brings together the games used for learning, but could also be used without a game component $[44,124]$.

\subsubsection{Developmental Stages}

Arguably, Piaget's best known and most critiqued contribution is his idea of developmental stages. In spite of the criticism of the concept 
of stages, Piaget's descriptions of each stage are useful in identifying why children may have difficulty with a particular type of interaction. Piaget proposed that all children go through a series of stages in their development on their way to attaining logical, analytical, and scientific thinking. At each stage, children present typical behaviors, and are limited in the types of mental operations they conduct. All children go through the stages in the same order, and none of the stages may be skipped. Piaget proposed age spans for each of the stages but also acknowledged that different children will go through the stages at different speeds and thus will reach stages at different ages [235, 239]. Piaget proposed four stages: the sensory-motor stage (0-2-year olds), the preoperational stage (2-7-year olds), the concrete operations stage (7-11-year olds), and the formal operations stage (11-16-year olds). Below are some developmental issues that Piaget identified that have an impact on the design of technologies.

Preoperational children (2-7-year olds) are egocentric, that is they see the world only from their own perspective, and have great difficulty seeing the world from someone else's point of view [236, 237]. This can be seen in the difficulty of partnering with children in this age group in the design of technologies [111]. Children in the concrete operations stage (7-11-year olds) are more likely to appreciate someone else's perspective which enables them to better work in teams and as design partners with adults. Preoperational children also tend to concentrate on only one characteristic of an object at a time. This limitation extends to understanding hierarchies [236, 238]. This is one important lesson to remember when designing technologies for this age group: interfaces that require navigation through hierarchies should be avoided and alternatives should be provided. Concrete operations children on the other hand, are able to understand hierarchies and reverse actions in their head which can enable them to use a greater variety of technologies and software [238]. More abstract concepts such as using deductive reasoning and logically analyzing options tend to appear more consistently during the formal operations stage (11-16-year olds). More details on how children's problem solving abilities evolve can be found in Problem solving. 
The idea of developmental stages has been heavily criticized. One of the main criticisms is on the assertion that children will behave consistently on tasks given their developmental stage. Research has indicated that a child's development will only produce a likelihood that child will behave in a particular way [96]. Children's performance in tasks will also depend on several factors such as the amount of information in a task, social support, and instructions. For example, the amount of information can affect performance because larger amounts would be more difficult to handle by a limited working memory. As working memory capacity increases, so does the ability to complete certain tasks. Information-processing efficiency can also help explain changes [43]. These issues with the way tasks are setup explain an additional problem with Piaget's developmental stages. Recent research has provided evidence that children and infants are more competent than Piaget thought, while older children and adults appear to be less competent [96].

Another area where Piaget's developmental stages fall short is in addressing the role of social and cultural factors on children's learning and performance in tasks. These issues are explored under socio-cultural approaches. Another area of contention is the fact that Piaget considered logical-analytical thinking the highest form of intellectual development. Gardner's multiple intelligences theory proposes that there are other types of intelligences. His approach is explained under Multiple Intelligences. Sternberg's successful intelligence theory takes a practical and inclusive approach in defining intelligence and is described under Successful Intelligence.

\subsubsection{Socio-Cultural Approaches}

Lev Vygotsky, a Russian psychologist who conducted his research early in the 20th century, but whose work did not become widely known until the 1970s was one of the first to highlight the importance of social aspects in children's education. Vygotsky thought that language and signs played a crucial role in cognitive processes. For example, he thought children learned to plan actions by using speech, which later turned into the inner speech of adults. He also saw writing and more 
generally the use of external tools and signs as ways of augmenting human cognition. As an extension to this, he also saw learning as being social in nature, observing that children are able to complete tasks with a bit of help from adults or older children before they can complete them on their own. In making this observation, he stressed the importance of appropriate social supports as being critical for children's learning [327].

Out of Vygotsky's ideas come some concepts that are often cited in the interaction design and children as well as the learning sciences literature. One is the concept of scaffolding. This refers to the help children require to complete a task before they can complete it on their own. Some research on children's technologies refers to the technologies providing the scaffolding, instead of teachers or parents [297]. When children can complete a task with scaffolding, but cannot complete it on their own, they are in the zone of proximal development. Vygotsky thought that good learning occurs when children are in this zone, rather than when they are ready to complete tasks individually. Once children internalize the processes that help them accomplish the tasks, they are able to complete the processes individually.

Many other researchers have followed in the footsteps of Vygotsky, conforming what today are referred to as socio-cultural approaches to learning. In these approaches or theories, children's learning is seen as an active process where interactions with other people and tools are important and where children are not passive recipients of knowledge. Knowledge is not seen as constructed individually in the mind, but socially in the world. These approaches study learning in a given sociocultural context instead of studying individual children in isolation. They study children's cognition as it connects with society.

There are two levels at which the socio-cultural context can be studied. One is the society and culture the child belongs to. Researchers have pointed out that in different parts of the world, different kinds of knowledge and skills are valued. Similar claims can be made for different times in history. Thus, cognitive development will always be seen through the lens of a particular socio-cultural context. The other level at which the context can be studied is in the most immediate vicinity of the child, in how family and school environments provide learning 
opportunities and scaffolds. Different family and school values will lead children to different routes in cognitive development [96]. In many ways, the socio-cultural approach to learning goes back to the notion of an apprenticeship, similar to that in middle age guilds, and to what occurs in graduate schools between students and their advisors.

One example of more modern socio-cultural approaches is situated learning or situativity theory. This approach sees learning as occurring in activities where children interact with their environment as well as with adults and other children. [35, 47, 107, 108, 187]. Knowledge is not seen as belonging solely to individuals, but rather as being distributed between them and the tools, artifacts, and other people in their environment. The interactions between individuals and the environment transform both. Thus, these situations are studied rather than the individuals in them. These theories, as well as those in similar areas such as social constructivism, have led to instructional methods where context is seen as an integral part of learning, rather than simply influencing individual cognition [34, 54].

One problem with the use of personal computers in education is that they often tend to isolate children and can get in the way of collaboration because they have been designed for use by individuals. Certainly, the increasing likelihood that computers in schools and other educational environments are networked has facilitated sharing and collaboration, although shoulder-to-shoulder collaboration remains a challenge. Designers of technologies for children should do their best to support collaboration between children and those who can provide scaffolding. One technology that has shown promise in this regard through its light, tumble-proof and wireless nature is the XO laptop by the One Laptop Per Child (OLPC) Foundation [221, 130].

\subsubsection{Other Cognitive Development Theories}

\subsubsection{Information-Processing Theories}

These theories' main concern is understanding the processes involved in intellectual development. The human mind is seen as similar to a computer, a system that manipulates information. Thus, changes in mental hardware and on the information stored in the mind affect performance 
in cognitive tasks. Siegler and others have identified the issue of high variability in cognitive task performance within as well as between children. They have observed that children will choose from a variety of strategies and will not follow the same strategy consistently as would be suggested by Piaget's stages of development. However, children do adapt to the most successful strategy over time, even though it may not lead to immediate improvements in performance. Another cause for variability is that children may take some time before they can apply a strategy to a variety of tasks [49]. This variability in children's performance is something to be taken into account when conducting experiments and usability testing with children.

\subsubsection{Privileged-Domain Theories}

Privileged-domain theories consider that the mind is domain-specific, with specialized structures that are interconnected. Part of the evidence behind these theories comes from neuroscience and its study of brain activity during cognitive tasks showing certain parts of the brain to be most often dedicated to certain types of tasks. This work has provided evidence that both maturation and experience play a part in development. In addition, there is evidence that the brain can adapt to uncommon circumstances, reusing unused parts of the brain for purposes for which they may not normally be used (e.g., deaf children using parts of the brain normally dedicated to auditory processing for visual processing purposes instead). Some theorists also propose that children are born with learning mechanisms tuned to cognitive tasks that are particularly important for humans such as acquiring language, recognizing faces, perceiving objects, and discriminating between living and non-living things. These mechanisms explain why children learn very rapidly in some domains $[49,96]$. Recognizing the areas where children are likely to learn more quickly is important, particularly when designing technologies for young children.

\subsubsection{Behaviorism}

Behaviorism studies learning from the perspective of observing and measuring behaviors as a response to stimuli. It ignores what happens 
in the brain and treats it as a black box. Skinner [293] saw learners as operating on the environment and receiving feedback on behavior. Feedback to encourage learning a behavior given a set of stimuli include positive reinforcement where the learner receives something they want (e.g., a good grade), and negative reinforcement where the learner is rewarded by escaping or avoiding something they do not want (e.g., taking a final exam). Feedback to discourage behaviors is accomplished through punishment by either taking away something the learner wants, or giving them something they do not want (e.g., a low grade). Skinner also referred to the need to reinforce behaviors learned in this way. This theory puts emphasis on drills and practicing where learners remember and respond [136]. It can be useful for situations where automatic responses are useful or necessary. For example: remembering multiplication tables, spelling, and typing. These strategies have been used in educational games. This theory has also been useful in the design of interventions for children with cognitive disabilities such as autism [314].

\subsection{Theories of Intelligence}

Some of the controversy with Piaget's work has to do with his focus on logical-analytical thinking as the highest form of intelligence. In an educational setting where, particularly in the United States, increasing importance is given to testing and quantitative measures to demonstrate the educational effectiveness of technologies, it is important to be aware of the leading theories of intelligence.

\subsubsection{Psychometric Theories}

Psychometric theories make use of tests to assess and predict the intelligence of individuals, including children. These theories vary in the number of factors believed to influence intelligence. Some, like Spearman, proposed one general factor $(g)$, while Thurstone proposed seven factors, and Guilford 180 factors [49]. More recently, Carroll [42] developed a hierarchical theory with $(g)$ at the top, followed by two strata.

The results of numerous studies provide evidence that individual differences in psychometric scores stabilize at about age five or six. These 
scores are also good at predicting performance in school. More recent research has found correlations between the performance of infants in tasks such as visual recognition and IQ scores later in life [49].

IQ tests throughout the last century show a sharp increase in IQ with every generation, to the point where someone who would have scored in the 90th percentile in 1892 would drop to the 5 th percentile in 1992. These differences suggest that the environment in which children grow up plays a much more important role than genetics in determining IQ, since genetic mutations explaining these gains could not have occurred in such a short span of time [305].

Criticism of psychometric theories centers on the difficulty of capturing the richness of intellectual abilities through a few numbers. These theories have also been criticized for not taking into account social and cultural issues, for not measuring some of the factors that people from different cultures consider key to intelligence, and for not having a strong correlation with success in life $[49,305]$. They also tend to be used as predictors of future performance, and not as a way to prescribe how to best educate children [100].

\subsubsection{Multiple Intelligences}

Gardner and Moran [100] propose that multiple, somewhat independent, yet interacting intelligences provide a useful way for understanding human cognitive abilities. They propose eight specific intelligences, each with a focus on different types of information: linguistic, logical-mathematical, musical, spatial, bodily kinesthetic, naturalistic (distinguishing between natural and manmade objects), interpersonal, and intrapersonal. Gardner argues that different combinations of intelligences are better matches for different types of professions. For example, he proposed that businessmen are better suited at having all intelligences at similar strength, while scientists and artists are better suited at having a few intelligences be particularly strong, overshadowing the rest.

Gardner's ideas have inspired educators to make educational activities that teach concepts by introducing them through many entry points, taking advantage of children's multiple intelligences. So instead 
of concentrating only on linguistic or logical-mathematical intelligences, as a lot of educational activities do, Gardner's theory suggests using other intelligences as well to introduce concepts. The more entry points into a concept, the more likely a greater number of children will understand it. Kornhaber et al. [176] discuss ways in which this approach has benefited students.

\subsubsection{Successful Intelligence}

Sternberg [304] proposes the concept of successful intelligence as an individual's ability to succeed in life given an individual's goals within a socio-cultural context. He argues that people achieve success by adapting to, shaping, and selecting environments. This requires people to know about their strengths and weaknesses, and compensating for these weaknesses by using analytical, creative, and practical abilities. These three abilities constitute the three interacting aspects of Sternberg's triarchic theory.

All three abilities come from the interactions of three informationprocessing components: meta-components, performance components, and knowledge-acquisition components. Meta-components are used for understanding, identifying, selecting, and evaluating problem-solving strategies. Performance components implement the instructions given by meta-components by encoding information related to a problem, making inferences, and so forth. Knowledge-acquisition components help individuals obtain the knowledge required to solve problems by selecting relevant information, integrating this information, and comparing this information to previously experienced information [303]. The components represent analytical abilities when applied to abstract problems, creative abilities when applied to novel problems or situations, and practical abilities when applied to concrete everyday problems [304].

Sternberg and Kaufman [305] argue that current educational practices overemphasize the use of analytical abilities to the detriment of creative and practical abilities. They propose that educational activities should match students' strengths in analytical, creative or practical abilities. 


\subsection{Perceptual Development}

Perception involves using the senses to construct an internal representation of space and the body. These abilities are key to making use of technologies, and thus it is crucial for developers of children's technologies to understand how they evolve as children grow up.

\subsubsection{Vision}

Even though the physical development of the eyeball is complete by age two, children at this age still have difficulty in perceptual tasks such as distinguishing objects from backgrounds, and tracking moving objects. One way to measure visual abilities is by assessing visual acuity. Visual acuity is the ability to distinguish details in objects and may be measured in static and dynamic settings. In the static setting, neither the object nor the person looking at it move. It is measured through the familiar Snellen eye chart used in optometrists' offices. Dynamic visual acuity involves perceiving detail in moving objects. Static visual acuity is usually mature by age ten, and undergoes rapid improvements between the ages of five and seven, and nine and ten. Dynamic visual acuity undergoes similar improvements, with a final improvement between ages 11 and 12. Boys have been found to have better static and dynamic visual acuity than girls at all ages [99].

Figure-ground perception, or the ability to distinguish objects from a background, improves during childhood. This perceptive ability becomes stable by age eight to ten, with additional refinement through age 13, with possible continued improvement through age 18 [99].

Visual-motor coordination, the ability to track and make judgments about how to intercept objects also improves during childhood. Tracking is associated with dynamic visual acuity. By age five or six, children can track objects moving in the horizontal plane. By age eight or nine, they can track objects moving in an arc. Object interception refers to the ability to estimate an object's future location and use a motorresponse to intercept it. For example, a goalkeeper catching a ball in a soccer game would use his object interception skills. This ability also 
improves throughout childhood as can be seen by observing children play sports that involve object interception skills [99].

\subsubsection{Perceptual-Motor Abilities}

The perceptual-motor process involves obtaining environmental stimuli through the senses, organizing and integrating information from the senses in the brain, making a decision on how to move based on sensory and long-term memory information, transmitting that decision to the muscles, performing the movement, sensing the outcome of the movement and storing the success or failure of the movement for future reference. The process can be executed in a loop to accomplish complex movements [99]. Even though motor and cognitive skills were studied separately in the past, there is increasing evidence that they are highly interrelated. Research has found that similar parts of the brain are involved in motor and cognitive skills, and that children with cognitive problems such as attention deficit hyperactive disorder, dyslexia, and autism show deficits in motor tasks [253].

\subsubsection{Attention}

Attention plays a role in motor skills as well as computer use. Attention is selective, as it involves the ability to filter unwanted stimuli, helping us concentrate on the task at hand. While there is evidence for selective attention from birth, some attention-related skills are not fully developed until children are in elementary school. For example, children are not capable of actively searching for objects until early elementary school [253].

\subsection{Memory}

\subsubsection{Working Memory}

Working memory, often referred to as short-term memory, can store information in the short-term that can be manipulated. It helps coordinate perception, long-term memory, and action. According to Baddeley [17], it consists of a central executive, storage for phonological information, and a visuospatial sketch pad. The central executive controls 
attention as well as the two storage systems. The phonological storage system can keep a limited amount of phonological information that can be manipulated. Likewise, the visuospatial sketchpad can store and manipulate visual representations [16].

Working memory, which for adults holds, on average, seven chunks of information, can only hold four or five for five-year olds, and six for nine-year olds [63]. This limited working memory capacity affects the complexity of tasks that children can handle. A smaller working memory limits the amount of information children can keep in mind when problem-solving as well as the relationships children can establish between pieces of information. Working memory capacity seems to be correlated with information processing speed [158]. Experience plays a role in the efficient use of working memory by giving older children and adults strategies that can be used to improve performance, such as chunking information or using external aids [96].

\subsubsection{Long-Term Memory}

Explicit memory involves memories that are consciously recalled, and includes semantic memory (remembering facts) and episodic memory (remembering events). Implicit memory keeps information that is not consciously stored. It usually involves information about how to complete tasks. It tends to build slowly through repetition (e.g., typing). Older children have advantages in explicit memory tasks, while there are no differences in the performance of older and younger children when forming implicit memories [253].

Children use a number of strategies to store information in longterm memory. Verbal rehearsal is one such strategy that begins to appear in early elementary school. Other strategies include clustering or organizing information, linking concepts through visual images, selecting the most relevant information to store, and techniques for learning complex material. The ability to make practical use of these strategies improves during childhood, although in a nonlinear manner that can even include regression [96]. Designers of children's technologies can leverage these strategies to aid children's learning. 


\subsection{Symbolic Representation}

DeLoache has studied symbolic representation in young children and found that by the time they are three-years old, most children can understand that a symbol stands for something else, that something can be both an object and a symbol, and that a symbol can represent something in the real world. In order to use symbols, children need to relate the symbol and what it represents, match corresponding elements, and use information from the symbol to infer information about what it represents [62]. This should be taken into account when designing icons and other visual representation in technologies for children.

Preschoolers can understand and use simple maps, such as a point inside a rectangle to represent the location of an object in a sandbox [137], but still have difficulty understanding the representational nature of maps (e.g., red lines representing roads that are not red) [193]. This is important to know for the increasing number of educational technologies that make use of handheld devices that map children's locations [269].

Preschoolers are capable of putting together scripts with information on how tasks should be carried out that involve a sequence of actions, locations, and objects. The complexity of scripts children can develop increases during elementary school and is related to narrative thinking abilities [96]. This is one of the reasons behind the development of storytelling tools for children.

Many technologies make use of categorizations and hierarchies in order to organize content. Results from studies suggest that children begin categorizing objects as early as 14 months of age [96]. While preschool children can sometimes make use of hierarchical categorizations, reasoning and problem-solving using hierarchies does not begin to appear until the elementary school years, consistent with Piaget's concrete operations stage [96, 333].

\subsection{Problem Solving}

Children in elementary school, in Piaget's concrete operations stage, are able to infer facts given certain evidence, even if the facts contradict 
what they perceive at the time. An example is Piaget's conservation task, where, for example, when water is poured into taller thinner glasses, preoperational children (preschoolers) usually think that they hold more water than shorter thicker glasses [96].

Preschoolers are also more likely to concentrate on one aspect of a task and neglect others, while older children can perceive a wider array of information about a task that can enable them to make better decisions and inferences. Likewise, preschoolers are more likely to concentrate on the current state of a task, without paying much attention to what happened previously or anticipating what will occur next. Elementary school children, on the other hand, keep previous events in mind when problem-solving and making decisions, thus obtaining better results [96]. These developmental differences suggest, for example, that the way information is presented in order to make decisions in technologies should be handled differently for preschoolers when compared to older children.

Preschoolers are unable to reverse actions in their head, something that older children can accomplish. In addition, elementary school children can also use the concept of compensation, which applies to the conservation task, whereas they can say that a taller glass has the same amount of liquid as a shorter glass because it is thinner [96]. Reversibility is important when troubleshooting issues in software, and can help in the navigation of user interfaces. Elementary school children are also more likely than preschoolers to use quantitative measures to solve problems or make decisions, while preschoolers are more likely to make qualitative assessments [96]. Designers should take this into account when giving feedback to children.

Middle school children, in transition between Piaget's concrete and formal operations stages, tend to use empirical evidence when reasoning. They usually base their decisions on evidence they perceive through their senses. On the other hand, teenagers and adults, in Piaget's formal operations stage, are more likely to reason abstractly, concentrating on the logic of statements and situations. For example, middle school children presented with rigged empirical evidence that violates logic are more likely to believe the empirical evidence than teenagers and adults who would object using logical arguments [96]. This in some 
ways suggests that children are more likely to suffer from poorly written software and poorly implemented technologies or purposefully deceptive technologies that present illogical or ill advised recommendations and dialogs.

Middle school children are also more likely to approach problem solving by concentrating on information that is immediately available (mostly through the senses). They solve problems one at a time, within the empirical context of the problem, usually not developing overarching theories. On the other hand, teenagers and adults are more likely to consider all the possible situations and situate the current problem within those. Thus, when problem solving, they will likely consider theories within which a particular problem falls, hypothesize that a particular theory may be the correct one, and deduce from empirical evidence whether this is correct. Furthermore, they are more likely to consider the logical relationship between a series of problems or events and use this information in problem-solving [96].

Preschoolers have advanced reasoning abilities when it comes to informal tasks that involve probable or likely facts. For example, preschoolers have the ability to relate new situations to situations previously experienced based on similarities. They are also capable of analogical reasoning, although the performance in these tasks improves over the years as children obtain more knowledge about the world. In addition, they have a basic understanding of causality, understanding that a particular action can trigger something else to happen [96].

The use of appropriate problem-solving strategies can be sporadic at first, with use becoming more often over time. This change involves becoming more proficient in the new strategy as well as suppressing the use of previously used inferior strategies. The use of planning improves as children get older, with children as young as five beginning to use planning on a regular basis [96].

\subsubsection{The Role of Memory}

Working memory and information processing capacity help problem solving by helping keep in mind goals and facts, as well as providing the ability to evaluate possible strategies and solutions. Experience in 
problem solving helps develop expertise as children get older. Domain knowledge helps older children retrieve more relevant information about a particular problem as well as to recognize the best strategies with which to solve a problem. Familiarity with domain specific information helps free working memory resources, which in turn helps keep more information in mind. This advantage is to the point where expertise tends to override age, with several studies showing that young children can perform at older children or adult levels in areas where they are experts. Expertise, however, is easier to develop for older children and adults. Meta-cognitive capabilities also improve during childhood, providing children a better awareness of their cognitive resources and a wider range of strategies to choose from.

The above mentioned factors can play an enormous role in how children use and perform with technologies. It is very important to document children's background and expertise when conducting experiments and usability studies, and make an effort to have it match that of children in the target population for a given technology. These expertise issues may also explain some differences that have been found in experiments being conducted recently when compared to experiments conducted 10 years ago when young children in particular were much less likely to have experience using computers. One particular case is with studies comparing drag-and-drop to click-move-click interactions. This topic is covered later in this survey.

\subsubsection{Social Aspects}

Older children and adults play an important role in teaching children how to solve problems, and their problems-solving approaches are influenced by the problem-solving they have been taught or have observed [96]. While oftentimes children collaborating with children can provide advantages in problems-solving tasks, there is evidence that sometimes it can also get in the way of children's learning [270].

\subsection{Language}

Human brains appear to be best suited for learning languages early in life. An example of this comes from learning a second language. This is 
easiest for the youngest children, with this ability decreasing as children get older, with no advantages by the time children reach adolescence [145]. The reason for why children with less working memory and information processing capacity would learn languages better is still unclear [96]. Children learn words at an amazing rate of 800-900 words a year between ages of one and twelve. This is not true of every child though as there is a lot of variation [27].

In terms of milestones for children in the United States, by Kindergarten most children can identify and name letters, read their name, and a few simple common words. By third grade, most children can spell common words correctly and read primary-level fiction and nonfiction. By sixth grade, most children read with confidence and can spell a majority of words correctly [5]. 
Fine motor skills are necessary for operating input devices, and thus learning about how these skills develop in children is important for understanding the types of issues they may face when using these devices. Much of this research is slowly being replicated through research on children's handwriting abilities with computer devices as well as on children's use of pointing devices such as the mouse.

Fine motor movements are produced by the smaller muscle groups in the human body such as those involved in manual activities. Fine motor movements are precise and adaptive. Most research on fine motor skills is focused on manipulation: the use of the hands. Intrinsic movements involve the use of the fingers to manipulate an object in the hand. Extrinsic movements involve moving the hand and the object it holds [233].

\subsection{Manipulation}

A great increase in intrinsic movements of the hand occurs between ages three and seven. During this time, children learn to complete tasks such as buttoning that require them to coordinate the action of both 
hands as well as differentiate the movements of the fingers. Studies on how children complete motor tasks in this age group suggest that they first try a number of approaches for a particular task, eventually settling on the most efficient one. Older children see the speed of their movements increase and the variability in their movements decrease. Reaction times to start movements also decrease [234].

Handwriting by children has been extensively studied. Between the ages of two and six, as the ability to use writing or drawing implements develops, children develop a grip closer to that of adults, moving their hold of implements closer and closer to the tip, thus increasingly using the muscles in their fingers to control movement [272]. A study found that by age three, 48 percent of children had an adult grip, and by age seven, 90 percent had an adult grip. The length of the writing instrument and the orientation of the writing surface (vertical vs. horizontal) can have an impact on the maturity of the grip [338]. Given the increasing popularity of pen-based computing interactions in handheld computers and tablets, this should be taken into account when young children are the users.

In terms of drawing, children are able to trace simple shapes by six years of age, can copy simple shapes using a line grid by age nine, and can copy simple shapes freehand by age 11. Children copy and trace shapes usually starting at the bottom-left and moving up vertically with their first stroke [28]. Drawing programs should avoid obstacles in this part of the drawing canvas.

Children are capable of writing recognizable characters and numbers by age four, but these are most often not organized in any particular way. By age five or six, most children are able to print names. Most children master the ability to write uppercase letters by age seven. By age nine most children gain the ability to space letters correctly [233].

Bimanual coordination involves coordinating the use of both hands in space and time. Common tasks include throwing a ball with two hands, opening small containers, or playing a musical instrument. On the computer, multi-key strokes on the keyboard, or combinations between keyboard and mouse action make use of bimanual coordination. Basic bimanual coordination is usually achieved by age two, with 
the complexity of these types of tasks increasing significantly in the following years [46].

Hand preference is usually not well-established until children reach the ages of four to six. Besides being left or right handed, children can also grow up to be ambidextrous (performing at or above their age with both hands), or switched-handers (left-handers who learn to write and draw with the right hand) [177]. In most cases, handedness is not clear until children begin writing at age six or seven [46]. Hand preference is most significant for the skilled use of tools, as well as bimanual actions [40]. One of the most widely used tests for hand preference is the Edinburgh Handedness Inventory, in which people are observed conducting a variety of activities such as writing, using a toothbrush, and throwing a ball [220]. This is something to take into account when conducting studies using input devices. Hand preference can be a factor, but it may be difficult to assess hand preference with very young children.

\subsection{Reaching Movements}

Reaching movements use the perceptual motor process. Reaching and pointing movements are usually made up of one initial long movement that gets the hand close to the object, followed by smaller movements to either grasp an object or point at it. Research studies have provided evidence suggesting that visual feedback affects these tasks even while long movements are being conducted. In other words, visual feedback can help adjust movements as they are being made. Proprioception, or the perception of where our body parts are located based on feedback from muscles, joints, and skin also provides feedback [271]. This implies, according to the perceptual-motor process, that the feedback must be integrated, processed, and decisions on how to adjust need to be made. The quality and speed of perception, information processing, decision making, and muscular response will all thus have an impact on children's performance in these types of tasks. This underlies the importance of motor, perceptual, and cognitive development in children's performance of simple tasks with input devices on a computer.

The neural pathways used for motor tasks such as repetitive tapping, aiming, and pegboard transportation provide quick increases in 
speed in early childhood, reaching a plateau with similar speed to that of adults by age 10 [218]. Reaching trajectories become more direct and less variable, again reaching adult levels by age 10 [280]. This goes together with a reduction in the number of sub-movements required to reach a target, and a smooth transition between reaching and grasping movements, once again by age 10 [178]. Rösblad [271] found that movements to complete a particular aiming task become more consistent as children get older, being almost the same every time by the time children reached the age of 12 [271]. Lhuisset and Proteau [191] found that while six-, eight-, and ten-year old children planned their movements, their plans were still not as consistent as those of adults. Children also become more proficient with bimanual tasks, especially those involving asymmetric use of the hands [88]. These results are a close match for what has been observed when children conduct operations with input devices (e.g., with the mouse). These studies are reviewed later in this survey. 
Technologies do not always provide advantages to children and may in fact harm them. The following is a brief overview of the various risks children face when using technologies and provides suggestions on how to avoid these.

\subsection{Physical}

Technologies for children need to follow common sense in their design to avoid physical injuries. The American Academy of Pediatrics [9] provides some common sense recommendations including avoiding sharp edges, toxic materials, and choking, squeezing or strangulation hazards. Technology designers should also be aware of less immediate physical impacts such as obesity. There is evidence that heavy television watching leads to obesity and through it to type 2 diabetes and cardiovascular disease although it is unclear whether this occurs due to a sedentary lifestyle, exposure to advertisements for unhealthy food, or a combination of both $[8,10,11,319]$. Computers have the potential of multiplying the problem as Risden et al. [263] found that interactive advertising where advertising is included as part of games was more effective with 
10 to 14-year old children than advertising seen on television, with children more likely to recall brand names and products. Parents should make an effort to be aware of advertising content within games, and game designers should be upfront with parents on the advertisements placed within games. Technologies for children should avoid interactions that will keep children from being physically active as well as be aware of the negative consequences of content that promotes unhealthy eating habits.

Social network websites and online communities can also put children at physical risk. In creating profiles in these communities, writing in blogs, sharing pictures and videos, and participating in chat rooms children can reveal personal information that can put them in danger of being targeted by predators. While this phenomenon mostly affects teenagers, it is relatively easy for younger children to lie about their age and participate in these communities.

\subsection{Intellectual}

Heavy television watching by toddlers has been correlated with attention problems in elementary school as well as with poor reading skills $[53,262]$. The verdict on computers is less clear. A study found that preschoolers exposed to computers scored higher than those not exposed in standardized tests of school concepts and cognition. However, frequency of use did not have an impact on these scores [192]. Studying the same issue, Plowman and Stephen [241] reviewed literature on preschool children's use of technologies and suggest that technologies need to be designed with the specific needs of these children in mind. They also argue for better evaluation of technologies aimed at this age group.

\subsection{Social, Emotional, and Moral}

Television has also been linked to reduced time talking with friends and family and as well as playing outdoors [10,262]. The media content children access can also affect emotional health by causing fear, depression, nightmares, and sleep problems [7]. The most severe problems though 
have been linked to violent content. Viewing of television violence during childhood has been linked with violent and aggressive behavior both during childhood and adulthood in both males and females regardless of socioeconomic status, intellectual ability, and parenting factors such as aggression and television habits [135, 318]. A study that differentiated between different types of children's television found that children who watched violent television programs aimed at children (e.g., Power Rangers) during the ages of two and five were more like to have antisocial behaviors between ages seven and ten than those who watched noneducational non-violent television (e.g., Rugrats) as well as educational non-violent television programs (e.g., Sesame Street) with the lowest associations with antisocial behavior for this last kind of programming [52]. Violent video games have also been linked to aggression [317]. Lieberman [194] warns against the negative consequences of violence in media content experienced by children which can lead to violent and hostile behavior, desensitization to the pain and suffering of those in the receiving end of violence, as well as fear and anxiety. Hoysniemi and Hamalainen [132] provide an example of what can happen. They found that a game in which players use real martial arts moves to fight virtual opponents led young children to not understand the consequences of violent behaviors such as throwing punches and kicks. They provide the example of a four-year old that punched his father, but did not think the punch would hurt. To avoid these issues, if violence is shown, it should be shown together with its negative consequences instead of being glorified, rewarded, and presented as entertaining [7].

Similarly, content can have negative effects in terms of risky sexual behavior and drug use. Instead of showing these activities as being casual, fun, and exciting, content providers should either avoid showing them or show them together with their negative consequences $[6,10]$. Interactive violence and risky behavior have been around for decades in video games. The difference with most recent offerings is that these interactive behaviors are much more realistic while before they were represented with a few pixels. This makes the violence and risky behavior seem as realistic as it may be on a television show, with the added fact that it is the children that drive it, as opposed to being passive 
consumers as they would when watching television. While rating systems, parental controls, and involved adults help, there are still plenty of children playing this type of games.

Media content and video games can also provide children with negative gender, ethnic, and racial stereotypes [291]. Gender themes can be problematic too, as Joiner [148] found that merely changing the motivating theme for a game to make it more appropriate for girls did not make it more attractive to girls, but made it less attractive to boys. Designers may have to go beyond motivating themes. Passig and Levin [232] found that the way of interacting with a multimedia application impacted kindergarten children's satisfaction differently depending on gender. Girls valued being able to write as they learned, receiving help, and visual appearance, while boys valued control, speed, and navigation.

Children can also be affected by content created by other children. This is often referred to as cyber bullying, where children use technology to harass, threaten, torment, humiliate, or embarrass other children. The technologies of choice vary, but these attacks can involve harassment through text or instant messages, emails, postings on websites, impersonation, identity theft, sending malware, and posting embarrassing video or pictures. 


\section{Design Methodologies}

Knowing about children's development and being aware of potential risks does not provide enough information to design technologies. Children need to be involved in some way as well. Following is an overview of the different ways in which children can participate in the design process, paying particular attention to techniques where children participate as design partners.

In studying the different ways in which children have participated in the design of children's technologies, Druin [71] developed a classification method. Druin says children can participate in the design process as users, testers, informants or design partners. Furthermore, she states that each role supersedes and encompasses the next, with all testers also being users, all informants being testers, and all design partners being informants. This classification, presented at Druin's keynote speech at the first Interaction Design and Children conference in 2002, has been widely cited since then, with authors at subsequent Interaction Design and Children conferences referring to the where their research activities with children fit in Druin's classification. 


\subsection{Children as Users}

Children's participation as users often occurs at the beginning or at the end of the design process. Ethnographies are an example of the type of activities that can occur when children participate as users. These activities often involve observation. At the beginning of the design process, they can help assess children's interests, their current activities and how they currently use technology. At the end of the design process they can provide an understanding of how the technology that was developed affects children's lives and how or what they learn. For example, children could be tested on an academic subject before and after using an educational technology to assess its effectiveness. The main drawback of this approach is that children do not directly affect the design of the technology as it is being designed and provide no feedback until the work is completed. Thus, while participation of children as users is likely to be useful, when used by itself could significantly increase the chances of a technology being developed that will not serve children's needs or take their abilities into account.

\subsection{Children as Testers}

Perhaps the most common way in which children participate in the design process in both research and practice projects is as testers. When in this role, children test competing products, prototypes, and completed products so that designers and developers can obtain feedback on their designs as well as valuable information on making a technology competitive. Testing works very well with iterative design methodologies, which most researchers and practitioners agree provide advantages over traditional "waterfall" methodologies. Certainly, catching problems with designs as early as possible can greatly reduce costs and improve the quality of technologies, no matter the target user population. Testing can include techniques that are also used for adults including usability testing, peer-tutoring, Wizard of $\mathrm{Oz}$, and active intervention. More information on how these techniques have been used in research projects can be found under Evaluation. While children participating as testers can go a long way toward developing quality 
technologies, the approach still does not provide children with a voice in the design process. All design decisions are still made by adults who may not quite remember what it is like to be a child.

\subsection{Children as Informants}

The next step up in involvement is for children to participate as informants. The concept of children participating as informants comes from research activities conducted by Scaife et al. [279]. In this role, children share ideas and opinions with the design team acting as consultants at key points in the development and design process. This role provides a compromise that enables children to contribute their ideas to the design process and at the same time is flexible enough that it works for short-term projects or for projects that require a quick turnaround. Children can participate in this role through interviews, questionnaires, focus groups, and similar activities. Antle [14] proposed using personas (user profiles) to keep in mind the characteristics of child informants when they are not available.

\subsection{Children as Design Partners}

In Druin's classification, children's highest level of involvement in the design process is when they join it as design partners. The idea of this

role is for children to be equal partners in the design team. It does not mean that children tell adults what to do, but rather that design ideas come from the process of adults and children collaborating.

In Druin's research at the University of New Mexico and the University of Maryland, the design partnerships have involved the collaboration of academic researchers with groups of six to eight children. The researchers meet with the children twice a week during the school year at a research lab. Rather than work on one project at a time, the group of children are most often involved in several projects, which enables them to see progress and see something new every time they meet with adult researchers.

Druin adapted and developed a set of techniques to work with child design partners and called them cooperative inquiry [70, 71]. 
The techniques used under cooperative inquiry are: technology immersion, contextual inquiry, and participatory design. Technology immersion is used to introduce and expose children and possibly some adult design partners to the capabilities and possibilities of a particular technology. It is also useful as a way of understanding how well a particular technology may fit children's needs and abilities. Technology immersion tends to be most useful at the beginning of projects.

Contextual inquiry involves children and adult researchers observing each other while using a technology. In these sessions, children and adults get to express their opinions about what works well, what does not and what they would like to change about the technology. This can lead to useful discussions in the design team that can provide feedback on competing technologies, as well as on prototypes of technologies being developed.

In participatory design sessions, children and adults collaborate in developing low-fidelity prototypes of technologies. Early in the design process, or if they are designing something with physical attributes, they can use a variety of art supplies such as paper, markers, cardboard, boxes, socks, and wires. If designing an application for use on a computer, they may later concentrate on drawing sketches on large pieces of paper. Participatory design sessions are useful for producing design ideas at the beginning of the process and anytime new features need to be added, or new solutions need to be developed.

The advantage of children joining as design partners is that they will provide more input into the design process which is likely to result in technologies that better address their needs, interests, and abilities. The main challenge of children participating in this role is that it often takes time to develop these partnerships. Most children are not ready to contribute as partners right away because they are not used to being in such a role. In addition, if working on one project at a time, it may be difficult to make enough progress on prototypes to make it worth meeting with children on a regular basis. It may also be difficult to put such teams together as not all researchers have suitable places to meet with children for design activities, and it is also difficult to recruit a group of children that can meet on a regular basis. Another issue with design partnerships is that working with small groups of children 


\section{Design Methodologies}

could bias designs toward these children. This problem can be dealt with by testing the technology with a wider and more representative set of children. Other researchers have adapted cooperative inquiry techniques to their unique situations including children of different ages and abilities and locations other than research labs [103, 104, 111, 174, $268,316]$. 


\section{6}

\section{Design Principles}

In spite of the fact that the field of interaction design and children is relatively young, there are some basic design principles that researchers have developed over the years. Certainly many of the basic principles that founders of the human-computer interaction field like Norman and Shneiderman have set forth apply to children. Following is a description of those that are most important for children and that have been validated through empirical data.

\subsection{Visual Design}

\subsubsection{Icons}

Visual means of interacting with user interfaces are crucial to the success of software for children who are pre-literate or are just beginning to read. Problems with textual interfaces have been noted, for example, by Walter et al. [329]. Just as in the case of icons for adults, icons for children should be designed so they represent actions or objects in a recognizable manner, are easily distinguishable from each other, can be recognized as interactive and separate from the background, and have no more visual complexity than that required to accomplish 
the previous three requirements [118, 289]. Icons should also be sized so that children can easily click on them. See under Pointing for more information on sizing guidelines.

\subsubsection{Text}

As mentioned earlier, the use of text should be minimized, in particular for children who do not know how to read, or who are just beginning to read [74]. Obvious exceptions to limits to text can be made for software that has reading or writing as a goal.

\subsubsection{Visual Complexity}

High visual complexity can overwhelm any user, let alone children who cannot process visual information as quickly as adults [157]. One way of dealing with visual complexity is to use multilayer strategies where children are first presented with few actions and objects and as they become proficient with these can move on to add other actions and objects to the user interface [288].

\subsection{Interaction Styles}

\subsubsection{Direct Manipulation}

Shneiderman mentions three ideas behind the concept of direct manipulation: visibility of objects and actions of interest; rapid, reversible, incremental actions; and a replacement of typed commands by pointing actions on objects of interest [289]. Most software for children nowadays attempts to follow the ideas behind direct manipulation. The one idea that is often not followed in children's and adults' software alike is that of making actions rapid, reversible, and incremental.

Rapid actions are very important in children's user interfaces because children will often be less patient than adults when using software [118]. Children need quick feedback, and if they do not get it, they are likely to move to another activity. I experienced children's frustrations with waiting when working on digital library software [74]. For actions that take too long to complete in time to give quick feedback, 
children should be given feedback on the status of the action (e.g., through a progress bar) and should still be able to interact with the application and cancel the action if they wish to do so. I implemented such a solution for the initial version of the International Children's Digital Library [73]. In this software, children created visual queries that had to retrieve results over the Internet. As this occurred, children would see an animation in the area where results would appear and would then begin to see the books that matched their query as their covers were downloaded. Children were free to interact with the software at any time during the query execution, canceling the query, or navigating to a different part of the software as the query executed.

Reversibility of actions is also quite important for children to encourage the exploration of technologies while keeping the children in control. If taking an action can lead to children losing a drawing they worked on, for example, it will lead to a great deal of frustration and likely will lead the children to quit using the technology unless they can reverse the action.

Making actions incremental can also help children by avoiding the need for them to formulate complex instructions. Paired with timely and informative feedback, this can help children accomplish complex tasks.

\subsubsection{Menus}

In the broadest sense, children experience menus (i.e., sets of choices) in software all the time. The problems come when these choices are not immediately visible, and arranged in pull-down menus or other types of interactive structures. Indeed, navigation of menu structures has proved problematic for children [37, 74]. Even when working with ten to thirteen-year old children using handheld computers, Danesh et al. [60] found that menus that had to be brought up using a soft button were easy to forget. The problems though, are particularly dire with younger children, those in the pre-operational stage, usually aged under seven-years old, who do not have a good understanding of hierarchies. When working on the SearchKids project [74], I took a version of the 


\section{Design Principles}

software, which was developed with seven to eleven-year old children, to a Kindergarten class. SearchKids provided access to media about animals, which could be accessed by visiting a zoo with different areas, or by composing visual queries with the characteristics of the animals of interest. The zoo interface presented one level of hierarchies; a click on a part of the zoo took the children to media. The query interface on the other hand, required the navigation of multi-level hierarchies that presented a taxonomy of the animal kingdom. While the children in the Kindergarten class enjoyed the zoo interface, they could not understand the query interface and had difficulty understanding the way concepts were organized hierarchically.

\subsubsection{Text-Based Interactions}

Text can also be problematic if children need to interact with the computer by typing. If children do not know how to type, this can significantly slow down interactions and lead to frustrating experiences. Spelling can also cause problems if entering commands or search terms [329]. Even programming languages for children have moved from being text based, such as Logo to have a more visual approach such as Micro Worlds [228, 326].

\subsection{Using Pointing Devices}

Using pointing devices is a very valuable skill. One example of its value is in the work of Lane and Ziviani [184, 185], who are occupational therapists, and developed the Test of Mouse Proficiency with the aim of identifying children who have difficulty using the mouse in order to offer them appropriate interventions. The test assesses children's proficiency through four games, each requiring the use of a different mouse skill: pointing and clicking on stationary targets, pointing and clicking on moving targets, drawing, and dragging and dropping items.

Following is information on what types of devices are most appropriate for children, and then present information on how children perform in pointing and dragging tasks, and how they use mouse buttons. 


\subsubsection{Age-Appropriate Devices}

Much of the early research with children and input devices focused on identifying the most appropriate pointing input device for children. The mouse came out the winner in most studies when compared to a variety of devices such as trackballs, joysticks, and keyboards [150, 171, 172, 261]. Particularly interesting was the study conducted by Revelle and Strommen [261] who found that the mouse provided advantages to preschool children, but only after practicing with it for some time. This is something to take into account when evaluating input devices. The only exception to the mouse coming on top was a study by Strommen et al. [311] with three-year old children where the trackball was favored.

Little attention had been paid until recently to issues of input device size. Hourcade et al. [129] visited this issue in a study comparing four and five-year old children's performance with small and regular sized mice. The results suggest that mouse size does not affect performance. One limitation of this study is that all participants had experience using a regular-sized mouse. The results though, are in line with previous observations by researchers pointing at mouse size not making a difference [57].

Surprisingly, little work has been conducted on evaluating the merits of direct pointing technologies, such as styluses and touchscreens. In my experience, touchscreens are always well received by young children, perhaps because they provide a more concrete means for selecting options on the screen and, if icons are sized appropriately, can help remove difficulties children may find in pointing and operating an indirect pointing device like the mouse. When working on the International Children's Digital Library, for example, our child design partners at the University of Maryland would always prefer to work with the touchscreen in the laboratory as opposed to other computers where they had to use a mouse.

\subsubsection{Pointing}

A visit to a Kindergarten class with software I had designed with seven to eleven-year old children introduced me to the problems young children have with pointing. The children that tried to use the software 
were very frustrated as some of the icons were too small for them to accurately click on. Looking back at my experiences with the seven to eleven-year olds, I had seen some issues with pointing, that is why the icons in the software I designed were larger than those in applications designed for adults. I had also noticed one strategy children used to deal with their inaccurate clicks. They would click the mouse "machine gun style" until they found that the system responded. Sometimes this would lead to a click on the wrong icon, which would bring frustration. The barrage of clicks by children also made me realize the importance of ignoring clicks that occur as software transitions from one state to another while processing a click.

A look at the literature on children and pointing tasks reveals a long record of studies dating to the 1970s showing that young children's pointing performance is below that of older children and adults $[165$, $276,313,328]$. Several studies have shown that these differences persist when children use computer pointing devices [57, 124, 147, 150, 172]. A study I conducted with four and five-year olds showcased the differences between preschool children and young adults when conducting point-and-click tasks. Perhaps the clearest evidence was given by plots of the paths taken by participants to complete tasks, where the jagged paths taken by preschool children contrasted with the direct paths taken by young adults (see Figure 6.1 and Figure 6.2). There were also clear differences in terms of accuracy, with four-year olds needing targets four times larger in diameter than young adults to achieve an accuracy level of 90 percent [124].

A follow up analysis of the same study's data looking at submovements in pointing tasks suggested that the differences in performance between adults and children were largely due to the inaccuracy of children's sub-movements near the target both in terms of direction and length [123]. There was a balance between undershoots and overshoots of the target, and with larger targets, both children and adults tended to point at an area of the target closest to the location of the mouse cursor.

The easiest way to help young children with pointing is to make targets large enough. One challenge is that programmers can only control the number of pixels assigned to a target, and cannot control the actual 
(a)

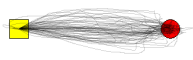

(b)

(c)

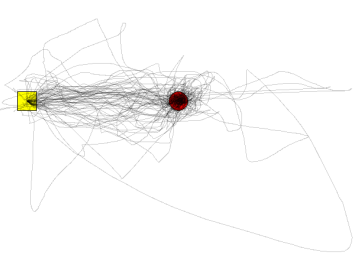

Fig. 6.1 Paths taken by participants to click on a 32 pixel target at a distance of 256 pixels. (a) Paths taken by all adult participants. (b) Paths taken by all five-year old participants. (c) Paths taken by all four-year old participants [126].

motor space that the targets occupy (i.e., how much one would have to physically move the mouse from one end of a target to the other). Furthermore, monitors with higher resolutions can also lead sizes in pixels to lose importance. That said, in Hourcade et al. [124], four-year olds achieved a level of accuracy of 90 percent with targets that had a diameter of 64 pixels, $3.6 \mathrm{~mm}$ in motor space, and $23.7 \mathrm{~mm}$ on the screen. Five-year olds achieved the same level of accuracy with targets half the diameter (i.e., 32 pixels). Young adults reached 90 percent accuracy with targets 16 pixels in diameter. 


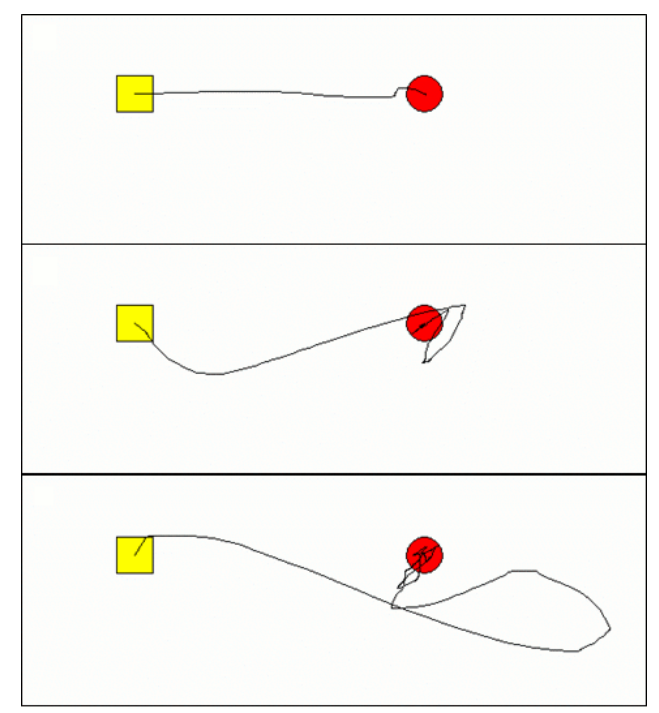

Fig. 6.2 Plots of three participants' mouse motion toward a 32 pixel circular target 256 pixels away from the home position. From top to bottom, a 21-year old female, a five year eight month old female, and a four year six month old female [126].

The other way to help children is to slow down the speed of the mouse cursor. This can provide for more precision when pointing at targets, but can also cause frustration in getting to them, especially given increasingly larger monitors and screen resolutions. This is something that can be done by parents or teachers if they notice children having difficulty. An alternative is to slow down the mouse cursor only when the mouse is being moved at slow speeds. More research needs to be conducted on whether this is a good option for children. One problem with the above mentioned solutions (including larger targets) is that they do not necessarily prepare children for more difficult pointing tasks.

Other solutions that have been suggested for adults also have limitations. Bubble or area cursors which make the active area of the cursor larger than a point do not help in cases where targets are clustered [110, 335]. The same problem happens with semantic pointing, where targets look smaller than their active area [29]. Expanding targets are unlikely to work because they attempt to predict the 
target the user intends to point at partly based on the direction of movements and young children's movements tend to lack directional precision [123, 207, 341]. All of the above solutions require knowledge of the location of the targets and thus would have to be implemented in each software title that wanted to use them, something that would make them less likely to be adopted.

I proposed an alternative approach designed for children that detects when children are having difficulty pointing at a target based on the characteristics of children's sub-movements [123]. It is based on the observation that sub-movements near a target tend to be slower and shorter than other sub-movements. This information could be used to trigger a precision pointing mechanism (e.g., slowing down the speed of the mouse cursor). My colleagues and I used this approach to develop PointAssist, which enabled four-year olds in a study to achieve accuracy rates similar to those of 18-22-year olds in previous studies that used very similar testing conditions [128].

The main advantages of PointAssist are that it does not need to know about the location of targets and thus can be implemented with software that runs in the background and affects all applications. Another advantage is that it works as a scaffold. When children cease to have difficulty in pointing tasks, the precision mode does not get triggered.

\subsubsection{Dragging}

Drag-and-drop interactions have been challenged in children's software by click-move-click interactions where users click on an object to move, move the mouse to a destination, and click again to drop the object. Click-move-click interactions assume that the objects are there to be moved only and not to be invoked as in an icon representing a file. Even in this case, there is controversy as to which type of interaction serves children best, as there have been contradicting results in studies conducted over the past ten years.

Joiner et al. [147] conducted two studies comparing drag-anddrop to click-move-click. They found that five to six-year old children took less time on average to complete tasks using the click-move-click 
technique and committed less errors. The problems were magnified for long-distance drag-and-drop tasks and did not seem to be present in short distance drag-and-drop tasks. There were no differences between click-move-click and drag-and-drop for older children.

Inkpen [138] recommended the use of click-move-click interactions over drag-and-drop interactions. In two experiments, nine to thirteenyear old children were quicker and committed less errors when using click-move-click interactions. There were some peculiarities to the way the click-move-click interactions were implemented that may partly explain differences in the results with other studies. The click-moveclick interactions, as described in detail for the second experiment, could be more precisely described as press-move-press interactions, as the location the release of the mouse button was not taken into account. This is in contrast to the standard way in which clicks work in Microsoft Windows, for example, where clicks require that the mouse cursor be on a target as the mouse button is pressed and released. In other words, pressing the mouse button inside a target and releasing it outside does not generate a click event on a target in Windows. The other design decision that favored click-move-click interactions in these studies is that a drop error in the click-move-click condition kept the target "picked-up." In other words, if children missed the target receptor when clicking, they could try again and again, with no penalty. Under the drag-and-drop condition however, if children released the mouse button somewhere outside the target receptor, the target would go back to its original location and would have to be picked up again.

Conducting a study almost a decade after Inkpen and Joiner, Donker and Reitsma [67] found the opposite result with five to sevenyear old children conducting drag-and-drop tasks faster and with less errors than when following a click-move-click approach. This study used letters as items to move, which had different sizes and aspect ratios, making it difficult to compare results with other studies. An additional experiment found that five to seven-year old children's and adults' drag-and-drop errors are not related to difficulty in keeping the mouse button down, but on errors at the beginning and end of a dragand-drop operation [68]. One of the most interesting findings was that 
movement distance did not affect the successful completion of a task. This is the opposite of what Joiner et al. [147] observed. The study was conducted with five and six-year old children, as well as university students. Donker and Reitsma recommend that feedback be provided to children when a target can be picked up and when it can be dropped off on a receptor by, for example, changing the appearance of the mouse cursor.

The conflicting results are somewhat puzzling. More studies need to be conducted to find out why there were differences. Some possible reasons for the differences may be due to young children, especially five to six-year olds, having more experience in this decade than in the previous one with using input devices and therefore having less problems with drag-and-drop tasks. It could also be that the mice used by Donker and Reitsma [67] had better designed buttons that enabled children to keep the button down more easily. Whatever the reason, it is unclear what interaction technique designers should select.

Another frequent use of dragging is for selecting a number of objects. For these situations, Berkovitz [24] recommends that marquee selection of objects be implemented by having children draw a circle around items to select instead of drawing a box. He found this advantageous in work with six and seven-year old children.

\subsubsection{Use of Mouse Buttons}

Hourcade et al. [125] studied the use of mouse buttons by four and fiveyear old children as well as young adults who were not told what button to use. The software the children used during the study responded to clicks from both the left and right mouse buttons. While all adults used the left mouse button in every task, and most of the five-year olds (ten out of thirteen) also used the left mouse button exclusively, most four-year olds used a combination of left and right button clicks (see Figure 6.3). A more recent study with four and five-year old children who had greater experience using the mouse found that a majority of the children used the left mouse button exclusively. Still, 10 percent of the children used the left mouse button less than 90 percent of the time. 

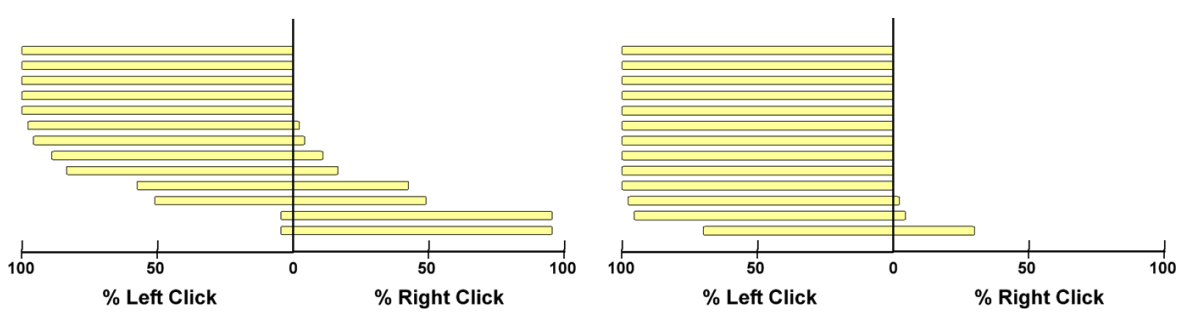

Fig. 6.3 From left to right, percentage of left and right clicks by four- and five-year olds [125]. Each bar represents one participant.

Three strategies can be used to prevent frustration in young children who do not get what they expect when they click. One is to provide the same functionality through all mouse buttons. I used this successfully in developing KidPad [124]. The other approach is to provide functionality only through the left mouse button, with other buttons not providing any functionality. The advantage of this approach is that it could prepare children better for applications where different buttons provide different functionality. On the other hand, I have observed children get frustrated when they are clicking a button and nothing happens. The third option is for children to use platforms where mice have only one button (e.g., Macintosh), which avoid these problems altogether.

\subsection{Use of Sound}

Very little research has been conducted on the use of sound in user interfaces designed for children. Jacko [143] studied children's identification of auditory icons and found that as children get older, they improve their ability to identify icons. Mann et al. [201] found twelve-year olds did not benefit from listening to important information in multimedia educational software when compared to the same information being presented in text. 
The following is a survey of research conducted in the field of interaction design and children. The description of the research conducted is organized into 10 areas based on the aims of the research: supporting creativity and problem solving; supporting collaboration and communication; accessing, organizing, gathering and exploring content; learning from simulations; supporting children with special needs; interacting with "intelligent" characters; developing guidelines for interaction design; mobile, tangible and ubiquitous computing; designing and evaluating technologies; supporting healthy lifestyles; and learning skills. Many projects fall under more than one category and in those cases they are described under the area where the majority of research efforts were directed. These descriptions are followed by a discussion of challenges for future research.

\subsection{Supporting Creativity and Problem Solving}

Piaget's constructivist ideas support the idea of children learning by experiencing the world and being active learners. These theories, together with more modern constructionist and social-constructivist 
ideas have yielded a large number of projects that aim to use technologies to support children's creativity and problem solving.

\subsubsection{Programming}

The origins of the field of interaction design and children could be traced back to Papert's and others' work at the MIT on making programming accessible to children. This led to children's involvement with computers at schools to be mainly directed at programming activities throughout the 1980s and part of the 1990s, to be later replaced by educational games, multimedia activities, and web-based interactions. Regardless of this change, much research is still being conducted on providing children with programming tools that fit their needs and abilities. Over the years, the emphasis has gone from text-based programming environments, to visual programming, to tangible and even room-based programming environments.

Starting with Logo [228], many programming tools have been developed with children as the intended users. One of the main motivations behind these tools is the idea that through programming children can learn mathematical and logical concepts while creating artifacts of interest. Micro Worlds is the latest incarnation of Logo, showing a more visual interface than the original [209, 326]. Other programming tools for children include ToonTalk [156], in which children learn to program while playing a game, Magic Words, where children control images by adding words to them [170], and Squeak [298] and Alice [56], intended mainly for teenagers and undergraduate students (see Figure 7.1).

Game and simulation builders are similar to some of the programming tools. In this case, they enable children to create their own interactive simulations. Examples of these tools include StageCast [296] and AgentSheets [258].

Harel and Kafai collaborated on projects where children from diverse backgrounds used the Logo programming language to design educational software on fractions for younger children [119]. Some of this work involved collaborating with peers as well as helping younger children with their own programming activities $[154,155]$. The emphasis was on the learning the programmers of the instructional 

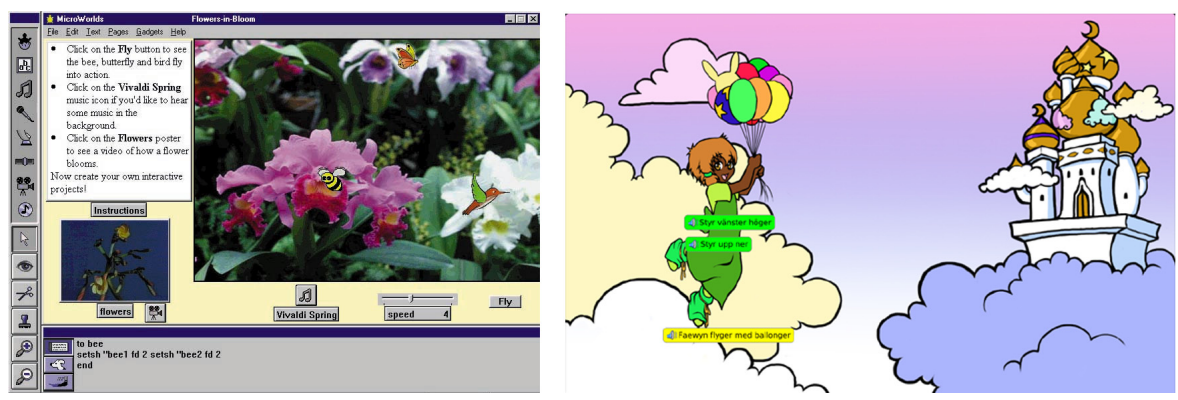

Fig. 7.1 From left to right, screenshots MicroWorlds by LCSI (MicroWorlds, 2006) and Magic Words [170].

software would do by having to think about how to design software to teach fractions [119]. Kafai continued a similar line of work, providing children with tools to create games for teaching fractions [151, 152], and instructional software to learn science concepts [153].

Subhi [312] found positive results from eight and nine-year old children's use of an Arabic version of Logo and recommends that students program in pairs to reduce the need for teacher intervention, and that they formulate their own goals in order to increase motivation.

In spite of these positive results, there was a change in school use of computers away from programming. Robertson [264] worried about the move from children having a high level of interaction and control of computers when using programming software such as Logo, to less interactive and controlled applications that provide multimedia content and educational games. Similarly, O'Reilly [222] argued for the incorporation of programming as part of the curriculum given that it provides opportunities for making use of logical and mathematical knowledge in activities where children can pursue their own goals.

Part of the reason for the move away from programming was the difficulty many children faced in producing complex programming constructs. Many research efforts have been undertaken to alleviate this problem. Bruckman and Edwards [39] studied six to sixteen-year old children's use of a programming environment using natural language. The language seemed to appeal mostly to children eight and older, with the children that went beyond a basic level of scripting being 
ten or older. Their conclusions were positive towards the use of natural language programming by children with the purpose of promoting learning. Wright and Cockburn [336] on the other hand, found that eleven-year old children understood algorithms more quickly if they saw them in conventional code than if they saw them in English. There were no differences in terms of accurately interpreting the algorithms.

Rader et al. [245] evaluated children in fourth and fifth grade using the KidSim/Cocoa visual programming environment. The assessment found that children were able to complete simple tasks with the environment such as drawing and animating characters but were not able to construct more complex behaviors.

Sheehan [286] developed recommendations for the development of programming environments for children based on six to ten-year old children's understanding of computer programming. He recommended making the use of multimedia resources an integrated part of the programming environment, providing high level instructions to match children's interests, providing an easy way to move from seeing programs running to showing why they run that way, and letting children easily run programs when they are not interested in programming.

Many research efforts have concentrated on the use of tangible elements for programming. One example is the work by McNerney [208] on tangible programming bricks. Zuckerman et al. [342] presented work on FlowBlocks and SystemBlocks, construction kits that enable children to create simulations of generic structures. The rationale behind these manipulatives is to provide children with the ability to interact with dynamic behavior at the symbolic level. Wyeth and Purchase's [337] electronic blocks included sensors, actuators, and logic blocks that could be put together to create simple programs that could act as part of play artifacts children created such as vehicles and robots. The blocks were evaluated with four and five-year old children. Horn and Jacob [121] have been developing the Quetzal language, which uses tangible parts that children can use to put together programs. The parts do not have any electronics; instead, they are scanned in order for a computer to then compile and run the code.

There has also been research on programming by example through the use of motion. Frei et al. [97] developed curlybot, a palm-sized robot 
shaped approximately like half a sphere with wheels at the bottom, with which children could record motions on the floor and then have curlybot repeat them, in a loop if desired. Raffle et al. [249] developed Topobo, a construction kit with kinematic memory. With Topobo, children can put together skeletal type structures that can then be physically transformed. These transformations can then be replayed. Eighth grade children were able to develop moving structures using Topobo. In follow up work, Raffle et al. [248, 246] added components that enabled the control of behavior through tangible devices and modified game controllers that extended Topobo's "record and play" functionality to enable recording, sampling, sequencing, and performing.

Programming for children has also been taken to larger environments. Montemayor et al. [215] studied the physical programming of interactive rooms by four to six-year old children. They found children had difficulty distinguishing programming from participating in the programmed environment, but were able to make simple programming constructs. Mattila and Vaatanen [205] developed prototypes for programmable interactive playground environments where children can create and play games. The playgrounds were indoors and provided children with inputs through a floor setup with sensors, providing feedback through audio and video. Children could program the environment using a visual programming environment. Fernaeus and Tholander [90, 91, 92] and Tholander and Fernaeus [321] have studied the design of innovative interactions to enable groups of children to collaboratively program in a room environment. They highlight the social and physical aspects of the activity. Rather than having a tight coupling between physical and digital elements, they moved all tools to the physical domain, and showed the results of actions in the digital domain. They found their setup enabled groups of children to program together, with most of the collaboration occurring without the use of technology.

Reflecting about experiences with construction kits for kids, Resnick and Silverman [260] commented on key guiding principles: support authoring, support novices, provide a wide range of exploratory activities, provide opportunities to encounter powerful ideas, support many ways of getting things done, favor simplicity, make basic instructions 
map to concepts that matter, enable children to get a lot done with little programming, invent things that you would want to use yourself, and iterate development. Past work by this team includes computationally augmented bricks, beads and badges [259].

\subsubsection{Storytelling}

Supporting storytelling has also been a popular theme in technologies that support creativity. Storytelling has played an important role for humanity as a way of transferring and retaining information, with oral traditions being an example. It is easier to remember sets of facts if they are put together in a story, than if they are in a list. In this way, storytelling also helps children develop communication skills. Technology can play a positive role in storytelling by allowing for storage, and the ability to copy, share, and edit stories. It can also provide the means to create nontraditional forms such as non-linear stories.

Some storytelling has been conducted with help from programming environments. A study by Vincent [325] found that ten and eleven-year old visual learners who normally had difficulty expressing themselves through writing improved the volume and complexity of their writing when combining it with visual displays programmed in MicroWorlds.

Some computer games now allow users to program their own characters, settings, and plots. Robertson and Good [266] studied children's storytelling through the construction of computer games. The children, between the ages of twelve and fifteen, built games using the Neverwinter Nights toolset. They were highly motivated by being able to design their own characters and put together plots. In earlier work, these researchers had studied the creation of virtual environments using game engines for children to participate in stories as characters [265]. Robertson and Nicholson [267] have continued this line of research by studying the scaffolding children need to develop their own adventure games.

There are other efforts involving the creation and manipulation of characters. Graphic StoryWriter automatically generates written stories based on children's manipulation of characters and props in the software [301, 302]. Machado et al. [199] developed Teatrix, which gave 
children the ability to collaboratively tell stories and participate in drama performances in a virtual environment. Garzotto and Forfori [102] developed a web-based multi-user environment called FaTe2 that enables children to engage in storytelling and games. The environment supports both co-present and remote collaboration in storytelling activities.

KidPad enables children to create visual stories in a large zoomable space where they can draw, type, and create hyperlinks across this zoomable space [21, 77, 124, 306]. Stanton et al. [299] augmented KidPad to function in a room environment with tangible controls (see Figure 7.2).

Other storytelling environments have children interact outside the computer. PETS enables children to put together their own robot they could then program to tell stories [75]. Also of note are Cassell's StoryMat and Sam the CastleMate [44]. StoryMat records children's stories involving stuffed animals and replays them to other children [45]. This line of research was followed by work on Sam, a conversational agent with whom children can tell stories [275].

Other researchers have used tangible technology to facilitate storytelling. The Pogo Project used specialized hardware to support

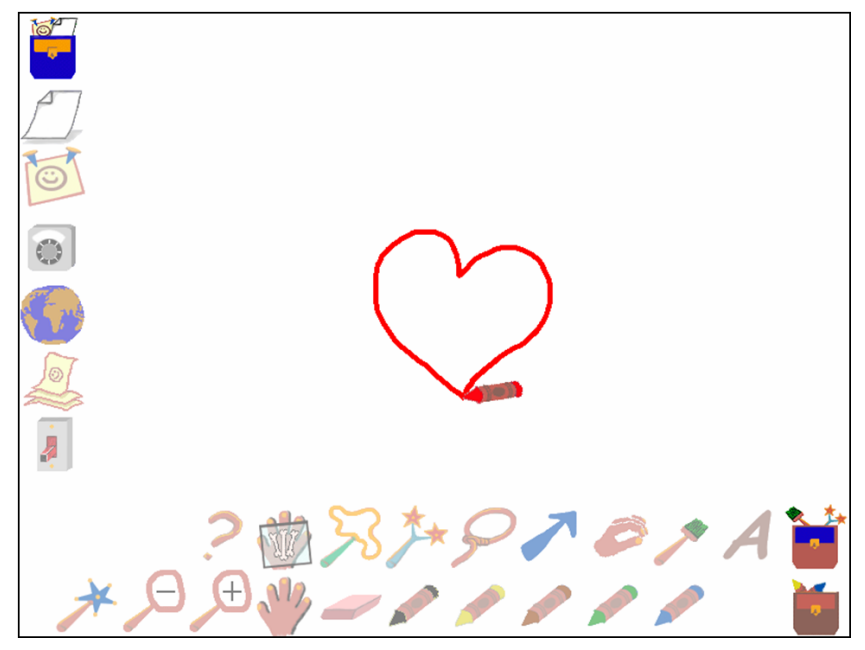

Fig. 7.2 Screenshot of KidPad [124]. 
collaborative storytelling activities by elementary school children [61, 98]. Pogo emphasized the use of tangible elements for storytelling, an active and physical participation of children, and a bridging of elements from the physical and digital worlds. In a similar vein, Montemayor et al. [214] developed a room-sized storytelling environment through the use of embedded sensors and actuators. This project had the goal of taking the storytelling that often occurs when children play with cardboard boxes and other physical items and augmenting it with technology.

Other lines of research have focused on designing innovative devices that can aid in storytelling activities. Labrune and Mackay [180] prototyped ideas for Tangicam, a mobile device designed for children to capture pictures and video and then use these to put together narratives, which they then extended with work on SketchCam [182]. Ryokai et al. [274] developed I/O Brush, an augmented paintbrush that enables children to capture images or video and then bring them to a special canvas to draw with them. Raffle et al. [247] developed Jabberstamp, which enables children to embed audio recordings into drawings, collages, and paintings they create on paper. Halloran et al. [115] used handheld devices to digitally augment a field trip by fifth graders with the goal of providing structure and activities that would lead to creative writing inspired by the field trip.

\subsubsection{Other}

Other work on supporting creativity includes that of Johnson et al. [146] who developed a way for children to control virtual characters by using a plush toy embedded with sensors. Manipulating the toy would in turn control a virtual character on the screen. The idea behind this work was to have the input device mirror the item that it acts upon, feel inviting and friendly, and produce different results given different contexts. Also using plush toys, Paiva et al. [226] studied how children may express emotions by using a doll with sensors [226].

Also using tangibles, Stringer et al. [308] developed a system to teach rhetoric skills to eleven-year old children. The system helped 
children construct arguments by helping them organize material they gathered from digital sources using physical tags.

Luchini et al. [195] studied thirteen-year old children's use of handheld computers in the classroom for creating concept maps. They found that the handheld version made it more difficult to create maps that are easy to read and do not contain orphan nodes when compared to a version using a regular computer monitor.

There has also been research on environments to support problem solving in mathematics. AquaMOOSE is an example of software that uses $3 \mathrm{D}$ environments to teach mathematical concepts. In AquaMOOSE, high-school students create three dimensional shapes as well as challenges for others to solve [84].

Cuthbertson et al. [58] developed a media environment that uses three-dimensional tracking of objects to provide audio and visual feedback. They have used it to design performances with fourth and fifth grade children.

Some of the most radical research on computer supported creative endeavors has been conducted by Eisenberg et al. [82] who designed several systems that allow children to design and build physical artifacts. These include artifacts made of folded paper [83], three-dimensional objects visualized through transparencies, mathematical surfaces modeled by slices of wood and gears also made out of wood cut in a laser cutter (see Figure 7.3). Eisenberg [81] has also proposed the use of a variety of novel materials in technologies for children. These include
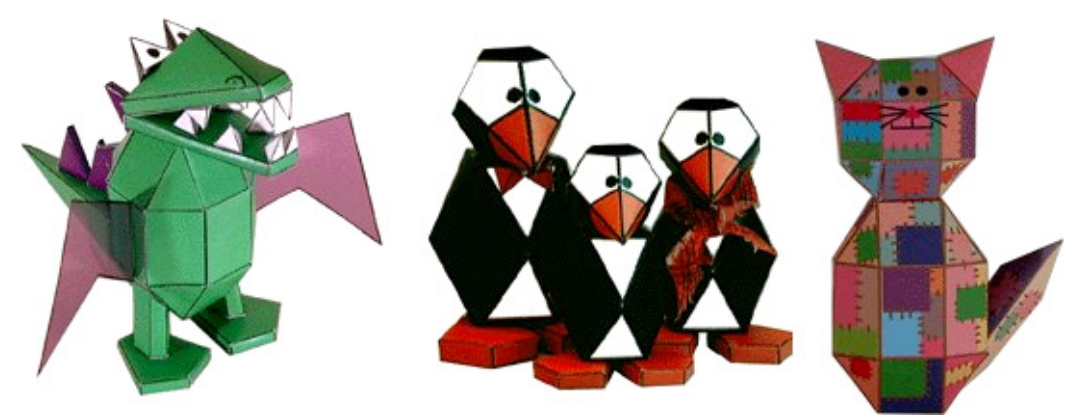

Fig. 7.3 Folder paper figures designed with JavaGami, in research led by Mike and Ann Eisenberg at the University of Colorado Boulder. 
materials that change color based on temperature, shape-memory alloys that return to a given shape, and piezoelectric materials that can produce electricity if someone applies force to them (e.g., pressing).

Also using novel materials, Berglin [23] began experimenting with smart textiles in the construction of interactive toys. She used textiles that transform thermal information, pressure, and optical information into electrical signals as sensors. She also used shape memory materials and chromic materials as actuators. Buechley et al. [41] explored the use of electronics combined with textiles and contributed a taxonomy of the types of activities children may engage in such projects including hardware, textile, and software related activities.

\subsection{Supporting Collaboration and Communication}

Socio-cultural approaches to child development have motivated researchers to look for ways to provide children with computing activities where at the very least collaboration is not hampered, and at best it is encouraged and facilitated. The challenge for researchers is to move away from the personal computer paradigm that sees one user per computer, with each computer having one set of input devices, preventing children from interacting in a computing experience at the same time. The research efforts in this area have gone from augmenting personal computers with multiple devices, to moving collaboration to tangible devices, and more recently have surprisingly made a comeback to the use of multiple devices.

Inkpen was one of the first to study the use of multiple input devices to support children's collaboration and found that when doing so children were more engaged, active, and preferred having their own device rather than sharing [139]. Further work by this research group found that children's collaborations in these settings were similar to collaborations in paper-based activities. This research also highlighted the need of considering the goal of the activity when deciding how to support collaboration (e.g., sharing a mouse and a display, sharing the display only, or not sharing a mouse or a display) [282].

Abnett et al. [2] observed five to seven-year old children use KidPad in pairs [124]. The pairs used one or two mice, shared a display, and 
were mixed gender or same gender. The children were asked to create stories together. When using two mice, mixed gender and all-male pairs were judged to have created better stories than when using one mouse. An analysis of the children's conversations showed that when using one mouse, males had great difficulty in sharing the mouse. This led either to one child dominating the creation of the story, or both children fighting over the mouse. When they did not have to share, the nondominant children were able to have some input in the story and the fighting subsided, leading to better stories.

Stanton and Neale [300] studied similar issues comparing children's behaviors with pairs sharing one mouse versus getting their own mouse in a content creation task. These six and seven-year old children showed different types of behaviors given the condition, with the two mouse condition leading to division of labor and work in parallel, and the one mouse condition leading to a range of behaviors from collaborative work to complete domination by one of the children.

Druin et al. [76, 73] explored the use of two ways of navigating through a digital library application where children had their own input devices but shared a display. In one condition called "confirmation collaboration" both children had to agree on where to navigate, while in the other condition, navigation occurred as soon as either of the children decided to navigate. Confirmation collaboration led to shared goals, less conversation, more concentration on the user interface, and better regard for the tasks by seven-year old children. Independent collaboration led to individual goals, more conversation, more concentration on content, and less regard for tasks by seven-year old children.

Pal et al. [227] argued for the need to support multiple children interacting with one computer in developing countries given the low number of computers available per child in schools. They supported this assertion with data on the learning disadvantages children face if they do not get to interact directly with software. Singh Pawar et al. [292] followed this work by conducting experiments to see the advantages gained by children sharing one display when they have access to multiple mice. The experiment compared four different modalities of use of educational software: one user-one computer, multiple-user 
single-mouse, multiple-user multiple-mouse independent, and multipleuser multiple-mouse confirmation. In the independent mode, the first click decided the navigation in the software, while in the confirmation mode all children had to agree. The multiple user conditions had five children share a computer. Pre and post tests of learning outcomes showed that children in the confirmation mode did as well as children who did not have to share a computer. Boys in particular were affected negatively by the conditions where they had to share a mouse and where there was no confirmation of how to navigate. The mode of sharing did not affect girls' performance. This confirms the findings of Abnett et al. [2]. It also shows that boys' problems with sharing cut across cultures as this study was conducted in India and Abnett et al.'s [2] was conducted in England.

Moving away from the computer, Ovaska et al. [224] provided kindergarteners with an electronic whiteboard to conduct creative activities. The whiteboard only allowed one child to interact with it at a time, which limited the types of collaborations available, but still enabled groups of children to discuss what was happening and provided for engagement through activities designed to give every child a turn to interact with the whiteboard.

Looking at how teachers can interact with children, Plowman and Stephen [242] used the concept of guided interaction to better understand ways in which adults can actively support preschool children in their interactions with technology both face-to-face and remotely both in terms of time and space. Examples of face-to-face support include demonstrating, explaining, instructing, monitoring, and providing feedback. Examples of remote support include arranging for access to technology, setting up activities, and checking on levels of engagement.

Other researchers have also looked at children's interactions with adults, but in this case within their families. Dalsgaard et al. [59] conducted a study of Danish families to learn about communication between parents and children to better learn how to support it through technology. The study revealed commonalities and differences between the communications in these relationships and those between adult couples that were studied by Vetere et al. [324]. For example, they found that the relationships are unequally balanced, with parents playing 
the role of protectors, usually seeking more disclosure from children than what they provide, and that important communications tend to occur in settings provided by parents. Related work on family communications was conducted by Plaisant et al. [240] who developed shared family calendars and Kim et al. [168] who designed home appliances to facilitate communication between family members.

Moving to the use of handhelds, Cole and Stanton [55] developed guidelines for the use of mobile devices in collaborative activities. They found sharing small displays was difficult and recommended sharing information only at specific points in an activity. Likewise, they recommended that activities be organized to support both tightly and loosely coupled collaboration, and to ensure it is visible from another child's physical actions what they are currently working on. Borovoy et al. [30] studied the creation of software objects with game-like qualities that could be passed between handheld devices. These objects called $i$-balls had to be created on a desktop computer, but then could be shared between handhelds. Makela et al. [200] conducted a study of the use of images captured by mobile devices to aid in children's communications. In this study, children ranging in age from eight to fifteen-years old used images to create stories, express affection, and create art. Children also expressed interest in annotating images.

Some work has also been conducted with tangible user interfaces. Price et al. [243] developed a game where children could use tangible devices to learn information about a creature called the Snark. An evaluation with pairs of six to ten-year old children found that the children were able to engage in playful activities in which they collaborated using both physical items and physical action to interact with the game. Chipman et al. [51] developed tangible flags, which enable children to tag objects (e.g., trees, rocks) and annotate them digitally. This technology enables collaboration by enabling other children to access previous annotations of an object and add their own.

Other lines of research in the support of collaboration include the use of remote collaboration by Ellis and Bruckman [85] who developed a system to support sixth grade children obtaining oral histories from elders, and creating stories based on these. 


\subsubsection{Online Communities and Social Networking}

While mostly a phenomenon for teenagers and young adults, social networking websites and online communities are also available for children under thirteen and have been very popular. In contrast to other research on collaboration and communication, there is very little scholarly research in this subject, with the leading examples being commercial ventures, and research being limited to examining these technologies. Some exceptions include Bruckman's [38] work on MOOSE Crossing, an online community for children to learn about object-oriented programming and practice creative writing, and Kaplan and Chisik's [161] work on collaborative reading and annotation of online books.

Examples of online communities targeted at children include Neopets (www.neopets.com), Club Penguin (www.clubpenguin.com), Webkinz (www.webkinz.com), Nicktropolis (www.nicktropolis.com), Funkeys (www.ubfunkeys.com), BarbieGirls (www.barbiegirls.com), and Ty Girlz (www.tygirlz.com). They are quite popular. As early as 2003, for example, Neopets claimed 16 million users [109]. These online communities give children the ability to create an avatar that they can use to explore a virtual world. The virtual worlds include games as well as the ability to chat with other children. In the virtual worlds, children can obtain accessories or buy improvements for their avatars or themselves in the virtual world. These require spending money on monthly fees or credits that can be transferred online, or can be obtained by participating in games that include advertising, or by completing market surveys (Grimes \& Regan Shade, 2005). In order to increase the safety of children, parents can limit chat to preset phrases, or can otherwise allow children to chat in areas that include filters to avoid disclosure of personal information as well as the use of foul language. Children's profiles are limited to sets of likes and dislikes that often involve products promoted by the sites (e.g., Nickelodeon characters). In addition, anything the children say or create in these sites belongs to the sites and not to the children given the terms and conditions that users of these sites must agree with in order to join.

Given the popularity of these sites, there is a clear need to conduct research to learn about how children understand what happens in these 
virtual worlds and how they change their behavior. These sites, for the most part, encourage consumerism, by rewarding the collection and acquisition of items that cannot be shared with others to enhance one's position in a virtual society. Most of the sites, in addition, conduct aggressive advertisement of products aimed at children. Will this affect children's buying patterns, generosity and sense of community as they grow up? Also, these sites enable children to develop online friendships and depending on chat setting, to open up to others and express their feelings. This seems like double-edged sword, on the one hand enabling children to express themselves and talk about feelings that may be difficult to talk about in person, while at the same time potentially getting in the way of personal relationships outside the virtual world. It is unclear how this will affect these children's social interactions as they grow up. Another aspect of these virtual worlds is that children can engage in chatting or instant messaging as they conduct other activities such as playing games. This type of multi-tasking was not available to previous generations and could have an impact on children's ability to multi-task as well as on their ability to concentrate and pay attention. This in turn could have an impact on children's learning styles and strategies.

\subsection{Accessing, Organizing, Gathering, and Exploring Content}

One of the main advantages computers can bring to children is access to content they would otherwise not be able to experience. These possibilities have been enhanced by the Internet, which allows children to access content from other countries, and in quantities that would never fit in school computers. Computers also provide new ways of capturing, gathering, and organizing information, enabling children to generate their own content and make sense out of it.

The International Children's Digital Library (ICDL), available at www.childrenslibrary.org, provides children with access to about 2000 books from dozens of countries in 39 different languages with ageappropriate interfaces for finding and reading books of interest [36, 72, $78,127]$. It provides a searching and browsing interface for elementary 
school children that eliminates the need to navigate classification hierarchies [37]. It was designed based on the experiences of the SearchKids project [74]. While the $I C D L$ was not designed to replace reading actual books, Korat and Shamir [175] found no differences in literacy improvements between kindergarten children who experienced electronic books and those who were read books by adults (see Figure 7.4).

Kaplan et al. [162] looked for ways to adapt the $I C D L$ to the requirements of ten to fourteen-year old children. They found these children wanted to personalize the look of the user interface, conduct text searches over the collection and within books, and share annotations of books with groups of friends or classmates. Kaplan and Chisik [161] continued this line of work, studying ways in which digital books could be augmented to enable collaborative annotation. They augmented a book reader with "stamps" expressing questions, joy, sadness, ideas, or calls for attention. These stamps could be associated with sticky notes that included text. Children had the option of sharing each annotation with other children reading the same book. Kaplan et al. [163] studied a book reader prototype that incorporated these ideas with a group of ten

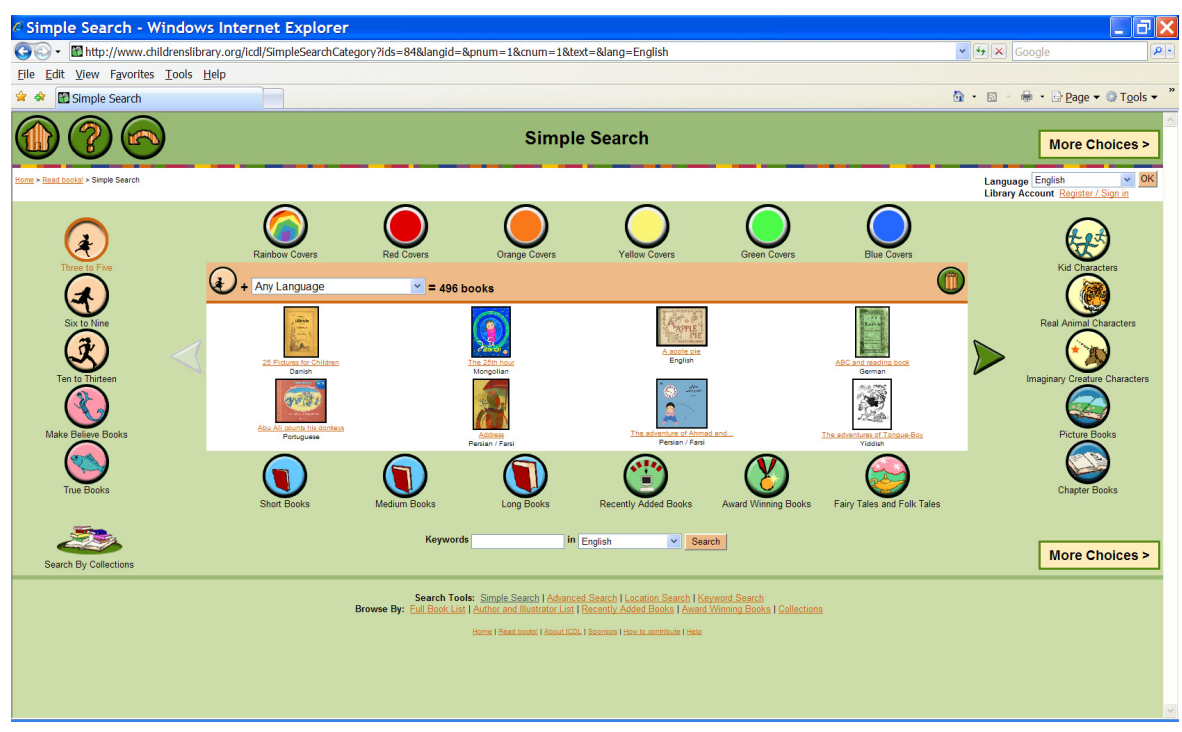

Fig. 7.4 Screenshot of search interface for the International Children's Digital Library showing a query for books for three to five-year old children (www.childrenslibrary.org). 
to fourteen-year old children. They found the children made ample use of annotations, sometimes even responding to questions others posed.

Other work on digital libraries includes that of Abbas et al. [1] who reported on middle school children's interactions with a digital library of web resource abstracts to support children's scientific inquiries. The web-based library was designed following the Learner Centered Design model that emphasizes the use of scaffolds to support and provide structure to children in their learning activities. Theng et al. [320] designed a digital library user interface for eleven to fourteen-year old children. One of their main goals was to enable children to submit their own content to the library and the prototype enabled children to submit writing and have it discussed by peers. Eriksson and Lykke-Olesen [86] developed a library catalog for the children's section of a library that children could browse by stepping on options on a large mat.

Other research projects have concentrated on providing ways for capturing and organizing content. Sharples et al. [285] used handheld computers for capturing and organizing content such as notes and photographs. The Ambient Wood project provided children with handheld devices to explore a digitally enhanced woodland environment where they could capture data and later organize it to understand environmental processes [252, 269]. Ambient Wood supported the activities highlighted by Marshall et al. [204] who argued tangibles should support both exploratory and expressive activities. In similar work, Bouvin et al. [31] developed a system that allows children to explore a city and annotate locations with information and share these annotations with classmates.

Children can also access valuable content at museums. Hall and Bannon $[113,114]$ provide guidelines for interactive museum exhibits. They recommend using a compelling narrative, making the exhibit inviting, allowing children to contribute to the exhibit, making sure technology does not get in the way of the experience, providing multisensory experiences, supporting both individuals and groups, supporting exploration, and incorporating the participation of experts.

Tangibles have also been used for retrieving information. Gorbet et al. [105] developed a tangible user interface for accessing and 


\section{Research Trends}

manipulating information based on triangles that represent query components and can be physically connected. Labrune and Mackay [181] developed prototypes for a system that incorporates technology into jewelry for the purpose of better managing contact lists, associating a piece of jewelry with an individual or group. Thus, instead of going through several menus to access the contact information for a friend, a teenager could touch a piece of jewelry they are wearing and be automatically connected.

\subsection{Learning From Simulations}

Computers can provide children with learning opportunities not otherwise available by taking them to places and situations they would otherwise not be able to experience. That is the motivation behind providing children with access to simulations. Following are some examples of this line of research.

Virtual reality has been used to create learning environments in which play is used for learning [273]. Göttel [106] used virtual environments to teach children about physical spaces and found that controlling avatars through a tangible user interface with haptic feedback worked better than mouse or cursor control. Moher et al. [213] used immersive virtual environments to teach third grade children that the Earth is round. They found that children not only needed to find the environments plausible, but activities were required to bridge knowledge gained while experiencing the simulation to the target domain. Moher [212] then moved his concentration to classroom based simulations that no longer use virtual environments. Instead, a simulation is scaled in time and space to fit within a classroom and its activities. These simulations called embedded phenomena work by providing children with displays to monitor phenomena. The simulations run continuously over weeks or months enabling children to monitor events and conduct scientific inquiries in a convenient setting.

There has also been work on simulating far away environments in children's playgrounds. Facer et al. [87] developed a game using handheld computers that simulated the African savannah, its resources and animals to teach children about lion behavior. In this simulation, 
children play the part of lions that have to work together in order to survive. The savannah environment is mapped onto a school playground, and each child carries a GPS enabled handheld computer that provides children with options on what to do at their given location [22].

\subsection{Supporting Children with Special Needs}

One encouraging trend in research in the past few years has been on designing technologies for children with special needs. Most of these technologies are aimed at aiding children's development and education.

\subsubsection{Children with Visual Impairments}

Jaime Sanchez and his research group have conducted a bulk of the research on educational technologies for children with visual impairments. Sanchez and Flores [277] designed and developed audio-based learning environments for and with children with visual impairments aged six to fifteen. The environments are geared at developing working memory and mathematics skills. An experiment showed particularly positive results in mathematics learning. Sanchez and Saenz [278] conducted similar work adding three dimensional sound in the context of solving problems related to geography and culture. This was based on earlier work on experiencing interactive stories using three dimensional sound [197].

Other researchers have followed similar strategies. McElligott and van Leeuwen [206] collaborated with blind children in the design of tools and toys combining tactile and audio interactions. They followed the philosophy of designing for children's abilities instead of designing around their disabilities. Raisamo et al. [250] designed and developed a game for children with visual impairments that uses haptic feedback from an off the shelf gamepad. The game was designed to help children in memory tasks.

\subsubsection{Children with Hearing and Speech Impairments}

Research on technologies for children with speech impairments has taken advantage of the Wizard of $\mathrm{Oz}$ technique, where children think 


\section{Research Trends}

they are interacting directly with a computer, but instead a human is interpreting their actions and interacting with the computer. Balter et al. [19] used a Wizard of $\mathrm{Oz}$ technique to test the interface to a computer based speech training system designed for children in need of speech therapy. The technique helped bridge the inaccuracies of the system in the detection of mispronunciations. Henderson et al. [120] designed a game for deaf children to learn American Sign Language. They used Wizard of Oz techniques to help with American Sign Language recognition. Further development of the game, called CopyCat showed encouraging accuracy levels for word recognition [32]. Iversen et al. [142] designed and implemented Stepstone, an interactive floor application for children with a cochlear implant that ties linguistic learning to body motion and group collaboration.

\subsubsection{Children with Autism}

In the past few years, researchers have begun to pay attention to research on technologies for children with autism. Pares et al. [231] developed an interactive environment for low functioning autistic children (see Figure 7.5). The system reacts to utterances, movements

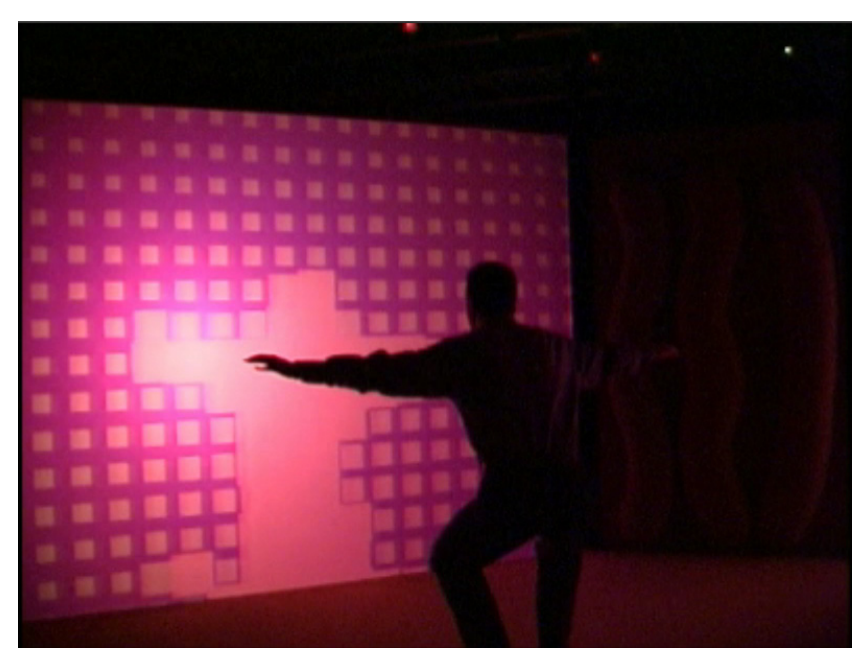

Fig. 7.5 Interactive environment for autistic children by Pares et al. [231]. 
and gestures from children and responds through sound, vibration, and visuals. It is thus designed to encourage non-repetitive activities where children can express themselves. Mohamed et al. [211] developed software to help children with autism focus on specific tasks. Through studying gaze and face orientation, it models how well children are paying attention and can make adjustments to stimuli based on this information.

\subsubsection{Hospitalized Children}

Children also need help when in stressful and uncomfortable situations such as being at a hospital. Weiss et al. [330] used video-conferencing to link hospitalized children with their classrooms. Bers et al. [26] provided pediatric patients in a dialysis unit with access to a virtual community through a graphical user interface. The idea was for children to receive support from their community while they were in a situation where they could not physically interact with others as they received treatment. The tool helped children communicate with others, and the children used it as a way to escape thinking about dialysis. The same research group had earlier worked on text-based storytelling technologies for children in a cardiology unit [25].

\subsubsection{Children with Motor, Learning, or Multiple Impairments}

Hornhof and Cavender [122] developed EyeDraw, which through eye tracking technology enables children with severe motor impairments to draw by using their eyes. They propose a multilayer approach to these type of user interfaces to enable children to easily get started with simple features while avoiding frustration from having too many features available.

Lathan and Malley [186] reported on the design of a system using robots to help children with a variety of disabilities in the development of motor skills, speech, and language. The robot was designed to be controlled by almost any part of the body, or even through voice. Ortega-Tudela and Gomez-Ariza [223] used multimedia tools to teach 
basic mathematics concepts to children with Down Syndrome who usually have learning and motor impairments and found that the children learned better than if conducting similar tasks using pencil and paper. Brederode et al. [33] designed and developed a game to bring together eight to fourteen-year old children with and without physical and learning disabilities. The design had the challenge of helping children with disabilities compete with others on an equal footing. The game was also designed to combine cooperation with competition in order to enhance participation and dialog.

Other research includes that of Sibert et al. [290] who developed a system for remedial reading instruction that uses eye gaze to trigger auditory prompts. Baloian et al. [18] studied the similarities and differences in technologies that map real world experiences into virtual environments for both blind and deaf children.

\subsection{Interacting with "Intelligent" Characters}

A controversial topic in human-computer interaction has also made its way to the field of interaction design and children. That is providing interactions with computers or computing power through the use of "intelligent" or "smart" characters. Some of the criticisms of interacting with these characters include that natural language interactions are not efficient, and that they hide the objects and actions of interest. Shneiderman [287] goes further and claims these designs involve deception by presenting computers as having human-like characteristics, which they have not. Moreover, characters that insist on conversing once users know what they are doing can get annoying and get in the way, as it happened with Microsoft's BOB and later with Microsoft Office 2000's animated agents [289]. Proponents of the use of this type of interactions claim that they can motivate children and make the computer more personable, increase engagement, and reduce anxiety and frustration (e.g., Lester et al. [189]).

When it comes to the use of these interactions with children, they are most often found in the form of "pedagogical agents." These are characters that teach children about a topic. These agents often follow the idea that knowledge is something to be transferred to the child, 
rather than constructed by the child. Most would thus fall under behaviorism. Researchers that work in this area though will usually claim that they actually are following socio-cultural approaches by providing a social dimension to learning through the characters [112]. The assumption is that computers are taking the place of actual tutors, mentors, teachers or children at times when they are not available [169]. This is a very dangerous assumption to make, as it can easily provide excuses for children not to get actual face-to-face interactions with people. Overall, the philosophy behind this work is not to use computers as tools to enhance children's potential to express their ideas, conduct inquiries, and create items of interest, but rather to use computers to replace the role humans play in children's lives because the world is not ideal and these helpful humans are unlikely to be available. There are good intentions in this line of research, but potentially dangerous and risky outcomes for children.

Studies have also shown that some of the assumptions made about agents are not supported by empirical evidence. Chiasson and Gutwin [50] conducted a study that suggested that user interfaces that exhibit social characteristics, albeit through text, do not affect the way children see the computer, their feelings about themselves, their perception of the computer as a partner, their perceived similarity with the computer or their confidence and trust in the computer. Gulz [112], through a study and a review of the literature cautions that the use of virtual pedagogical characters does not necessarily improve the motivation and engagement of children. The study's results point at some children enjoying the characters while others find they get in the way. The study, like most studies with agents, was very short and previous experiences (e.g., with Microsoft BOB) show that annoyance at characters increases with longer exposure to them.

One positive aspect of agents was found by Oviatt et al. [225] who found that when children converse with animated agents, they adapt their speech to more closely match that of the agents. This could be used to help keep children's speech within the boundaries of processing capabilities.

Another area where intelligent or human like characters are starting to appear is in terms of robots. Woods [334] conducted a study to 
understand nine to eleven-year old children's reactions to the visual design of robots. She found that children had very negative views of robots that resembled humans but could still be distinguished from humans. Children preferred a mixture of human and machine-like visual features. These happen to be the characteristics of robots that have worked well with children in the past [186].

On a somewhat different note, Ackermann [3] surveyed the different ways in which toys may be perceived as being animated or smart. She identified successful toys of this type to have the attributes of being perceived as artificial (i.e., not alive), consistent in ways of being and doing, and having the ability to engage in dialog while maintaining their own characteristics. Ackermann sees these toys as letting children explore a variety of interactions without hurting or getting hurt, learning about individuality, as well as limitations and alternative ways of getting something or someone to do something.

\subsection{Supporting Healthy Lifestyles}

One area where computers and technology have been criticized is in not promoting healthy behaviors. Some researchers are beginning to work on technologies that do support healthy lifestyles. For example, Andrews

et al. [12] used digitally tagged foods to simulate tooth decay and help preschool children understand the importance of brushing teeth. Fails et al. [89] developed a physical interactive environment to teach children about hazardous substances found in everyday life. They compared the environment with a similar desktop application and found the physical environment provided some qualitative advantages for children. Pre and post-tests showed that children learned about hazardous materials in both environments. Hoysniemi [131] found through an international survey that teenagers playing a popular dance game were motivated to exercise, lost weight, improved muscle strength, acquired a better sense of rhythm, slept better, and improved their body image.

\subsection{Learning Skills}

Much research in children's technologies has been directed at helping children learn valuable skills. Some of the foundations for this type of 
software were laid by Soloway et al. [297] who have conducted many projects on learning technologies for children using an approach called learner-centered design. The premise is that learners have three unique needs that need to be addressed by user interfaces: growth (learning by doing), diversity (not everyone will arrive with the same set of skills), and motivation. These can be addressed through the use of scaffolds, for example, by providing structure to a scientific inquiry task.

Guidelines are also useful in the development of educational technologies. Fisch [93] compared guidelines for successful children's television and magazines with those for successful educational software. He identified the main differences were in terms of literacy (some media requires reading skills), the need for parental or adult involvement, the ability to control the flow, usability and the ability to author. He identified the main issues in common as: appeal, clarity, explicitness, age-appropriateness, text legibility, and visual effects. In follow-up work, Fisch [94] outlined recommendations for the design of educational games. These include matching topics to the most appropriate media, putting the educational content at the core of the games, and providing feedback and hints as necessary to scaffold children's interactions for challenging content.

Looking to explore novel interactions, Marshall [203] developed a framework to guide the research and development of tangible user interfaces for children aimed at learning activities. The framework includes six perspectives: learning domains, learning activity, integration of representations, concreteness and directness, effects of physicality, and possible learning benefits. He argues that using this framework can lead to a better understanding of the learning benefits of tangibles, as well as the reasons behind the learning.

In terms of learning actual skills, writing is one of the most important skills children learn in early elementary school. While computers may be eroding children's skills in handwriting a group at the University of Central Lancashire has been studying the usefulness of handwriting recognition as a form of text entry for young children. In their research, they have studied the type of errors that occur with handwriting recognition software and how children deal with them as well as children's mental models of how handwriting recognition 
software works $[255,256]$ From there, they moved on to design and develop novel writing interfaces with six and seven-year old children [257]. In follow up work, Kano et al. [160] studied the use of phrase sets for the evaluation of handwriting recognition and found that a phrase set with phrases taken from children's books yielded similar results to a standard phrase set without issues of unsuitable, difficult, or regionalized language. An additional study by Read [254] found that seven and eight-year old children generally produced more text during a free writing activity when using handwriting recognition on a tablet computer than when typing on a QWERTY keyboard. Using paper and pencil was superior to both computer technologies. In related work Danesh et al. [60] found ten to thirteen-year old children using handheld computers were able to use Graffiti handwriting recognition to write (it was a Palm system).

Others have worked on supporting reading skills. Namatame et al. [219] found positive learning outcomes in elementary school children's learning of Japanese characters through the use of a game. Sluis et al. [294] developed a tabletop based game to teach five to seven-year old children how to read. The augmented tabletop included tangible objects that enabled collaboration between children. The tangible objects represented words that had to be matched with other words starting with the same sound. Zurita and Nussbaum [343] found using networked handheld computers provided benefits to children learning to read over those obtained with non-computer based activities. Segers and Verhoeven $[283,284]$ reported positive short- and long-term learning outcomes from the use of games that teach vocabulary to kindergarten children.

For young children, some researchers have looked to embed sensors into stuffed animals. Strommen [309] discussed the design of ActiMates Barney, a plush doll designed for two to five-year old children to interact with the computer. One of the main difficulties was in trying to keep the interface as consistent as possible while making it work for different learning scenarios. He also discussed efforts at making similar toys into social interfaces that make use of humor, praise, and affection [310]. Luckin et al. [196] evaluated the use of interactive toys in the form of stuffed animals with sensors that engaged children in educational games. They found the toys to fall short in terms of being useful 
collaborative learning partners, but at the same time found the children had no problem learning to interact with them.

Research in other areas of learning include the work of Khandelwal and Mazalek [167] who developed an interactive tabletop environment where preschool children can engage in activities aimed at developing early mathematics skills by manipulating objects on a table. Danesh

et al. [60] designed Geney, a collaborative application to teach children about genetics using handheld computers.

\subsection{Mobile, Tangible, and Ubiquitous Computing}

\subsubsection{Handheld Computers}

The design of technologies for children was an inspiration for the design of the first mobile computer, in Alan Kay's Dynabook [164]. Since then, many researchers have also seen promise in enabling children to use computers in ways that do not keep them at desks but allow them to explore the world with computing power as a companion. Handheld computers, personal digital assistants (PDAs) and mobile phones have been particularly prominent since the beginning of this decade. Early work involved studies of pictures taken by children with mobile devices [200]. Others have also looked at using handhelds for capturing and organizing information $[252,269,285]$. This includes using handhelds to better explore and annotate physical spaces [31, 115]. Other have looked at games designed for handheld computers, some of which also include the exploration of physical areas [22, 30, 60, 87]. Others have looked at handheld computers as an inexpensive alternative to other computer resources in the classroom [195], and as a way to more easily collaborate with other children [55].

\subsubsection{Robots and Dolls}

Incorporating computing into plush toys and dolls is now commonplace, with every holiday season bringing a wider selection of such toys for children. In the research arena, Noobie, a large (larger than an adult human) plush doll with sensors and an embedded Macintosh computer presents an early example of this line of research [69]. Druin continued 


\section{Research Trends}

a similar line of work with PETS, plush robots that children could program to tell stories [70]. Also with storytelling as well as other activities was ActiMates Barney, one of the first commercially available products of this kind [309, 310]. In similar work, Johnson et al. [146] looked at plush toys as input devices, Paiva et al. [226] studied affective issues with dolls and Luckin et al. [196] evaluated their effectiveness in educational games.

\subsubsection{Tangible}

There has been a lot of research on tangible computing for children. Some of the work involves single devices, such as Labrune and Mackay's [180] tangicam, Ryokai et al.'s [274] I/O Brush and Frei et al.'s [97] curlybot. Most of the research uses multiple tangible items. One area of work has been in accessing, annotating, and manipulating information [51, 86, 105, 181, 308], using a variety of items such as blocks, beads, mats, and flags. Another area has been using tangibles to program. Most of this work uses blocks [208, 337, 342], but there is also work involving physical programming by example [246, 248, 249], and even programming in a room environment [90, 91, 92, 321]. There has also been work on games that use tangibles [142, 243, 294], and storytelling environments [45, 61, 98, 275]. More recent work has begun to use new materials such as textiles, with Berglin [23] and Buechley et al. [41] among the pioneers. There is also the research of Mike Eisenberg who has dedicated to developing technologies to enable children to design tangible items, and to use novel materials $[81,82,83]$.

\subsubsection{Ubiquitous}

Some researchers have studied making computing available to children in larger spaces. For example Montemayor et al. [215] worked on Storyrooms, a room environment full of sensors and actuators that enabled children to author and experience stories. Mattila and Vaatanen [205] went for larger environments in studying augmented playgrounds, while Pares et al. [231] also went for a room-sized environment aimed at helping children with autism. 


\subsection{Designing and Evaluating Technologies}

\subsubsection{Design}

Much of the research in the field has concentrated on the process of designing technologies for children. In this, there is a range of participation for children, from testers to design partners as covered in Design Methodologies. Following is a survey of recent research efforts in this area.

Wyeth and Purchase [337] emphasized the need to take into account developmental psychology literature when forming concepts for the design of technologies for children. They proposed design principles based on recommendations for children in Piaget's pre-operational stage (under seven-years old). These included supporting open-ended and discovery-oriented activities, child-initiated play, active manipulation and transformation of physical items, easy ways to get started, increased challenges for better skills, and the opportunity to create something.

Many researchers have had children participate as informants. For example, Lewis et al. [190] reported on the use of walkthroughs to elicit designs for software where children could explore the creation of scientific models. Chen et al. [48] worked with ten and eleven-year old children to develop web-based user interfaces to community websites. The children were asked to develop layouts for the web pages. An evaluation comparing the user interface developed out of this activity found it to be more usable than a popular commercial user interface. Williams et al. [331] reported on two workshops conducted with eleven and twelve-year old children to assess the potential use of wearable computing by children. The children participated as informants in these workshops and were able to conduct dialogs with researchers, but there was no elaboration of ideas. The same team worked with children as informants again to develop and obtain feedback on mobile devices augmented with GPS that could be used by children to tag locations with sounds [332]. Sluis-Thiescheffer et al. [295] compared the use of brainstorming and prototyping to develop design ideas with children. They found that prototyping activities led children to mention more objects or technologies, while brainstorming activities led to 
more specifications of options (e.g., numbers, locations, functionality, and values).

Many researchers have proposed novel activities used to obtain requirements and develop designs with children. Bekker et al. [20] developed a method in which the children play reporters and use interviews, write articles, take pictures, draw, and fill out questionnaires as part of the process. Similarly taking advantage of children's creativity, Moraveji et al. [217] reported on the successful use of comics as a way to elicit design ideas from children. They found that if children get to fill in the blanks in comics that have a beginning and an end, that they are likely to produce more ideas than if they are given blank pages to do traditional storyboarding.

Antle [13] reported on the design of a web-based collaborative storytelling environment designed through informant-based techniques and child-centered usability testing. Antle [14] continued exploring informant-based techniques and augmented them through the successful use of child-based personas. The personas, user profiles embodied in fictional characters based on child informants, helped developers keep the diverse needs of the children in mind when they were not able to meet with children. Also taking into account personal characteristics, Flanagan et al. [95] discussed ways of discovering and incorporating values into software design for children, including the values of the project, the designers, and the children.

Dindler et al. [65] presented a technique called Mission for Mars designed to obtain requirements from children. In this technique children are made to believe that they are communicating with a Martian that would like to learn something about their lives. Verhaegh et al. [323] also used the Mission from Mars technique and found it very motivating for seven to ten-year old children.

Hoysniemi et al. [134] demonstrated the usefulness of the Wizard of $\mathrm{Oz}$ technique for designing interactive gestures for a game that uses computer vision. Working with seven to nine-year old children, they were able to learn how children would naturally move their bodies to accomplish tasks in the game.

Many researchers have reported on their use of activities where they partner with children in the design of technologies. Isomursu et al. [140] 
conducted design activities with girls aged nine to eighteen-years old. They used web-based storytelling activities to elicit design ideas. Jones et al. [149] used cooperative inquiry techniques in two separate projects and faced difficulties with seven to ten-year old children understanding the concept of low fidelity prototypes. Knudtzon et al. [174] used cooperative inquiry activities with ten to thirteen-year old children and found they had to be adjusted to be a bit closer to those used with adults in participatory design. Kam et al. [159] reported on experiences using participatory design techniques in a rural setting in India where the researchers did not understand the language and were not familiar with the culture. They observed issues with local power structures, recommended getting help from locals that could translate and help understand cultural issues, and found that they were able to get better feedback from high-fidelity rather than low-fidelity prototypes. Ramachandran et al. [251] extended this work by relating additional experiences that highlight the value of local stakeholders and social network structures in the successful design and deployment of technologies.

Others have reported on adaptations to cooperative inquiry and other techniques where children participate as design partners. Rode et al. [268] introduced the concept of curriculum-focused design. This technique is a variant of cooperative inquiry that incorporates design and evaluations as part of lessons for the students in order to be able to fit these activities into children's highly structured school days. Guha et al. [111] reported on the difficulties of using cooperative inquiry techniques with children aged four to six due to their egocentric characteristics. They recommend ways of still taking into account the ideas from many children while making them feel part of the design process in spite of the children's difficulties seeing issues from someone else's perspective. Stringer et al. [307] argue for using design activities in no particular order making the best use of order that will suit the design process. They see the four aspects of the design process that could change order as: technology introduction, problem statement, generation of ideas, and research results. Pardo et al. [230] encourages the full participation of teachers in the design process. Lamberty and Kolodner [183] reported on the positive effects of using a video camera as part 
of design activities with fourth grade children. Rather than being disruptive, the camera provided a way for children to give their opinions and ideas and provided designers with valuable information.

\subsubsection{Evaluation}

Many researchers have also looked at how to evaluate technologies with children. Hanna et al. [116] recommend that when evaluating games, children be presented separately with game ideas and game art in order to obtain the most feedback. They also recommend that pairs of children participate in evaluations together without an observer being present, and that they be good friends. There were also previous guidelines on usability testing from some of the same authors [117]. Als et al. [4] compared usability evaluation techniques and found that pairs of thirteen and fourteen year old children who knew each other identified more usability problems with less effort than pairs who did not know each other, or children thinking aloud as they used software individually. In contrast to these findings, Van Kesteren et al. [322] assessed six evaluation methods to see which elicited more verbal comments from six and seven-year old children. They found the most verbal comments were obtained in active intervention sessions when researchers asked questions during tasks. They did not find co-discovery sessions, where pairs of children work together, worked as well. Other techniques worked better, such as think-aloud, retrospection, and peer-tutoring. Edwards and Benedyk [79] compared active intervention, peer tutoring, and cross-age tutoring as usability evaluation methods with six to eight-year old children. They found that peer tutoring seemed to work best, and that cross age tutoring elicited the least amount of comments. Hoysniemi et al. [133] successfully used peer tutoring as a way to evaluate the usability of a system through its teachability and learnability. They tried peer tutoring with children aged five to nine who taught other children how to play a game. Donker and Reitsma [66] conducted usability testing of software to build literacy skills with five to seven-year old children. They found that they identified most problems by observing the children's behavior, and that thinking aloud helped mainly in assessing the importance of the problems. Novice users had 
more problems using the software than expert users and thus identified a longer list of problems. Höysniemi et al. [134] provide a literature review of the use of Wizard of $\mathrm{Oz}$ techniques, very valuable when evaluating visual or audio input, together with a useful example applied to a learning technology for children.

Working with young children can be even more of a challenge. Hutto Egloff [315] noted that conducting usability studies with preschool children was difficult because children in this age group cannot conduct a task for very long, try to please adults, are easily distracted, and have difficulty expressing their likes and dislikes.

Markopoulos and Bekker [202] developed a framework to assess usability testing methods with children. They established three dimensions to consider: the criteria to assess the methods, the characteristics describing the methods, and the characteristics of the children being tested. In terms of criteria for assessing the methods, they mention robustness, reliability, validity, thoroughness, and efficiency. In terms of method descriptions the characteristics are: number and grouping of participants, evaluator, context, procedure, data capture, and tasks. Finally the children could be characterized in terms of verbalization, extroversion, gender, concentration, thinking skills, trustworthiness of self-report, knowledge and age. Garzotto [101] presented empirically tested heuristics for the evaluation of educational multiplayer online games. The heuristics are organized in terms of content (e.g., target appropriateness, integration, scaffolding, extensibility, media matching), enjoyment (e.g., clear goals, concentration, feedback, immersion), and social interaction (e.g., connection, cooperation, competition).

MacFarlane et al. [198] studied the relationship between usability and fun measures. They found that there were positive correlations between the two based on observations of children as well as children's own assessments of software. They also found that the assessed usability and fun differed depending on whether they were obtained by observing children or by children's reports. Another interesting result was that scale ratings using a "smileyometer" were not particularly useful as most children were overly enthusiastic about all the software titles they tried. Instead, more interesting data was gleaned from asking the children to rank the titles based on different characteristics. Zaman 
and Vanden Abeele [340] discussed a framework for evaluating the likeability of children's software that takes into account five areas: challenge and control, social experiences, fantasy, creative and constructive expressions, and body and senses. Also in the area of self-reported measures, Milne et al. [210] studied the development of questionnaires for children in elementary and secondary school.

A popular method in evaluating user methods for adults is expert reviews. Baauw et al. [15] explored whether these could work for children's technologies by evaluating the use of a predictive evaluation method. The method, called Structured Expert Evaluation Method (SEEM), involves the use of checklists by experts to predict problems in educational games. They found this method could uncover most usability problems, but at the same time there were problems with issues that were identified in the expert reviews that did not turn out to be usability problems when nine to eleven-year old children tested the same games.

\subsection{Challenges for Future Research}

I believe there are three areas where not enough research has been conducted and that provide a challenge for future research: developing empirically grounded guidelines, demonstrating positive developmental effects for technologies, and empowering children of low socio-economic status and underrepresented cultural groups. Working on these challenges will turn the field of interaction design and children into a more

mature one and will help a broader set of children reap the benefits of computing.

\subsubsection{Developing Empirically Grounded Guidelines}

The first challenge is to conduct more basic research on children's evolving cognitive, perceptual and motor abilities and how these affect children's use of technologies. Most interaction design work in humancomputer interaction is applied, with the purpose of developing a specific technology. Most of the time, these technologies are designed based on experience, intuition, and work with children. Jensen and Skov's 
[144] review of over one hundred papers related to research on interaction design and children found that the same is true in the field of interaction design and children. Experimental data on children's abilities would be a positive addition to these interaction design ingredients. This work is often not very attractive to the human-computer interaction community at large because it usually does not involve innovation and may not provide immediate guidelines or recommendations for interaction design. However, it is crucial to the development of humancomputer interaction and interaction design and children as mature fields. There is a need for more basic research aimed at a deeper understanding of children's interactions with technology and the development of guidelines.

There are several challenges in developing guidelines for children that are not present when doing similar research with adults. The first challenge is that children are a moving target. They are quick learners and an interaction design guideline that is appropriate one day may no longer be appropriate in a few months. Furthermore, studies that have attempted to develop guidelines have consistently shown that the younger the children the more variability in their performance. In other words, two five-year olds are more likely to show differences in the way they interact with software than two ten-year olds. There is very little information on what specific factors cause this variability and affect the way a child interacts with technology. We do not know what experiences, environmental, contextual, physical, and cognitive factors play a role.

A third challenge in developing guidelines for children is that they are more likely than adults to use computers in unstructured ways that have little resemblance to a traditional adult office environment. This is a challenge because traditional studies on performance with input devices and usability are conducted in usability labs that resemble an office-like environment, are quiet, and provide no distractions. While some useful information may come out of such studies, it is important to develop new methods for evaluating interactions and developing guidelines that take into account the actual context in which technologies are going to be used, which may often involve children on the move, with friends, in noisy environments, with many distractions. 
Given these challenges, guidelines developed for the design of interactions for children need to take into account how children change as they get older, the factors that affect the way they interact with technologies, and the context in which they use technologies. Doing so will require a combination of methods that have rarely been used. One such method is the use of longitudinal studies. Longitudinal studies are necessary to understand how children change in their interactions with technology as they get older. It is not possible to learn about these changes by conducting cross-sectional studies comparing children of different ages. Studying these changes will provide valuable information on the factors related to children's performance with input devices. Longitudinal studies can provide information, for example, on the relation between factors such as having access to a computer at home or parental attitudes toward computers and children's performance with input devices as children grow up. Understanding the relationship between these factors and interactions with technologies will in turn provide valuable tools for developing software for children in terms of being able to better characterize guidelines for children's interactions, enable a more informed selection of children to participate in the design process, and better understand the diversity of children as a user population. A lack of understanding of these factors can lead to inconsistencies in guidelines such as those pitting click-move-click interactions versus drag-and-drop interactions.

Novel methodologies and techniques will also have to be developed to follow children "in the wild" as they interact with technologies. It is not easy to obtain information "in the wild" due to the difficulty in observing without influencing behavior and the many privacy issues involved in obtaining information from people as they go about their day, let alone children. A combination of logging techniques using a variety of sensors in combination with cultural probes may provide ways of getting at this information.

\subsubsection{Empowering Disadvantaged Children}

Another area where there has been some work, but more is needed is in terms of using technologies to empower children of low socioeconomic 
status and underrepresented cultural groups. Oftentimes research in this field refers to children in general, but it is really just referring to some children in the countries where the researchers live. There is a need to broaden target populations across social, economic, and cultural lines.

Perhaps the most important reason to conduct research in this area is the increasing digital divide that can be seen between children in developed and developing countries, and also within each country across socioeconomic lines. This growing gap threatens to increase economic disparities by denying information and computer literacy and preventing children from gaining a wider view of the world.

Working with these populations often brings challenges in terms of hardware and infrastructure. The sad reality is that disadvantaged children will not have access to top of the line hardware. The One Laptop Per Child (OLPC) project is an example of an attempt to find a solution to this problem, with the objective of providing lowcost laptops to children in developing countries [221]. These laptops have features that take into account the infrastructure challenges for these populations by using little electrical power, providing a way to manually charge the battery, as well as the ability to communicate with other computers even if there is no Internet access available. These challenges also pose human-computer interaction design problems that need to be investigated. For example, how should software be designed so that it can gracefully work through spotty Internet connectivity and inconsistent access to electrical power? In some cases, the best hardware available may be cell phones which bring about a host of challenges in terms of limited options to interact with them as well as small screens.

Another challenge has to do with the localization of user interfaces. Most disadvantaged children come from different cultures and in many cases speak different languages from those spoken by most interaction design and children and human-computer interaction researchers. If user interfaces and content do not adjust to local cultures they may have a very negative impact on the perception of technology and its use. For example, during a visit to a school in Uruguay where every child received an XO-B2 laptop from the OLPC Foundation we found that 
the children disliked a music authoring program because they could not author music with local popular rhythms [128].

Localization is also challenging because in order to be successful, it requires that designers and researchers work with the disadvantaged children, ideally using participatory design techniques. Cultural and most often language barriers provide challenges along with a potential increase in power issues which can always be present when adults work with children. It is also unclear whether participatory design techniques that have been developed in western countries will apply well to other parts of the world. Early results in this area point at the importance of involving local stakeholders in these design activities to help in conducting the activities and in the communication between designers and children. Even better results can be obtained if locals have experience in conducting participatory design sessions and can conduct them themselves as we have seen in our experience working with children in a rural school in Uruguay, the country where I grew up [128].

\subsubsection{Demonstrating Positive Results}

Finally, the interaction design and children community needs to do a better job of demonstrating that the research outcomes in the community have a positive measurable impact on children's lives. Demonstrating positive results is a necessary step before any major revolution and evolution in education that involves the use of computers occurs. While research sometimes shows short-term gains, there is very little research on the long-term impact of the technologies being developed. How many studies are out there that follow children using a novel technology for at least a year to understand the impact the technology has in their lives? The lack of this type of studies is often related to an issue of funding, but at the same time, these are the types of studies that can bring further funding and solidify the reputation of the field.

Longitudinal studies are again necessary in these situations. Shortterm studies can provide information on usability and short-term gains, but only longitudinal studies can tell us whether technologies for children have a positive effect on their lives. Relying on short-term studies can be dangerous with some user interface approaches, such as 
conversational user interfaces, providing advantages for novices but often getting in the way as users, including children, become more proficient. Evaluations of software for children should thus follow them as they become experts at using the technology. Ideally, children should continue to be followed to see whether they use the technology and whether this use has a positive impact.

Longitudinal studies can also provide information on what factors contribute to success. It may be that the same technology is successful in some classrooms and not others, or with children from a particular socioeconomic group and not others. Longitudinal studies can also prove useful in assessing the impact of providing computers and software to children on society at large. This is particularly relevant for situations where children are the first members of the family that are introduced to computers, as is occurring in developing countries with the OLPC project.

\subsubsection{Science, Universality, and Broader Impacts}

In making progress in these three areas, the field of interaction design and children can grow by having empirically based guidelines contribute to designs, by committing to reaching as many children as possible, and by learning about the long-term and broader impacts of technologies for children. This will make the field stronger in its scientific basis, extend the benefits to a much greater number of children, and provide clear evidence of the benefits of technology use by children. 
Shneiderman and Plaisant listed their "Ten Plagues of the Information Age" in an appendix of the Fourth edition of Designing the User Interface [289]. In this list, they go over some of the dangers that the widespread use of computers could bring and is bringing upon society. To conclude this survey I would like to touch on three plagues that children face as a user population, and on the cures that our field can provide. The focus is on plagues that are not particularly obvious, unlike, for example, children's exposure to violent media.

The first plague is for interactions with computers to take the place of face-to-face communications. This can happen when computers replace humans in children's lives. The replaced humans can be play partners, family, or teachers. It can happen when children play games on a computer on their own instead of playing with other children, when computers are used as babysitters, and when "intelligent" tutors replace teachers. It can also happen when children use the computer to communicate with others they do not get to see face-to-face. While this can have positive effects in helping children express feelings and get comfort they otherwise could not get, there is clearly no substitute for a real human smile, a friendly hug, or a facial expression that says 
"I care." Children growing up with less face-to-face interactions could have difficulty developing relationships with the people they interact with on a daily basis, and could suffer from limited social skills in faceto-face interactions. In addition, there is evidence that participation in social interactions facilitates general cognitive functioning [339].

The second plague is brought by advertising in interactive products, and the design of many children's online communities that put an emphasis on acquiring items and on children defining themselves by what they own. The aim of these communities appears to be to turn children into super-consumers. I do not see anything wrong with purchasing items that reflect one's values; I am sure we all do this. At the same time, that is far from the situation in these online communities where children are encouraged to acquire items for the sake of acquiring them, where sharing is not possible, and where one's value in society directly depends on the amount of items acquired. Someone wrote graffiti near the University of Iowa campus saying "you are not what you own." This is a useful quote to remember when designing technologies for children.

The third plague is that only a small fraction of the children in the world will benefit from the positives that computer technology can bring. The digital divide is real and it is likely to increase economic and social gaps. There are projects that are trying to remediate this issue, but even with great publicity, the One Laptop Per Child project has so far failed to reach expectations in terms of adoption by countries in developing regions. Even if hardware is made available there are infrastructure limitations that will need to be taken into account when developing solutions to address less fortunate populations.

The way to combat these plagues is to put the needs of all children first when designing technologies. The ideas and values from the UTOPIA project, the pioneering work of Scandinavian researchers and workers that led to the development of participatory design techniques, are relevant as a way of curing these plagues. The UTOPIA project developed three principles to guide the design of technology that are still often cited and interpreted in new contexts: quality of work and products, democracy at work, and emancipation [80, 141]. 
When referring to quality of work and products, the UTOPIA project made an emphasis on designing technologies to augment user skills rather than replacing them. Following this principle we should study how we can use computer technology to enhance or encourage face-to-face interactions. In a visit to a rural school using XO laptops from the OLPC foundation I saw this happening [128]. The wireless, lightweight, and tumble-proof nature of the laptops encouraged children to share their work and to seek help from others by moving around with the computer as they would with a paper notebook. The computer technology in this case encouraged face-to-face social interactions.

The principle of democracy at work was meant to state that workers should have the right to participate equally in the design of technologies that affect their jobs. If we extend this principle to children, it means that they and their parents should also participate in design decisions for technologies designed for their use. We see this reflected in cooperative inquiry and other techniques that put an emphasis on partnering with children in the design process. This can be one of the best cures for the plague of advertising and consumerism. One area in which the research community needs to do more work is in incorporating parents into the design process together with their children.

The principle of emancipation referred to designing technologies so that they can prevent workers from being exploited. This can apply to the second plague as well since in some ways children are being exploited by being encouraged to purchase items for use online and in some cases being asked to fill out market surveys. On a broader sense, the principle of emancipation is applicable to the third plague. Can we design technologies in such a way that they will not increase the economic and social gaps between children? Can we provide less fortunate children with technologies that will enable them to succeed later in life and be full citizens of the world? Can we design technologies that will make fortunate children more aware of the situation of others around the world?

In remembering and following these principles from the UTOPIA project, we can provide children with technologies that will help them 
grow up to be sociable, responsible, participatory, and globally aware adults. Many of the research projects cited in this survey have made inroads in this direction. My hope is that the article will encourage responsible research in this area, putting children first, to help build it into a vigorous field recognized for its contributions to society. 


\section{References}

[1] J. Abbas, C. Norris, and E. Soloway, "Middle school children's use of the ARTEMIS digital library," in Proceedings of JCDL 02, pp. 98-105, ACM Press, 2002.

[2] C. Abnett, D. Stanton, H. Neale, and C. O'Malley, "The effect of multiple input devices on collaboration and gender issues," in Proceedings of European Perspectives on Computer-Supported Collaborative Learning (EuroCSCL 2001), pp. 29-36, The Netherlands: Maastricht, March 22-24 2001.

[3] E. K. Ackermann, "Playthings that do things: A young kid's 'incredibles'," in Proceedings of Interaction Design and Children 2005, pp. 1-8, ACM Press, 2005.

[4] B. S. Als, J. J. Jensen, and M. B. Skov, "Comparison of think-aloud and constructive interaction in usability testing with children," in Proceedings of Interaction Design and Children 2005, pp. 9-16, ACM Press, 2005.

[5] America Reads Challenge, Checkpoints for Progress in Reading and Writing for Teachers and Learning Partners. 1998. Retrieved March 7, 2007 from http://www.ed.gov/pubs/CheckTeachers/index.html.

[6] American Academy of Pediatrics, "Children, adolescents, and television," Pediatrics, vol. 107, no. 2, pp. 423-426, 2001.

[7] American Academy of Pediatrics, "Media violence," Pediatrics, vol. 108, no. 5, pp. 1222-1226, 2001.

[8] American Academy of Pediatrics, "Prevention of pediatric overweight and obesity," Pediatrics, vol. 112, no. 2, pp. 424-430, 2003.

[9] American Academy of Pediatrics, "Selecting appropriate toys for young children: The pediatrician's role," Pediatrics, vol. 111, no. 4, pp. 911-913, 2003. 
[10] American Academy of Pediatrics, "Television and the Family," retrieved on March 8, 2007 from http://www.aap.org/family/tv1.htm, 2007.

[11] American Diabetes Association, "Type 2 diabetes in children and adolescents," Pediatrics, vol. 105, no. 3, pp. 671-680, 2000.

[12] G. Andrews, E. Woodruff, K. A. MacKinnon, and S. Yoon, "Concept development for kindergarten children through a health simulation," Journal of Computer Assisted Learning, vol. 19, pp. 209-219, 2003.

[13] A. Antle, "Case study: The design of CBC4kids' storybuilder," in Proceedings of Interaction Design and Children 2003, pp. 59-68, ACM Press, 2003.

[14] A. Antle, "Supporting children's emotional expression and exploration in online environments," in Proceedings of Interaction Design and Children 2004, pp. 97-104, ACM Press, 2004.

[15] E. Baauw, M. M. Bekker, and P. Markopoulos, "Assessing the applicability of the structured expert evaluation method (SEEM) for a wider age group," in Proceedings of Interaction Design and Children 2006, pp. 73-80, ACM Press, 2006.

[16] A. Baddeley, "Working memory," Centre Royal Academy of Sciences III, vol. 321, no. 2-3, pp. 167-173, 1998.

[17] A. Baddeley, "Working memory: Looking back and looking forward," Nature Reviews, Neuroscience, vol. 4, no. 10, pp. 829-839, 2003.

[18] N. Baloian, W. Luther, and J. Sanchez, "Modeling educational software for people with disabilities: Theory and practice," in Proceedings of ASSETS 02, pp. 111-118, ACM Press, 2002.

[19] O. Balter, O. Engwall, A. M. Oster, and H. Kjellstrom, "Wizard of Oz test of ARTUR - A computer based speech training system with articulation correction," in Proceedings of ASSETS 2005, pp. 36-43, ACM Press, 2005.

[20] M. Bekker, J. Beusmans, D. Keyson, and P. Lloyd, "KidReporter: A user requirements gathering technique for designing with children," Interacting with Computers, vol. 15, pp. 187-202, 2003.

[21] S. Benford, B. B. Bederson, K. Akesson, V. Bayon, A. Druin, P. Hansson, J. P. Hourcade, R. Ingram, H. Neale, C. O'Malley, K. Simsarian, D. Stanton, Y. Sundblad, and G. Taxen, "Designing storytelling technologies to encourage collaboration between young children," CHI 2000, ACM Conference on Human Factors in Computing Systems, CHI Letters, vol. 2, no. 1, pp. 556-563, 2000.

[22] S. Benford, D. Rowland, M. Flintham, A. Drozd, R. Hull, J. Reid, J. Morrison, and K. Facer, "Life on the edge: Supporting collaboration in location-based experiences," in Proceedings of Human Factors in Computing Systems 2005, pp. 721-730, ACM Press, 2005.

[23] L. Berglin, "Spookies: Combining smart materials and information technology in an interactive toy," in Proceedings of Interaction Design and Children 2005, pp. 17-24, ACM Press, 2005.

[24] J. Berkovitz, "Graphical interfaces for young children in a software-based mathematics curriculum," in Proceedings of Human Factors in Computing Systems 1994, pp. 247-248, ACM Press, 1994. 
[25] M. U. Bers, E. Ackermann, J. Cassell, B. Donegan, J. Gonzalez-Heydrich, D. R. DeMaso, C. Strohecker, S. Lualdi, D. Bromley, and J. Karlin, "Interactive storytelling environments: Copying with cardiac illness at Boston's children's hospital," in Proceedings of Conference on Human Factors in Computing Systems (CHI '98), pp. 603-610, Los Angeles, CA, 1998.

[26] M. U. Bers, J. Gonzalez-Heydrich, and D. R. DeMaso, "Identity construction environments: Supporting a virtual therapeutic community of pediatric patients undergoing dialysis," in Proceedings of Human Factors in Computing Systems 2001, pp. 380-387, ACM Press, 2001.

[27] A. Biemiller, "Vocabulary: Needed if more children are to read well," Reading Psychology, vol. 24, pp. 323-335, 2003.

[28] H. G. Birch and A. Lefford, "Visual differentiation, intersensory integration, and voluntary motor control," Monographs of the Society for Research in Child Development, vol. 32, 1967.

[29] R. Blanch, Y. Guiard, and M. Beaudouin-Lafon, "Semantic pointing: Improving target acquisition with control-display ratio adaptation," CHI Letters, vol. 6, no. 1, pp. 519-526, 2004.

[30] R. Borovoy, B. Silverman, T. Gorton, J. Clan, M. Notowidigdo, B. Knep, and M. Resnick, "Folk computing: Revisiting oral tradition as a scaffold for co-present communities," in Proceedings of Human Factors in Computing Systems 2001, pp. 466-473, ACM Press, 2001.

[31] N. O. Bouvin, C. Brodersen, F. A. Hansen, O. S. Iversen, and P. Norregaard, "Tools of contextualization: Extending the classroom to the field," in Proceedings of Interaction Design and Children 2005, pp. 24-31, ACM Press, 2005.

[32] H. Brashear, V. Henderson, K. H. Park, H. Hamilton, S. Lee, and T. Starner, "American Sign Language recognition in game development for deaf children," in Proceedings of ASSETS 06, pp. 79-86, ACM Press, 2006.

[33] B. Brederode, P. Markopoulos, M. Gielen, A. Vermeeren, and H. de Ridder, "Powerball: The design of a novel mixed-reality game for children with mixed abilities," in Proceedings of Interaction Design and Children 2005, pp. 32-39, ACM Press, 2005.

[34] A. L. Brown and J. C. Campione, "Psychological theory and the design of innovative learning environments: On procedures, principles, and systems," in Innovations in Learning: New Environments for Education, (L. Schauble and R. Glaser, eds.), Mahwah, NJ: Erlbaum, 1996.

[35] J. S. Brown, A. Collins, and P. Duguid, "Situated cognition and the culture of learning," Educational Researcher, vol. 18, no. 1, pp. 32-42, 1989.

[36] H. Browne Huchinson, A. Druin, and B. B. Bederson, "Supporting elementaryage children's searching and browsing: Design and evaluation using the international children's digital library," Journal of the American Society for Information Science and Technology (JASIST), vol. 58, no. 11, pp. 1618-1630, 2007.

[37] H. Browne Hutchinson, B. B. Bederson, and A. Druin, "The evolution of the International Children's Digital Library searching and browsing interface," in Proceedings of Interaction Design and Children 2006, pp. 105-112, ACM Press, 2006. 
[38] A. Bruckman, "MOOSE Crossing: Construction, Community, and Learning in a Networked Virtual World for Kids," PhD dissertation, MIT Media Lab. Advisor: Mitchel Resnick, 1997.

[39] A. Bruckman and E. Edwards, "Should we leverage natural-language knowledge? An analysis of user errors in a natural-language-style programming language," in Proceedings of Human Factors in Computing Systems 99, pp. 207214, ACM Press, 1999.

[40] M. P. Bryden, Laterality: Functional Asymmetry in the Intact Brain. New York: Academic Press, 1982.

[41] L. Buechley, N. Elumeze, and M. Eisenberg, "Electronic/Computational textiles and children's crafts," in Proceedings of Interaction Design and Children 2006, pp. 49-56, ACM Press, 2006.

[42] J. B. Carroll, Human Cognitive Abilities: A Survey of Factor-Analytic Studies. New York: Cambridge University Press, 1993.

[43] R. Case, The Mind's Staircase: Exploring the Conceptual Understandings of Children's Thoughts and Knowledge. Hillsdale, New Jersey: Erlbaum, 1992.

[44] J. Cassell, "Towards a model of technology and literacy development: Story listening systems," Applied Developmental Psychology, vol. 25, pp. 75-105, 2004.

[45] J. Cassell and K. Ryokai, "Making space for voice: Technologies to support children's fantasy and storytelling," Personal and Ubiquitous Computing, vol. 5, pp. 169-190, 2001.

[46] D. J. Cech and S. Martin, Functional Movement Development Across the Life Span. Philadelphia: W. B. Saunders, second ed., 2002.

[47] S. Chaiklin and J. Lave, Understanding Practice: Perspectives on Activity and Context. Cambridge: Cambridge University Press, 1993.

[48] C. H. Chen, F. G. Wu, P. L. P. Rau, and Y. H. Hung, "Preferences of young children regarding interface layouts in child community websites," Interacting with Computers, vol. 16, pp. 311-330, 2004.

[49] Z. Chen and R. S. Siegler, "Intellectual development in childhood," in Handbook of Intelligence, (R. J. Sternberg, ed.), Cambridge, UK: Cambridge University Press, 2004.

[50] S. Chiasson and C. Gutwin, "Testing the media equation with children," in Proceedings of Human Factors in Computing Systems 2005, pp. 829-838, ACM Press, 2005.

[51] G. Chipman, A. Druin, D. Beer, J. A. Fails, M. L. Guha, and S. Simms, "A case study of tangible flags: A collaborative technology to enhance field trips," in Proceedings of Interaction Design and Children 2006, pp. 1-8, ACM Press, 2006.

[52] D. A. Christakis and F. J. Zimmerman, "Violent television viewing during preschool is associated with antisocial behavior during school age," Pediatrics, vol. 120, pp. 993-999, 2007.

[53] D. A. Christakis, F. J. Zimmerman, D. L. DiGiuseppe, and C. A. McCarty, "Early television exposure and subsequent attentional problems in children," Pediatrics, vol. 113, no. 4, pp. 708-713, 2004. 
[54] P. Cobb and E. Yackel, "Constructivist, emergent, and sociocultural perspectives in the context of developmental research," Educational Psychologist, vol. 31, no. 3-4, pp. 175-190, 1996.

[55] H. Cole and D. Stanton, "Designing mobile technologies to support co-present collaboration," Personal and Ubiquitous Computing, vol. 7, pp. 365-371, 2003.

[56] M. Conway, S. Audia, T. Bumette, D. Cosgrove, K. Christiansen, R. Deline, J. Durbin, R. Gossweiler, S. Koga, C. Long, B. Mallory, S. Miale, K. Monkaitis, J. Patten, J. Pierce, J. Shochet, D. Staack, B. Steams, R. Stoakley, C. Sturgill, J. Viega, J. White, G. Williams, and R. Pausch, "Alice: Lessons learned from building a 3D system for novices," in Proceedings of Human Factors in Computing Systems (CHI 2000), pp. 486-493, ACM Press, 2000.

[57] C. Crook, "Young children's skill in using a mouse to control a graphical computer interface," Computers and Education, vol. 19, no. 3, pp. 199-207, 1992.

[58] A. Cuthbertson, S. Hatton, G. Minyard, H. Piver, C. Todd, and D. Birchfield, "Mediated education in a creative arts context: Research and practice at whittier elementary school," in Proceedings of Interaction Design and Children 2007, pp. 65-72, ACM Press, 2007.

[59] T. Dalsgaard, M. B. Skov, M. Stougaard, and B. Thomassen, "Mediated intimacy in families: Understanding the relation between children and parents," in Proceedings of Interaction Design and Children 2006, pp. 145-152, ACM Press, 2006.

[60] A. Danesh, K. Inkpen, F. Lau, K. Shu, and K. Booth, "Geney: Designing a collaborative activity for the palm handheld computer," in Proceedings of Human Factors in Computing Systems 2001, pp. 388-395, ACM Press, 2001.

[61] F. Decortis, A. Rizzo, and B. Saudelli, "Mediating effects of active and distributed instruments on narrative activities," Interacting with Computers, vol. 15, pp. 801-830, 2003.

[62] J. DeLoache and C. M. Smith, "Early symbolic representation," in Development of mental representation: Theories and Applications, (I. E. Sigel, ed.), Mahwah, NJ: Earlbaum, 1999.

[63] F. N. Dempster, "Memory span: Sources of individual and developmental differences," Psychological Bulletin, vol. 89, pp. 63-100, 1981.

[64] J. Dewey, The School and Society. Chicago: University of Chicago Press, 1959.

[65] C. Dindler, E. Eriksson, O. S. Iversen, A. Lykke-Olesen, and M. Ludvigsen, "Mission from Mars - A method for exploring user requirements for children in a narrative space," in Proceedings of Interaction Design and Children 2005, pp. 40-47, ACM Press, 2005.

[66] A. Donker and P. Reitsma, "Usability testing with young children," in Proceedings of Interaction Design and Children 2004, pp. 43-48, ACM Press, 2004.

[67] A. Donker and P. Reitsma, "Young children's ability to use a computer mouse," Computers and Education, vol. 48, pp. 602-617, 2005.

[68] A. Donker and P. Reitsma, "Drag-and-drop errors in young children's use of the mouse," Interacting with Computers, vol. 19, pp. 257-266, 2007.

[69] A. Druin, "Noobie: The animal design playstation," In ACM SIGCHI Bulletin, vol. 20 , no. 1 , pp. $45-55,1988$. 
[70] A. Druin, "Cooperative inquiry: Developing new technologies for children with children," in Proceedings of Human Factors in Computing Systems (CHI 99), pp. 223-230, ACM Press, 1999.

[71] A. Druin, "The role of children in the design of new technology," Behaviour and Information Technology, vol. 21, no. 1, pp. 1-25, 2002.

[72] A. Druin, "What children can teach us: Developing digital libraries for children," Library Quarterly, vol. 75, no. 1, pp. 20-41, 2005.

[73] A. Druin, B. Bederson, A. Weeks, A. Farber, J. Grosjean, M. L. Guha, J. P. Hourcade, J. Lee, S. Liao, K. Reuter, A. Rose, Y. Takayama, and L. Zhang, "The International children's digital library: Description and analysis of first use," First Monday, vol. 8, no. 5, 2003.

[74] A. Druin, B. B. Bederson, J. P. Hourcade, L. Sherman, G. Revelle, M. Platner, and S. Weng, "Designing a digital library for young children: An intergenerational partnership," in Proceedings of JCDL 01, pp. 398-405, ACM Press, 2001.

[75] A. Druin, J. Montemanyor, J. Hendler, B. McAlister, A. Boltman, E. Fiterman, A. Plaisant, A. Kruskal, H. Olsen, I. Revett, T. P. Schwenn, L. Sumida, and R. Wagner, "Designing PETS: A personal electronic teller of stories," in Proceedings of Human Factors in Computing Systems 99, pp. 326-329, ACM Press, 1999.

[76] A. Druin, G. Revelle, B. B. Bederson, J. P. Hourcade, A. Farber, J. Lee, and D. Campbell, "A collaborative digital library for children," Journal of Computer Assisted Learning, vol. 19, pp. 239-248, 2003.

[77] A. Druin, J. Stewart, D. Proft, B. Bederson, and J. Hollan, "KidPad: A design collaboration between children, technologists, and educators," in Proceedings of Human Factors in Computing Systems 97, pp. 463-470, ACM Press, 1997.

[78] A. Druin, A. Weeks, S. Massey, and B. B. Bederson, "Children's interests and concerns when using the International Children's Digital Library: A four country case study I," in Proceedings of Joint Conference on Digital Libraries (JCDL'2007), pp. 167-176, Canada, BC: Vancouver, 2007.

[79] H. Edwards and R. Benedyk, "A comparison of usability evaluation methods for child participants in a school setting," in Proceedings of Interaction Design and Children 2007, pp. 9-15, ACM Press, 2007.

[80] P. Ehn, Work-Oriented Design of Computer Artifacts. Stockholm, Sweden: Arbetslivcentrum, 1988.

[81] M. Eisenberg, "Tangible ideas for children: Materials science as the future of educational technology," in Proceedings of Interaction Design and Children 2004, pp. 19-26, ACM Press, 2004.

[82] M. Eisenberg, A. Eisenberg, S. Hendrix, G. Blauvelt, D. Butter, J. Garcia, R. Lewis, and T. Nielsen, "As we may print: New directions in output devices and computational crafts for children," in Proceedings of Interaction Design and Children 2003, pp. 31-38, ACM Press, 2003.

[83] M. Eisenberg, A. Nishioka, and M. E. Schreiner, "Helping users think in three dimensions: Steps toward incorporating spatial cognition in user modeling," pp. 113-120, 1997. 
[84] J. Elliot and A. Bruckman, "Design of a 3D interactive math learning environment," in Proceedings of DIS 2002, pp. 64-74, ACM Press, 2002.

[85] J. B. Ellis and A. S. Bruckman, "Designing a palaver tree online: Supporting social roles in a community of oral history," in Proceedings of Human Factors in Computing Systems 2001, pp. 474-481, ACM Press, 2001.

[86] E. Eriksson and A. Lykke-Olesen, "StorySurfer - A playful book browsing installation for children's libraries," in Proceedings of Interaction Design and Children 2007, pp. 57-64, ACM Press, 2007.

[87] K. Facer, R. Joiner, D. Stanton, J. Reid, R. Hull, and D. Kirk, "Savannah: Mobile gaming and learning," Journal of Computer Assisted Learning, vol. 20, pp. 399-409, 2004.

[88] I. Fagard, "The development of bimanual coordination," in Development of Eye-hand Coordination Across the Life Span, (C. Bard, M. Fleury, and L. Hay, eds.), Charleston, SC: University of South Carolina Press, 1990.

[89] J. A. Fails, A. Druin, M. L. Guha, G. Chipman, S. Simms, and W. Churaman, "Child's play: A comparison of desktop and physical interactive environments," in Proceedings of Interaction Design and Children 2005, pp. 48-55, ACM Press, 2005.

[90] Y. Fernaeus and J. Tholander, "Designing for programming as joint performances among groups of children," Interacting with Computers, vol. 18, pp. 1012-1031, 2006.

[91] Y. Fernaeus and J. Tholander, "Finding design qualities in a tangible programming space," in Proceedings of Human Factors in Computing Systems 2006, pp. 447-456, ACM Press, 2006.

[92] Y. Fernaeus and J. Tholander, "Rethinking children's programming with contextual signs," in Proceedings of Interaction Design and Children 2006, pp. 121-128, ACM Press, 2006.

[93] S. Fisch, "What's so 'new' about 'new media?': Comparing effective features of children's educational software, television, and magazines," in Proceedings of Interaction Design and Children 2004, pp. 105-112, ACM Press, 2004.

[94] S. Fisch, "Making educational computer games 'educational'," in Proceedings of Interaction Design and Children 2005, pp. 56-61, ACM Press, 2005.

[95] M. Flanagan, D. C. Howe, and H. Nissenbaum, "Values at play: Design tradeoffs in socially-oriented game design," in Proceedings of Human Factors in Computing Systems 2005, pp. 751-780, ACM Press, 2005.

[96] J. H. Flavell, P. H. Miller, and S. A. Miller, Cognitive Development. Upper Saddle River, NJ: Pearson, fourth ed., 2002.

[97] P. Frei, V. Su, B. Mikhak, and H. Ishii, "Curlybot: Desigining a new class of computational toys," in Proceedings of Human Factors in Computing Systems 2000, pp. 129-136, ACM Press, 2000.

[98] C. Fusai, B. Saudelli, P. Marti, F. Decortis, and A. Rizzo, "Media composition and narrative performance at school," Journal of Computer Assisted Learning, vol. 19, pp. 177-185, 2003.

[99] D. L. Gallahue, Understanding Motor Development: Infants, Children, Adolescents. Indianapolis, IN: Benchmark Press, 1989. 
[100] H. Gardner and S. Moran, "The science of multiple intelligences theory: A response to Lynn waterhouse," Educational Psychologist, vol. 41, no. 4, pp. 227-232, 2006.

[101] F. Garzotto, "Investigating the educational effectiveness of multiplayer online games for children," in Proceedings of Interaction Design and Children 200\%, pp. 29-36, ACM Press, 2007.

[102] F. Garzotto and M. Forfori, "Hyperstories and social interaction in 2D and 3D edutainment spaces for children," in Proceedings of HT 06, pp. 57-67, ACM Press, 2006.

[103] L. Gibson, P. Gregor, and S. Milne, "Designing with 'Difficult' children," in Proceedings of Interaction Design and Children International Workshop, pp. 42-52, Shaker Publishing, 2002.

[104] L. Gibson, F. Newall, and P. Gregor, "Developing a web authoring tool that promotes accessibility in children's designs," in Proceedings of Interaction Design and Children 2003, pp. 23-30, ACM Press, 2003.

[105] M. G. Gorbet, M. Orth, and H. Ishii, "Triangles: Tangible interface for manipulation and exploration of digital information topography," in Proceedings of Human Factors in Computing Systems 1998, pp. 49-56, ACM Press, 1998.

[106] T. Göttel, "ProBoNO: Transferring knowledge of virtual environments to real world situations," in Proceedings of Interaction Design and Children 200\%, pp. 81-88, ACM Press, 2007.

[107] J. G. Greeno, "The situativity of knowing, learning, and research," American Psychologist, vol. 53, no. 1, pp. 5-26, 1998.

[108] J. G. Greeno, A. Collins, and L. Resnick, "Cognition and learning," in Handbook of Educational Psychology, (D. Berliner and R. Calfee, eds.), pp. 15-46, New York: Simon and Schuster Macmillan, 1996.

[109] S. M. Grimes and L. R. Shade, "Neopian economics of play: Children's cyberpets and online communities as immersive advertising in NeoPets.com," International Journal of Media and Cultural Politics, vol. 1, no. 2, pp. 181-198, 2005.

[110] T. Grossman and R. Balakrishnan, "The bubble cursor: Enhancing target acquisition by dynamic resizing of the cursor's activation area," in Proceedings of Human Factors in Computing Systems (CHI 2005), pp. 281-290, ACM Press, 2005.

[111] M. L. Guha, A. Druin, G. Chipman, J. A. Fails, S. Simms, and A. Farber, "Mixing ideas: A new technique for working with young children as design partners," in Proceedings of Interaction Design and Children 2004, pp. 35-42, ACM Press, 2004.

[112] A. Gulz, "Social enrichment by virtual characters — Differential benefits," Journal of Computer Assisted Learning, vol. 21, pp. 405-418, 2005.

[113] T. Hall and L. Bannon, "Designing ubiquitous computing to enhance children's interaction in museums," in Proceedings of Interaction Design and Children 2005, pp. 62-69, ACM Press, 2005.

[114] T. Hall and L. Bannon, "Designing ubiquitous computing to enhance children's learning in museums," Journal of Computer Assisted Learning, vol. 22, pp. 231-243, 2006. 
[115] J. Halloran, E. Hornecker, and G. Fitzpatrick, "The literacy fieldtrip: Using ubicomp to support children's creative writing," in Proceedings of Interaction Design and Children 2006, pp. 17-24, ACM Press, 2006.

[116] L. Hanna, D. Neapolitan, and K. Risden, "Evaluating computer game concepts with children," in Proceedings of Interaction Design and Children 2004, pp. 49-56, ACM Press, 2004.

[117] L. Hanna, K. Risden, and K. Alexander, "Guidelines for usability testing with children," Interactions, vol. 4, no. 5, pp. 9-14, 1997.

[118] L. Hanna, K. Risden, M. Czerwinski, and K. J. Alexander, "The role of usability research in designing children's computer products," in The Design of Children's Technology, (A. Druin, ed.), San Francisco: Morgan Kauffman, 1998.

[119] I. Harel, Children Designers: Interdisciplinary Constructions for Learning and Knowing Mathematics in a Computer-Rich School. Norwood, NJ: Ablex, 1991.

[120] V. Henderson, S. Lee, H. Brashear, H. Hamilton, T. Starner, and S. Hamilton, "Development of an American Sign Language game for deaf children," in Proceedings of Interaction Design and Children 2005, pp. 70-79, ACM Press, 2005.

[121] M. S. Horn and R. J. K. Jacob, "Designing tangible programming languages for classroom use," in Proceedings of TEI 07, pp. 159-162, ACM Press, 2007.

[122] A. J. Hornhof and A. Cavender, "EyeDraw: Enabling children with severe motor impairments to draw with their eyes," in Proceedings of Human Factors in Computing Systems 2005, pp. 161-170, ACM Press, 2005.

[123] J. P. Hourcade, "Learning from preschool children's pointing sub-movements," in Proceedings of Interaction Design and Children 2006, pp. 65-72, ACM Press, 2006.

[124] J. P. Hourcade, B. B. Bederson, and A. Druin, "Building kidPad: An application for children's collaborative storytelling," Software Practice and Experience, vol. 34, pp. 895-914, 2004.

[125] J. P. Hourcade, B. B. Bederson, and A. Druin, "Preschool children's use of mouse buttons," in Extended Abstracts of Human Factors in Computing Systems (CHI 2004), pp. 1411-1412, ACM Press, 2004.

[126] J. P. Hourcade, B. B. Bederson, A. Druin, and F. Guimbretiere, "Differences in pointing task performance between preschool children and adults using mice," ACM Transactions on Computer-Human Interaction, vol. 11, no. 4, pp. 357-386, 2004.

[127] J. P. Hourcade, B. B. Bederson, A. Druin, A. Rose, A. Farber, and Y. Takayama, "The international children's digital library: Viewing digital books online," Interacting with Computers, vol. 15, pp. 151-167, 2003.

[128] J. P. Hourcade, D. Beitler, F. Cormenzana, and P. Flores, "Early OLPC experiences in a rural uruguayan school," Extended Abstracts of Human Factors in Computing Systems (CHI 2008), 2008.

[129] J. P. Hourcade, M. Crowther, and L. Hunt, "Does mouse size affect study and evaluation results? A study comparing preschool children's performance with small and regular-sized mice," in Proceedings of Interaction Design and Children 2007, pp. 109-116, ACM Press, 2007. 
[130] J. P. Hourcade, K. B. Perry, and A. Sharma, "PointAssist: Helping four-year olds point with ease," in Proceedings of Interaction Design and Children 2008, 2008.

[131] J. Hoysniemi, "International survey on the dance revolution game," $A C M$ Computers in Entertainment, vol. 4, no. 2, pp. 1-29, 2005.

[132] J. Hoysniemi and P. Hamalainen, "Children's and parents' perception of fullbody interaction and violence in a martial arts game," in Proceedings of Designing for User Experience 2005, pp. 2-16, 2005.

[133] J. Hoysniemi, P. Hamalainen, and L. Turkki, "Using peer tutoring in evaluating the usability of a physically interactive computer game with children," Interacting with Computers, vol. 15, pp. 203-225, 2003.

[134] J. Hoysniemi, P. Hamalainen, and L. Turkki, "Wizard of Oz prototyping of computer vision based action games for children," in Proceedings of Interaction Design and Children 2004, pp. 27-34, ACM Press, 2004.

[135] L. R. Huesmann, J. Moise-Titus, C. L. Podolski, and L. D. Eron, "Longitudinal relations between children's exposure to TV violence and their aggressive and violent behavior in young adulthood: 1977-1992," Developmental Psychology, vol. 39, no. 2, pp. 201-221, 2003.

[136] D. Hung, "Theories of learning and computer-mediated instructional technologies," Education Media International, vol. 38, no. 4, pp. 281-287, 2001.

[137] J. Huttenlocher, N. Newcombe, and M. Vasilyeva, "Spatial scaling in young children," Psychological Science, vol. 10, pp. 393-397, 1999.

[138] K. M. Inkpen, "Drag-and-drop versus point-and-click mouse interaction styles for children," ACM Transactions on Computer-Human Interaction, vol. 8, no. 1, pp. 1-33, 2001.

[139] K. M. Inkpen, W. Ho-Ching, O. Kuederle, S. D. Scott, and G. B. D. Shoemaker, in Proceedings of Computer Supported Collaborative Learning 1999. Article 311999.

[140] M. Isomursu, P. Isomursu, and K. Still, "Capturing tacit knowledge from young girls," Interacting with Computers, vol. 16, pp. 431-449, 2004.

[141] O. S. Iversen, A. M. Kanstrup, and M. G. Petersen, "A visit to the 'new Utopia': Revitalizing democracy, emancipation and quality in cooperative design," in Proceedings of the Third Nordic Conference on HumanComputer Interaction, Tampere, Finland, October 23-27 2004. NordiCHI '04, vol. 82. New York, NY, ACM, 171-179. DOI= http://doi.acm.org/ 10.1145/1028014.1028040.

[142] O. S. Iversen, K. J. Kortbek, K. R. Nielsen, and L. Aagaard, "Stepstone An interactive floor application for hearing impaired children with a cochlear implant," in Proceedings of Interaction Design and Children 200\%, pp. 117124, ACM Press, 2007.

[143] J. Jacko, "The identifiability of auditory icons for use in education software for children," Interacting with Computers, vol. 8, no. 2, pp. 121-133, 1996.

[144] J. J. Jensen and M. B. Skov, "A review of research methods in children's technology design," in Proceedings of Interaction Design and Children 2005, pp. 80-87, ACM Press, 2005. 
[145] J. Johnson and E. Newport, "Critical period effects in second language learning: The influence of maturational state on the acquisition of English as a second language," Cognitive Psychology, vol. 21, pp. 60-99, 1989.

[146] M. P. Johnson, A. Wilson, B. Blumberg, C. Kline, and A. Bobick, "Sympathetic interfaces: Using a plush toy to direct synthetic characters," in Proceedings of Human Factors in Computing Systems 99, pp. 152-158, ACM Press, 1999.

[147] R. Joiner, D. Messer, P. Light, and K. Littleton, "It is best to point for young children: A comparison of children's pointing and dragging," Computers in Human Behavior, vol. 14, no. 3, pp. 513-529, 1998.

[148] R. W. Joiner, "The effect of gender on children's software preferences," Journal of Computer Assisted Learning, vol. 14, pp. 195-198, 1998.

[149] C. Jones, L. McIver, L. Gibson, and P. Gregor, Experiences Obtained from Designing with Children, pp. 69-74. ACM Press, 2003.

[150] T. Jones, "An empirical study of children's use of computer pointing devices," Journal of Educational Computing Research, vol. 7, no. 1, pp. 61-76, 1991.

[151] Y. B. Kafai, Minds in Play: Computer Game Design as a Context for Children'S Learning. Hillsdale, NJ: Lawrence Erlbaum Associates, 1995.

[152] Y. B. Kafai, "The Educational Potential of Electronic Games: from Gamesto-Teach to Games-to-Learn," in Proceedings of Playing by the Rules: The Cultural Policy Challenges of Video Games, University of Chicago Cultural Policy Center, available at http://culturalpolicy. uchicago.edu/ conf2001/papers/kafai.html, October 26-27 2001.

[153] Y. B. Kafai and C. Carter Ching, "Affordances of collaborative software design planning for elementary students' science talk," Journal of the Learning Sciences, vol. 10, no. 3, pp. 323-363, 2001.

[154] Y. B. Kafai and I. Harel, "Children learning through consulting: When mathematical ideas, knowledge of programming and design, and playful discourse are intersturined," in Constructionism: Research Reports and Essays, 1985-1990, (I. Harel and S. Papert, eds.), Norwood, NJ: Ablex Publishing, 1991.

[155] Y. B. Kafai and I. Harel, "Learning through design and teaching: Exploring social and collaborative aspects of constructionism," in Constructionism, (I. Harel and S. Papert, eds.), Norwood, NJ: Ablex, 1991.

[156] K. Kahn, "ToonTalk: An animated programming environment for children," Journal of Visual Languages and Computing, vol. 7, no. 2, pp. 197-217, 1996.

[157] R. Kail, "Developmental change in speed of processing during childhood and adolecense," Psychological Bulletin, vol. 109, no. 3, pp. 490-501, 1991.

[158] R. V. Kail, "Phonolgical skill and articulation time independently contribute to the development of memory span," Journal of Experimental Child Psychology, vol. 67, pp. 57-68, 1997.

[159] M. Kam, D. Ramachandran, A. Raghavan, J. Chiu, S. Urvashi, and J. Canny, "Practical considerations for participatory design with rural school children in underdeveloped regions: Early reflections from the field," in Proceedings of Interaction Design and Children 2006, pp. 25-32, ACM Press, 2006.

[160] A. Kano, J. C. Read, and A. Dix, "Children's phrase set for text input method evaluations," in Proceedings of NordiCHI 2006, pp. 449-452, ACM Press, 2006. 
[161] N. Kaplan and Y. Chisik, "Reading alone together: Creating sociable digital library books," in Proceedings of Interaction Design and Children 2005, pp. 88-94, ACM Press, 2005.

[162] N. Kaplan, Y. Chisik, K. Knudtzon, R. Kulkarni, S. Moulthrop, K. Summers, and H. Weeks, "Supporting sociable literacy in the international children's digital library," in Proceedings of Interaction Design and Children 2004, pp. 89-96, ACM Press, 2004.

[163] N. Kaplan, Y. Chisik, and D. Levy, "Reading in the wild: Sociable literacy in practice," in Proceedings of Interaction Design and Children 2006, pp. 97-104, ACM Press, 2006.

[164] A. C. Kay, "The early history of smalltalk," SIGPLAN Not. 28, 3 (Mar. 1993), 69-95. DOI= http://doi.acm.org/10.1145/155360.155364, 1993.

[165] R. Kerr, "Movement control and maturation in elementary-grade children," Perceptual and Motor Skills, vol. 41, pp. 151-154, 1975.

[166] D. Kestenbaum, "The challenges of interaction design and children: What have we learned from our past," Communications of the ACM, vol. 48, no. 1, pp. 35-38, 2005.

[167] M. Khandelwal and A. Mazalek, "Teaching table: A tangible mentor for pre-K math education," in Proceedings of TEI 07, pp. 191-194, ACM Press, 2007.

[168] S. H. Kim, A. Chung, J. H. Ok, I. S. Myung, H. J. Kang, J. K. Woo, and M. J. Kim, "Communication enhancer - Appliances for better communication in a family," Personal and Ubiquitous Computing, vol. 8, pp. 221-226, 2004.

[169] Y. Kim and A. L. Baylor, "A social-cognitive framework for pedagogical agents as learning companions," Educational Technology Research and Development, vol. 54, no. 6, pp. 569-590, 2006.

[170] M. Kindborg and P. Sökjer, "How preschool children used a behaviour-based programming tool," in Proceedings of Interaction Design and Children 200\%, pp. 149-152, ACM Press, 2007.

[171] J. King and N. Alloway, "Preschooler's use of microcomputers and input devices," Journal of Educational Computing Research, vol. 8, no. 4, pp. 451468, 1992.

[172] J. King and N. Alloway, "Young children's use of microcomputer input devices," Computers in the Schools, vol. 9, pp. 39-53, 1993.

[173] Knowledge Adventure, Math Blaster: Master the Basics. Torrance, CA: Knowledge Adventure, 2005.

[174] K. Knudtzon, A. Druin, N. Kaplan, K. Summers, Y. Chisik, R. Kulkarni, S. Moulthrop, H. Weeks, and B. Bederson, "Starting an intergenerational technology design team: A case study," in Proceedings of Interaction Design and Children 2003, pp. 51-58, ACM Press, 2003.

[175] O. Korat and A. Shamir, "Electronic books versus adult readers: Effects on children's emergent literacy as a function of social class," Journal of Computer Assisted Learning, vol. 23, pp. 248-259, 2007.

[176] M. Kornhaber, E. Fierros, and S. Veenema, Multiple Intelligences: Best Ideas from Research and Practice. Boston, MA: Allyn \& Bacon, 2004.

[177] E. Kraus, "Handedness in children," in Hand Function in the Child: Foundations for Remediation, (A. Henderson and C. Pehoski, eds.), St. Louis, MO: Mosby Elsevier, 2006. 
[178] J. P. Kuhtz-Buschbeck, H. Stolze, K. Johnk, A. Boczek-Funcke, and M. Illert, "Development of prehension movements in children: A kinematic study," Experimental Brain Research, vol. 122, no. 4, pp. 424-432, 1998.

[179] Kutoka Interactive, Mia's Math Adventure: Just in Time. Montreal, Canada: Kutoka Interactive, 2003.

[180] J. B. Labrune and W. Mackay, "Tangicam: Exploring observation tools for children," in Proceedings of Interaction Design and Children 2005, pp. 95102, ACM Press, 2005.

[181] J. B. Labrune and W. Mackay, "Telebeads: Social network mnemonics for teenagers," in Proceedings of Interaction Design and Children 2006, pp. 5764, ACM Press, 2006.

[182] J. B. Labrune and W. Mackay, "SketchCam: Creative photography for children," in Proceedings of Interaction Design and Children 2007, pp. 153-156, ACM Press, 2007.

[183] K. K. Lamberty and J. L. Kolodner, "Camera talk: Making the camera a partial participant," in Proceedings of Human Factors in Computing Systems 2005, pp. 839-848, ACM Press, 2005.

[184] A. E. Lane and J. M. Ziviani, "Enabling children computer access: Introduction to the test of mouse proficiency," Occupational Therapy Journal of Research, vol. 22, no. 3, pp. 111-118, 2002.

[185] A. E. Lane and J. M. Ziviani, "Assessing children's competence in computer interactions: Preliminary reliability and validity of the test of mouse proficiency," Occupational Therapy Journal of Research, vol. 23, no. 1, pp. 18$26,2003$.

[186] C. E. Lathan and S. Malley, "Development of a new robotic interface for telerehabilitation," in Proceedings of WUAUC 01, pp. 80-83, ACM Press, 2001.

[187] J. Lave and E. Wenger, Situated Learning: Legitimate Peripheral Participation. Cambridge, UK: Cambridge University Press, 1991.

[188] Learning Company, Zoombinis Logical Journey. San Francisco, CA: Riverdeep, 2006.

[189] J. C. Lester, S. T. Barlow, S. A. Converse, B. A. Stone, S. E. Kahler, and R. S. Bhogal, "The persona effect: Affective impact of animated pedagogical agents," in Proceedings of Human Factors in Computing Systems 97, pp. 359366, ACM Press, 1997.

[190] C. Lewis, C. Brand, G. Cherry, and C. Rader, "Adapting user interface design methods to the design of educational activities," in Proceedings of Human Factors in Computing Systems 98, pp. 619-626, ACM Press, 1998.

[191] L. Lhuisset and L. Proteau, "Visual control of manual aiming movements in 6- to 10-year old children and adults," Journal of Motor Behavior, vol. 36, pp. 255-264, 2004.

[192] X. Li and M. S. Atkins, "Early childhood computer experience and cognitive and motor development," Pediatrics, vol. 113, no. 6, pp. 1715-1722, 2004.

[193] L. S. Liben and R. M. Downs, "The role of graphic representations in understanding the world," in Visions of Aesthetics, the Environment, and Development: The Legacy of Joachim Wohlwill, (R. M. Downs, L. S. Liben, and D. S. Palermo, eds.), Hillsdale, NJ: Erlbaum, 1991. 
[194] D. A. Lieberman, "Impacts of media violence on children and youth," in SIGCHI Bulletin, January-February 2001, p. 5, ACM Press, 2001.

[195] K. Luchini, C. Quintana, and E. Soloway, "Pocket PiCoMap: A case study in designing and assessing a handheld concept mapping tool for learners," in Proceedings of Human Factors in Computing Systems 2003, pp. 321-328, ACM Press, 2003.

[196] R. Luckin, D. Connolly, L. Plowman, and S. Airey, "Children's interactions with interactive toy technology," Journal of Computer Assisted Learning, vol. 19, pp. 165-176, 2003.

[197] M. Lumbreras and J. Sanchez, "Interactive 3D sound hyperstories for blind children," in Proceedings of Human Factors in Computing Systems 99, pp. 318-325, ACM Press, 1999.

[198] S. MacFarlane, G. Sim, and M. Horton, "Assessing usability and fun in educational software," in Proceedings of Interaction Design and Children 2005, pp. 103-109, ACM Press, 2005.

[199] I. Machado, R. Prada, and A. Paiva, "Bringing drama into a virtual stage," in Proceedings of CVE 2000, pp. 111-117, ACM Press, 2000.

[200] A. Makela, V. Giller, M. Tscheligi, and R. Sefelin, "Joking, storytelling, artsharing, expressing affection: A field trial of how children and their social network communicate with digital images in leisure time," in Proceedings of Human Factors in Computing Systems 2000, pp. 548-555, ACM Press, 2000.

[201] B. Mann, P. Newhouse, J. Pagram, A. Campbell, and H. Schulz, "A comparison of temporal speech and text cueing in educational multimedia," Journal of Computer Assisted Learning, vol. 18, pp. 296-308, 2002.

[202] P. Markopoulos and M. M. Bekker, "On the assessment of usability testing methods for children," Interacting with Computers, vol. 15, pp. 227-243, 2003.

[203] P. Marshall, "Do tangible interfaces enhance learning?," in Proceedings of TEI 07, pp. 163-170, ACM Press, 2007.

[204] P. Marshall, S. Price, and Y. Rogers, "Conceptualising tangibles to support learning," in Proceedings of Interaction Design and Children 2003, pp. 101109, ACM Press, 2003.

[205] J. Mattila and A. Vaatanen, "UbiPlay: An interactive playground and visual programming tools for children," in Proceedings of Interaction Design and Children 2006, pp. 129-136, ACM Press, 2006.

[206] J. McElligott and L. van Leeuwen, "Designing sound tools and toys for blind and visually impaired children," in Proceedings of Interaction Design and Children 2004, pp. 65-72, ACM Press, 2004.

[207] M. McGuffin and R. Balakrishnan, "Acquisition of expanding targets," CHI Letters, vol. 4, no. 1, pp. 57-64, 2002.

[208] T. S. McNerney, "From turtles to tangible programming bricks: Explorations in physical language design," Personal and Ubiquitous Computing, vol. 8, pp. 326-337, 2004.

[209] MicroWorlds Home Page. Retrieved April 1, 2008 from http://www. microworlds.com/, 2008.

[210] S. Milne, L. Gibson, P. Gregor, and K. Keighren, "Pupil consultation online: Developing a web-based questionnaire system," in Proceedings of Interaction Design and Children 2003, pp. 127-133, ACM Press, 2003. 
[211] A. O. Mohamed, K. Sehaba, V. Courboulay, and M. Menard, "Attention analysis in interactive software for children with autism," in Proceedings of ASSETS 06, pp. 133-140, ACM Press, 2006.

[212] T. Moher, "Embedded phenomena: Supporting science learning with classroom-sized distributed simulations," in Proceedings of Human Factors in Computing Systems 2006, pp. 691-700, ACM Press, 2006.

[213] T. Moher, A. Johnson, S. Ohlsson, and M. Gillingham, "Bridging strategies for VR-based learning," in Proceedings of Human Factors in Computing Systems 1999, pp. 536-543, ACM Press, 1999.

[214] J. Montemayor, A. Druin, G. Chimpan, A. Farber, and M. L. Guha, "Tools for children to create physical interactive StoryRooms," ACM Computers in Entertainment, vol. 2, no. 1, article 3, 2004.

[215] J. Montemayor, A. Druin, A. Farber, S. Simms, W. Churaman, and A. D'Amour, Physical Programming: Designing Tools for Children to Create Physical Interactive Environments, pp. 299-306. ACM Press, 2002.

[216] M. Montessori, The Montessori Method. (A. E. George, Trans.), New York: Schocken, 1964.

[217] N. Moraveji, J. Li, J. Ding, P. O'Kelley, and S. Woolf, "Comicboarding: Using comics as proxies for participatory design with children," in Proceedings of Human Factors in Computing Systems 2007, pp. 1371-1374, ACM Press, 2007.

[218] K. Müller and V. Hömberg, "Development of speed of repetitive movements in children is determined by structural changes in corticospinal efferents," Neuroscience Letters, vol. 144, pp. 57-60, 1992.

[219] M. Namatame, Y. Harada, F. Kusunoki, S. Inagaki, and T. Terano, "To use PYA tool or not for learning Japanese hand alphabets," in Proceedings of $A C E$ 2006, article 51, 2006.

[220] R. C. Oldfield, "The assessment and analysis of handedness: The edinburgh inventory," Neuropsychologia, vol. 9, pp. 97-113, 1971.

[221] OLPC, One Laptop Per Child. http://laptop.org, 2007.

[222] D. O'Reilly, "School programming as literacy: The case for BOXER," Journal of Computer Assisted Learning, vol. 14, pp. 51-58, 1998.

[223] J. M. Ortega-Tudela and C. J. Gomez-Ariza, "Computer-assisted teaching and mathematical learning in Down Syndrome children," Journal of Computer Assisted Learning, vol. 22, pp. 298-307, 2006.

[224] S. Ovaska, P. Hietala, and M. Kangassalo, "Electronic whiteboard in kindergarten: Opportunities and requirements," in Proceedings of Interaction Design and Children 2003, pp. 15-22, ACM Press, 2003.

[225] S. Oviatt, C. Darves, and R. Coulston, "Toward adaptive conversational interfaces: Modeling speech convergence with animated personas," ACM Transactions on Computer-Human Interaction, vol. 11, no. 3, pp. 300-328, 2004.

[226] A. Paiva, G. Andersson, K. Hook, D. Mourao, M. Costa, and C. Martinho, "SenToy in FantasyA: Designing an affective sympathetic interface to a computer game," Personal and Ubiquitous Computing, vol. 6, pp. 378-389, 2002.

[227] J. Pal, U. Singh Pawar, E. A. Brewer, and K. Toyama, "The case for multiuser design for computer aided learning in developing regions," in Proceedings of WWW06, pp. 781-789, ACM Press, 2006. 
[228] S. Papert, Mindstorms: Children, Computers, and Powerful Ideas. New York: Basic Books, 1993.

[229] S. Papert and I. Harel, "Situating constructionism," in Constructionism, (S. Papert and I. Harel, eds.), Norwood, NJ: Ablex, 1991.

[230] S. Pardo, F. Vetere, and S. Howard, "Broadening stakeholder involvement in UCD: Designers' perspectives on child-centered design," in Proceedings of OZCHI 2005, pp. 1-9, ACM Press, 2005.

[231] N. Pares, A. Carreras, J. Durany, J. Ferrer, P. Freixa, D. Gomez, O. Kruglanski, R. Pares, J. I. Ribas, M. Soler, and A. Sanjurjo, "Promotion of creative activity in children with severe autism through visuals in an interactive multisensory environment," in Proceedings of Interaction Design and Children 2005, pp. 110-116, ACM Press, 2005.

[232] D. Passig and H. Levin, "Gender preferences for multimedia interfaces," Journal of Computer Assisted Learning, vol. 16, pp. 64-71, 2000.

[233] V. G. Payne and L. D. Isaacs, Human Motor Development: A Lifespan Approach. New York: McGraw-Hill, 2005.

[234] C. Pehoski, "Object manipulation in infants and children," in Hand Function in the Child: Foundations for Remediation, (A. Henderson and C. Pehoski, eds.), St. Louis, MO: Mosby Elsevier, 2006.

[235] J. Piaget, The Child and Reality. New York: Grossman, 1973.

[236] J. Piaget, "Judgement and reasoning in the child," in The Essential Piaget, (H. E. Gruber and J. J. Voneche, eds.), pp. 89-117, London: Aronson, 1995.

[237] J. Piaget, "The language and thought of the child," in The Essential Piaget, (H. E. Gruber and J. J. Voneche, eds.), pp. 65-88, London: Aronson, 1995.

[238] J. Piaget, "Logic and psychology," in The Essential Piaget, (H. E. Gruber and J. J. Voneche, eds.), pp. 445-477, London: Aronson, 1995.

[239] J. Piaget and B. Inhelder, The Psychology of the Child. (H. Weaver, Trans.), New York: Basic Books, 1969.

[240] C. Plaisant, A. Clamage, H. Browne Hutchinson, B. B. Bederson, and A. Druin, "Shared family calendars: Promoting symmetry and accessibility," ACM Transactions on Computer-Human Interaction, vol. 13, no. 3, pp. 313346, 2006.

[241] L. Plowman and C. Stephen, "A 'benign addition'? Research on ICT and preschool children," Journal of Computer Assisted Learning, vol. 19, pp. 149$164,2003$.

[242] L. Plowman and C. Stephen, "Guided interaction in pre-school settings," Journal of Computer Assisted Learning, vol. 23, pp. 14-26, 2007.

[243] S. Price, Y. Rogers, M. Scaife, D. Stanton, and H. Neale, "Using 'tangibles' to promote novel forms of playful learning," Interacting with Computers, vol. 15, pp. 169-185, 2003.

[244] S. R. Quartz and T. J. Sejnowski, "The neural basis of cognitive development: A constructivist manifesto," Behavioral and Brain Sciences, vol. 20, pp. 537596, 1997.

[245] C. Rader, C. Brand, and C. Lewis, "Degrees of comprehension: Children's understanding of a visual programming environment," in Proceedings of Human Factors in Computing Systems 97, pp. 351-358, ACM Press, 1997. 
[246] H. Raffle, H. Ishii, and L. Yip, "Remix and Robo: Sampling, sequencing and real-time control of a tangible robotic construction system," in Proceedings of Interaction Design and Children 200\%, pp. 89-96, ACM Press, 2007.

[247] H. Raffle, C. Vaucelle, R. Wang, and H. Ishii, "Jabberstamp: Embedding sound and voice in traditional drawings," in Proceedings of Interaction Design and Children 2007, pp. 137-144, ACM Press, 2007.

[248] H. S. Raffle, A. Parkes, H. Ishii, and J. Lifton, "Beyond record and play," in Proceedings of Human Factors in Computing Systems 2006, pp. 681-690, ACM Press, 2006.

[249] H. S. Raffle, A. J. Parkes, and H. Ishii, "Topobo: A constructive assembly system with kinetic memory," in Proceedings of Human Factors in Computing Systems 2004, pp. 647-654, ACM Press, 2004.

[250] R. Raisamo, S. Patomaki, M. Hasu, and V. Pasto, "Design and evaluation of a tactile memory game for visually impaired children," Interacting with Computers, vol. 19, pp. 196-205, 2007.

[251] D. Ramachandran, M. Kam, J. Chiu, J. Canny, and J. L. Frankel, "Social dynamics of early stage co-design in developing regions," in Proceedings of Human Factors in Computing Systems 2007, pp. 1087-1096, ACM Press, 2007.

[252] C. Randell, S. Price, Y. Rogers, E. Harris, and G. Fitzpatrick, "The ambient horn: Designing a novel audio-based learning experience," Personal and Ubiquitous Computing, vol. 8, pp. 177-183, 2004.

[253] A. K. Rao, "Cognition and motor skills," in Hand Function in the Child: Foundations for Remediation, (A. Henderson and C. Pehoski, eds.), St. Louis, MO: Mosby Elsevier, 2006.

[254] J. C. Read, "A study of the usability of handwriting recognition for text entry by children," Interacting with Computers, vol. 19, pp. 57-69, 2007.

[255] J. C. Read, S. MacFarlane, and C. Casey, "Oops! Silly me! Errors in a handwriting recognition based text entry interface for children," in Proceedings of NordiCHI 2002, pp. 35-40, ACM Press, 2002.

[256] J. C. Read, S. MacFarlane, and C. Casey, "What's going on? Discovering what children understand about handwriting recognition interfaces," in Proceedings of Interaction Design and Children 2003, pp. 135-140, ACM Press, 2003.

[257] J. C. Read, S. MacFarlane, and P. Gregory, "Requirements for the design of a handwriting recognition based writing interface for children," in Proceedings of Interaction Design Children 2004, pp. 81-88, ACM Press, 2004.

[258] A. Repenning, A. Ioannidou, and J. Zola, "AgentSheets: End-User programmable simulations," Journal of Artificial Societies and Social Simulation, vol. 3, no. 3, Retrieved April 1, 2006 from http://jasss.soc.surrey. ac.uk/ 3/3/forum/1.html, 2000.

[259] M. Resnick, F. Martin, R. Berg, R. Borovoy, V. Colella, K. Kramer, and B. Silverman, "Digital manipulatives: New toys to think with," in Proceedings of Human Factors in Computing Systems 98, pp. 281-287, ACM Press, 1998.

[260] M. Resnick and B. Silverman, "Some reflections on designing construction kits for kids," in Proceedings of Interaction Design and Children 2005, pp. 117-122, ACM Press, 2005. 
[261] G. L. Revelle and E. F. Strommen, "The effects of practice and input device used on young children's computer control," Journal of Computing in Childhood Education, vol. 2, pp. 33-41, 1990.

[262] V. J. Rideout, E. A. Vandewater, and E. A. Wartella, Zero to Six: Electronic Media in the Lives of Infants, Toddlers, and Preschoolers. The Henry J. Kaiser Family Foundation, Retrieved on April 20, 2007 from http://www.kff.org, 2003.

[263] K. Risden, M. Czerwinski, S. Worley, L. Hamilton, J. Kubiniec, H. Hoffman, N. Mickel, and E. Loftus, "Interactive advertising: Patterns of use and effectiveness," in Proceedings of Human Factors in Computing Systems 98, pp. 219224, ACM Press, 1998.

[264] J. Robertson, "Paradise lost: Children, multimedia and the myth of interactivity," Journal of Computer Assisted Learning, vol. 14, pp. 31-39, 1998.

[265] J. Robertson and J. Good, "Ghostwriter: A narrative virtual environment for children," in Proceedings of Interaction Design and Children 2003, pp. 85-91, ACM Press, 2003.

[266] J. Robertson and J. Good, "Children's narrative development through computer game authoring," in Proceedings of Interaction Design and Children 2004, pp. 57-64, ACM Press, 2004.

[267] J. Robertson and K. Nicholson, "Adventure author: A learning environment to support creative design," in Proceedings of Interaction Design and Children 2007, pp. 37-44, ACM Press, 2007.

[268] J. A. Rode, M. Stringer, E. F. Toye, A. R. Simpson, and A. F. Blackwell, "Curriculum-focused design," in Proceedings of Interaction Design and Children 2003, pp. 119-126, ACM Press, 2003.

[269] Y. Rogers, S. Price, G. Fitzpatrick, R. Fleck, E. Harris, H. Smith, C. Randell, H. Muller, C. O'Malley, D. Stanton, M. Thompson, and M. Weal, "Ambient wood: Designing new forms of digital augmentation for learning outdoors," in Proceedings of Interaction Design and Children 2004, pp. 3-10, ACM Press, 2004.

[270] B. Rogoff, "Cognition as a collaborative process," in Handbook of Child Psychology: Vol. 2. Cognition, Perception, and Language, (D. Kuhn and R. S. Siegler, eds.), New York: Wiley, 1998.

[271] B. Rösblad, "Reaching and eye-hand coordination," in Hand Function in the Child: Foundations for Remediation, (A. Henderson and C. Pehoski, eds.), St. Louis, MO: Mosby Elsevier, 2006.

[272] L. Rosenbloom and M. E. Horton, "The maturation of fine prehension in young children," Developmental Medicine and Child Neurology, vol. 13, p. 38, 1971.

[273] M. Roussou, "Learning by doing and learning through play: An exploration of interactivity in virtual environments for children," ACM Computers in Entertainment, vol. 2, pp. 1-23, 2004.

[274] K. Ryokai, S. Marti, and H. Ishii, "I/O brush: Drawing with everyday objects as ink," in Proceedings of Human Factors in Computing Systems 2004, pp. 303-310, ACM Press, 2004. 
[275] K. Ryokai, C. Vaucelle, and J. Cassell, "Virtual peers as partners in storytelling and literacy learning," Journal of Computer Assisted Learning, vol. 19, pp. 195-208, 2003.

[276] A. W. Salmoni and J. S. McIlwain, "Fitts' reciprocal tapping task: A measure of motor capacity," Perceptual and Motor Skills, vol. 49, pp. 403-413, 1979.

[277] J. Sanchez and H. Flores, "Memory enhancement through audio," in Proceedings of ASSETS 04, pp. 24-31, ACM Press, 2004.

[278] J. Sanchez and M. Saenz, "3D sound interactive environments for problem solving," in Proceedings of ASSETS 05, pp. 173-179, ACM Press, 2005.

[279] M. Scaife, Y. Rogers, F. Aldrich, and M. Davies, "Designing for or designing with? Informant design for interactive learning environments," in Proceedings of Human Factors in Computing Systems 97, pp. 343-350, ACM Press, 1997.

[280] S. Schneiberg, H. Sveistrup, B. McFadyen, P. McKinely, and M. F. Levin, "The development of coordination for reach-to-grasp movements in children," Experimental Brain Research, vol. 146, no. 2, pp. 142-154, 2002.

[281] Scholastic, Math Missions: The Amazing Arcade Adventure Grades 3-5. New York: Scholastic, 2003.

[282] S. D. Scott, R. L. Mandryk, and K. M. Inkpen, "Understanding children's collaborative interactions in shared environments," Journal of Computer Assisted Learning, vol. 19, pp. 220-228, 2003.

[283] E. Segers and L. Verhoeven, "Effects of vocabulary training by computer in kindergarten," Journal of Computer Assisted Learning, vol. 19, pp. 557-566, 2003.

[284] E. Segers and L. Verhoeven, "Long-term effects of computer training of phonological awareness in kindergarten," Journal of Computer Assisted Learning, vol. 21 , pp. 17-27, 2005.

[285] M. Sharples, D. Corlett, and O. Westmancott, "The design and implementation of a mobile learning resource," Personal and Ubiquitous Computing, vol. 6, pp. 220-234, 2002.

[286] R. Sheehan, "Children's perception of computer programming as an aid to designing programming environments," in Proceedings of Interaction Design and Children 2003, pp. 75-83, ACM Press, 2003.

[287] B. Shneiderman, Leonardo's Laptop: Human Needs and the New Computing Technologies. Cambridge, MA: MIT Press, 2002.

[288] B. Shneiderman, "Promoting universal usability with multi-layer interface design," in Proceedings of the 2003, ACM Conference on Universal Usability, pp. 1-8, ACM Press, 2003.

[289] B. Shneiderman and C. Plaisant, Designing the User Interface: Strategies for Effective Human-Computer Interaction. Boston: Addison-Wesley, fourth ed., 2004.

[290] J. L. Sibert, M. Gokturk, and R. A. Lavine, "The reading assistant: Eye gaze triggered auditory prompting for reading remediation," in Proceedings of UIST 00, pp. 101-107, ACM Press, 2000.

[291] N. Signorielli, "Television and the perpetuation of gender-role stereotypes," AAP News, pp. 103-104, February, 1998. 
[292] U. Singh Pawar, J. Pal, R. Gupta, and K. Toyama, "Multiple mice for retention tasks in disadvantaged schools," in Proceedings of Human Factors in Computing Systems 2007, pp. 1581-1590, ACM Press, 2007.

[293] B. F. Skinner, The Technology of Teaching. New York: Appleton, 1968.

[294] R. J. W. Sluis, I. Weevers, C. H. G. J. van Schijndel, L. Kolos-Mazuryk, S. Fitrianie, and J. B. O. S. Martens, "Read-it: Five to seven-year old children learn to read in a tabletop environment," in Proceedings of Interaction Design and Children 2004, pp. 73-80, ACM Press, 2004.

[295] W. Sluis-Thiescheffer, T. Bekker, and B. Eggen, "Comparing early design methods for children," in Proceedings of Interaction Design and Children 2007, pp. 17-24, ACM Press, 2007.

[296] D. C. Smith, A. Cypher, and L. Tesler, "Novice programming comes of age," Communications of the ACM, vol. 43, no. 3, pp. 75-81, 2000.

[297] E. Soloway, S. L. Jackson, J. Klein, C. Quintana, J. Reed, J. Spitulnik, S. J. Stratford, S. Studer, J. Eng, and N. Scala, "Learning theory in practice: Case studies of learner-centered design," in Proceedings of Human Factors in Computing Systems 96, pp. 189-196, ACM Press, 1996.

[298] Squeak Home Page, Retrieved April 1, 2006 from http://www.squeak.org/, 2006.

[299] D. Stanton, V. Bayon, H. Neale, A. Ghali, S. Benford, S. Cobb, R. Ingram, C. O'Malley, J. Wilson, and T. Pridmore, "Classroom collaboration in the design of tangible interfaces for storytelling," in Proceedings of Human Factors in Computing Systems 2001, pp. 482-489, ACM Press, 2001.

[300] D. Stanton and H. Neale, "The effects of multiple mice on children's talk and interaction," Journal of Computer Assisted Learning, vol. 19, pp. 229-238, 2003.

[301] K. E. Steiner and T. Moher, "Encouraging task-related dialog in 2D and 3D shared narrative workspaces," in Proceedings of the 4th International Conference on Collaborative Virtual Environments, pp. 39-46, ACM Press, 2002.

[302] K. E. Steiner and T. G. Moher, "Graphic storywriter: An interactive environment for emergent story construction," in Proceedings of Human Factors in Computing Systems (CHI 92), pp. 357-363, ACM Press, 1992.

[303] R. J. Sternberg, Beyond IQ: A Triarchic Theory of Human Intelligence. New York: Cambridge University Press, 1985.

[304] R. J. Sternberg, "Our Research program validating the triarchic theory of successful intelligence: Reply to Gottfredson," Intelligence, vol. 31, no. 4, pp. 399413, 2003.

[305] R. J. Sternberg and J. C. Kaufman, "Human abilities," Annual Review of Psychology, vol. 49, pp. 479-502, 1998.

[306] J. Stewart, B. B. Bederson, and A. Druin, "Single display groupware: A model for co-present collaboration," in Proceedings of Human Factors in Computing Systems 99, pp. 286-293, ACM Press, 1999.

[307] M. Stringer, E. Harris, and G. Fitzpatrick, "Exploring the space of near-future design with children," in Proceedings of NordiCHI 2006, pp. 351-360, ACM Press, 2006. 
[308] M. Stringer, E. F. Toye, J. A. Rode, and A. F. Blackwell, "Teaching rhetorical skills with a tangible user interface," in Proceedings of Interaction Design and Children 2004, pp. 11-18, ACM Press, 2004.

[309] E. Strommen, "When the interface is a talking dinosaur: Learning across media with ActiMates Barney," in Proceedings of Human Factors in Computing Systems 98, pp. 288-295, ACM Press, 1998.

[310] E. Strommen and K. Alexander, "Emotional interfaces for interactive aardvarks: Designing affect into social interfaces for children," in Proceedings of Human Factors in Computing Systems 99, pp. 528-535, ACM Press, 1999.

[311] E. F. Strommen, G. L. Revelle, L. M. Medoff, and S. Razavi, "Slow and steady wins the race? Three-year-old children and pointing device use," Behaviour and Information Technology, vol. 15, no. 1, pp. 57-64, 1996.

[312] T. Subhi, "The impact of LOGO on gifted children's achievement and creativity," Journal of Computer Assisted Learning, vol. 15, pp. 98-108, 1999.

[313] D. A. Sugden, "Movement speed in children," Journal of Motor Behavior, vol. 12, pp. 125-132, 1980.

[314] M. L. Sundberg and J. Michael, "The benefit of skinner's analysis of verbal behavior for children with Autism," Behavior Modification, vol. 25, no. 5, pp. 698-724, 2001.

[315] T. Hutto Egloff, "Edutainment: A case study of interactive CD-ROM playsets," ACM Computers in Entertainment, vol. 2, no. 1, article 4, 2004.

[316] G. Taxen, A. Druin, C. Fast, and M. Kjellin, "KidStory: A technology design partnership with children," Behaviour and Information Technology, vol. 20, no. 2, pp. 119-125, 2001.

[317] The Henry J. Kaiser Family Foundation, Key Facts: Children and Video Games. Retrieved on April 20, 2007 from http://www.kff.org, 2002.

[318] The Henry J. Kaiser Family Foundation, Key Facts: TV Violence. Retrieved on April 20, 2007 from http://www.kff.org, 2003.

[319] The Henry J. Kaiser Family Foundation, Issue Brief: The Role of Media in Childhood Obesity. Retrieved on April 20, 2007 from http://www.kff.org, 2004.

[320] Y. L. Theng, N. Mohd-Nasir, G. Buchanan, B. Fields, H. Thimbleby, and N. Cassidy. Dynamic Digital Libraries for Children, pp. 406-415, ACM Press, 2001.

[321] J. Tholander and Y. Fernaeus, "Multimodal interaction in children's programming with tangible artefacts," in Proceedings of ICLS 06, pp. 771-777, ACM Press, 2006.

[322] I. E. H. Van Kesteren, M. M. Bekker, A. P. O. S. Vermeeren, and P. A. Lloyd, "Assessing usability evaluation methods on their effectiveness to elicit verbal comments from children subjects," in Proceedings of Interaction Design and Children 2003, pp. 41-49, ACM Press, 2003.

[323] J. Verhaegh, I. Soute, A. Kessels, and P. Markopoulos, "On the design of Camelot, an outdoor game for children," in Proceedings of Interaction Design and Children 2006, pp. 9-16, ACM Press, 2006.

[324] F. Vetere, M. R. Gibbs, J. Kjeldskov, S. Howard, F. Mueller, S. Pedell, K. Mecoles, and M. Bunyan, "Mediating intimacy: Designing technologies to 
support strong-tie relationships," in Proceedings of Human Factors in Computing Systems 2005, pp. 471-480, ACM Press, 2005.

[325] J. Vincent, "The role of visually rich technology in facilitating children's writing," Journal of Computer Assisted Learning, vol. 17, pp. 242-250, 2001.

[326] J. Vincent, "MicroWorlds and the integrated brain," in Proceedings of Seventh World Conference on Computers in Education, pp. 131-137, ACS, 2002.

[327] L. S. Vygotsky, Mind in Society: The Development of Higher Psychological Processes. Cambridge, MA: Harvard University Press, 1978.

[328] S. A. Wallace, K. M. Newell, and M. G. Wade, "Decision and response times as a function of movement difficulty in preschool children," Child Development, vol. 49, pp. 509-512, 1978.

[329] V. A. Walter, C. L. Borgman, and S. G. Hirsh, "The science library catalog: A springboard for information literacy," School Library Media Quarterly, vol. 24, pp. 105-112, 1996.

[330] P. L. Weiss, C. P. Whiteley, J. Treviranus, and D. I. Fels, "Pebbles: A personal technology for meeting educational, social and emotional needs of hospitalized children," Personal and Ubiquitous Computing, vol. 5, pp. 157-168, 2001.

[331] M. Williams, O. Jones, and C. Fleuriot, "Wearable computing and the geographies of urban childhood - Working with children to explore the potential of new technology," in Proceedings of Interaction Design and Children 2003, pp. 111-118, ACM Press, 2003.

[332] M. Williams, O. Jones, C. Fleuriot, and L. Wood, "Children and emerging wireless technologies: Investigating the potential for spatial practice," in Proceedings of Human Factors in Computing Systems 2005, pp. 819-828, ACM Press, 2005.

[333] G. A. Winer, "Class inclusion reasoning in children: A review of the empirical literature," Child Development, vol. 51, pp. 309-328, 1980.

[334] S. Woods, "Exploring the design space of robots: Children's perspectives," Interacting with Computers, vol. 18, pp. 1390-1418, 2006.

[335] A. Worden, N. Walker, K. Bharat, and S. Hudson, "Making computers easier for older adults to use: Area cursors and sticky icons," in Proceedings of Human Factors in Computing Systems (CHI 97), pp. 266-271, ACM Press, 1997.

[336] T. Wright and A. Cockburn, "Evaluation of two textual programming notations for children," in Proceedings of Australasian User Interface Conference 2005, pp. 55-62, Australian Computer Society, 2005.

[337] P. Wyeth and H. C. Purchase, "Using developmental theories to inform the design of technology for children," in Proceedings of Interaction Design and Children 2003, pp. 93-100, ACM Press, 2003.

[338] J. E. Yakimishyn and J. Magill-Evans, "Comparisons among tools, surface orientation, and pencil grasp for children 23 months of age," American Journal of Occupational Therapy, vol. 56, no. 5, pp. 564-572, 2002.

[339] O. Ybarra, E. Burnstein, P. Winkielman, M. C. Keller, M. Manis, E. Chan, and J. Rodriguez, "Mental exercising through simple socializing: Social interaction promotes general cognitive functioning," Personality and Social Psychology Bulletin, vol. 34, no. 2, pp. 248-259, 2007. 
[340] B. Zaman and V. Vanden Abeele, "Towards a likeability framework that meets child-computer interaction and communication sciences," in Proceedings of Interaction Design and Children 2007, pp. 1-8, ACM Press, 2007.

[341] S. Zhai, S. Conversy, M. Beaudouin-Lafon, and Y. Guiard, "Human on-line response to target expansion," CHI Letters, vol. 5, no. 1, pp. 177-184, 2003.

[342] O. Zuckerman, S. Arida, and M. Resnick, "Extending tangible interfaces for education: Digital Montessori-inspired manipulatives," in Proceedings of Human Factors in Computing Systems 2005, pp. 859-868, ACM Press, 2005.

[343] G. Zurita and M. Nussbaum, "A constructivist mobile learning environment supported by a wireless handheld network," Journal of Computer Assisted Learning, vol. 20, pp. 235-243, 2004. 